AGING AND DECISIONS FROM EXPERIENCE:

\title{
DIFFERENCES IN INFORMATION SEARCH AND SUBSEQUENT DECISION QUALITY
}

\author{
BY \\ Pete Wegier \\ BSc, Ryerson University, Toronto, ON, 2008 \\ MSc, Ryerson University, Toronto, ON, 2010 \\ A dissertation \\ presented to Ryerson University \\ in partial fulfillment of the \\ requirements for the degree of \\ Doctor of Philosophy \\ in the program of \\ Psychology
}

Toronto, Ontario, Canada, 2015

(C) Pete Wegier 2015 



\section{DECLARATION}

I hereby declare that I am the sole author of this dissertation. This is a true copy of the dissertation, including any required final revisions, as accepted by my examiners.

I authorize Ryerson University to lend this dissertation to other institutions or individuals for the purpose of scholarly research

I further authorize Ryerson University to reproduce this dissertation by photocopying or by other means, in total or in part, at the request of other institutions or individuals for the purpose of scholarly research.

I understand that my dissertation may be made electronically available to the public. 



\section{AGING AND DECISIONS FROM EXPERIENCE:}

DIFFERENCES IN INFORMATION SEARCH AND SUBSEQUENT DECISION QUALITY

Doctor of Philosophy, Summer 2015

Pete Wegier

Psychology, Ryerson University

Across a wide variety of choice tasks requiring information to be learned prior to a decision be made, older adults have been found to search for less information than their younger adult counterparts. This dissertation proposed and investigated several potential causes of this age-related decline in the extent of information search: (1) Domain familiarity; (2) Search patterns; (3) Affect; and (4) Risk. The results of four experiments are presented. In each, no significant age-related decline in the extent of information search was found. Despite this, each experiment presents novel findings, adding to our understanding of how information search and subsequent decision quality in choice changes with age.

Experiment 1 revealed an age-related shift in search pattern selection during predecisional information search. Older adults showed a preference for the use of a comprehensive, infrequent-switch, pattern during search. Experiment 2 demonstrated the significant impact that search patterns can have on decision quality. Search pattern use was strictly enforced and it was found that searching using a piecewise search pattern resulted in a significant improvement in performance, relative to comprehensive search, across both younger 
and older adult age groups, despite older adults showing declines in their fluid intelligence. Experiment 3 investigated the role of affective feedback on decision quality. When given affectrich and affect-poor feedback, an interaction of age and affective feedback on decision quality was observed. Younger adults' performance was greater when they were provided with affectpoor performance feedback compared to affect-rich feedback, but a similar trend was not observed in older adults. Experiment 4 found older adults to be no less efficient in identifying higher value outcomes than younger adults.

Overall, this dissertation presents several novel findings in the field of decision-making research. The importance of search pattern selection on decision quality was demonstrated. More critical is the finding that older adults are no less effective in their decisions across a wide array of tasks and manipulations, despite existing stereotypes and evidence of age-related declines in cognitive abilities. Moving forward, the work presented here could be used to guide the future creation of decision aids and new approaches to choice. 


\section{ACKNOWLEDGEMENTS}

Thank you to the many wise and magnanimous people that helped this work along the way:

To Julia Spaniol for supervising this work - it is better than it could have possibly been without your guidance

To the members of my advisory committee for insights I could not have made on my own

To the faculty in the Department of Psychology for giving me the knowledge to get this far

To Madhu, my loving and extremely patient wife, for sticking through this whole process

To my parents for making sure I was always okay despite staring at a laptop screen for most of my waking hours

To the Natural Sciences and Engineering Research Council of Canada for providing the funding to help pay for all this

And to the smart and good-looking participants, whose generously donated time formed the body of this work 

For Madhu:

You mean everything. 

I INTRODUCTION 1

2 LITERATURE REVIEW 7

2.1 GENERAL CHANGES IN DECISION-RELATED COGNITIVE PROCESSES OVER THE LIFESPAN 7

2.2 INFORMATION SEARCH AND AGING 10

2.2.1 FACTORS INFLUENCING INFORMATION SEARCH 11

2.2.2 DOMAIN FAMILIARITY 14

2.2.3 INFORMATION SEARCH PATTERNS 16

2.3 EMOTION, COGNITION, AND AGING 19

2.3.1 EMOTION AND COGNITION 20

2.3.2 AGE-RELATED DIFFERENCES IN EMOTION REGULATION 22

2.3.3 INFORMATION SEARCH AND EMOTION 24

2.4 RISK TAKING OVER THE LIFESPAN 26

2.4.1 THE WHO 26

2.4.2 THE WHEN 27

2.4.3 THE INTERACTION OF WHO AND WHEN 28

\section{OVERVIEW OF EXPERIMENTS 33}

3.1 EXPERIMENT $1 \quad 34$

3.2 EXPERIMENT 235

3.3 EXPERIMENT $3 \quad 36$

3.4 EXPERIMENT $4 \quad 37$

\section{EXPERIMENT I 41}

4.1 METHOD 42

4.1.1 PARTICIPANTS 42

4.1.2 PROCEDURE 43

4.2 RESULTS 45

4.2.1 ACCURACY 46

4.2.2 EXTENT OF INFORMATION SEARCH 46

4.2.3 SEARCH PATTERNS 47

4.2.4 BACKGROUND MEASURES 48

$4 \cdot 3 \quad$ DISCUSSION $\quad 48$ 
5 EXPERIMENT 253

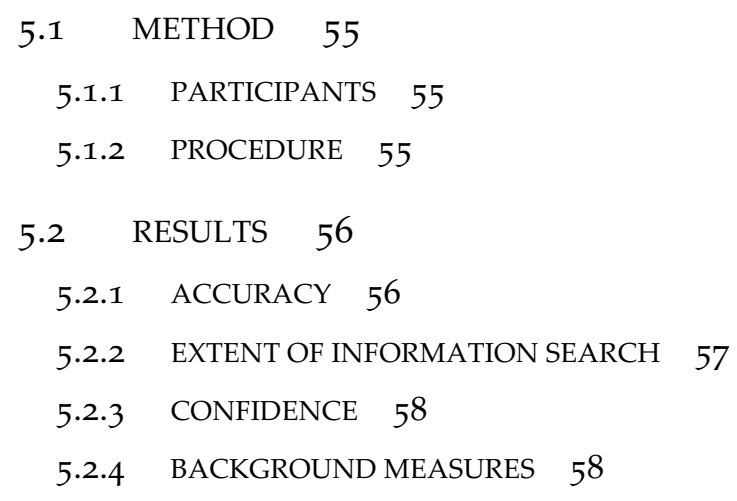


8 GENERAL DISCUSSION 87

8.1 INFORMATION SEARCH 89

8.2 DECISION QUALITY 95

8.3 LIMITATIONS AND FUTURE DIRECTIONS 100

8.4 CONCLUSIONS 104

REFERENCES 143 



\section{LIST OF TABLES}

TABLE 1. Experiment 1: Participant characteristics 107

TABLE 2. Experiment 2: Participant characteristics 108

TABLE 3. Experiment 2: Problem list 109

TABLE 4. Experiment 2: Correlations with background measures 110

TABLE 5. Experiment 3: Participant characteristics 111

TABLE 6. Experiment 3: Problem list 112

TABLE 7. Experiment 3: Rating scores of affect-rich feedback images 113

TABLE 8A. Experiment 3: Correlations with background measures, affect-rich condition 114

TABLE 8B. Experiment 3: Correlations with background measures, affect-poor feedback 115

TABLE 9. Experiment 4: Participant characteristics 116

TABLE 10. Experiment 4: Choice problem sets 117

TABLE 11. Experiment 4: Descriptive statistics 120

TABLE 12. Experiment 4: Correlations with background measures across choice sets 121 



\section{LIST OF FIGURES}

FIGURE 1. Illustration of the marbles task 123

FIGURE 2. Kernel density plot of switch ratios, across participants in each age group in Experiment 1124

FIGURE 3. Experiment 2: Proportion of correct responses as a function of age group and pattern of information search 125

FIGURE 4. Experiment 2: Number samples drawn as a function of trial difficulty, shown for both (A) patterns of search and (B) age groups 126

FIGURE 5. Experiment 3: Proportion of correct responses as a function of age group and feedback type 127 



\section{LIST OF APPENDICES}

APPENDIX I. Initial ethics board approval letter 129

APPENDIX II. Recruitment flyer 130

APPENDIX III. Sample consent form 131

APPENDIX IV. Demographic screening form 134

APPENDIX V. The Positive And Negative Affect Schedule 136

APPENDIX VI. Need for Cognition Scale 137

APPENDIX VII. Lipkus et al. (2001) Numeray Scale 138

APPENDIX VIII. Digit span task 139

APPENDIX IX. Mini Mental State Exam 140

APPENDIX X. Affect-rich feedback images used in Experiment $3 \quad 141$ 



\section{INTRODUCTION}

Every day we each make dozens of decisions. Some are small and have relatively little long-term impact-whether or not to carry an umbrella when leaving the house-while others, such as health care decisions or financial investments, may have repercussions for years to come. The ways in which we approach these decisions may change over the lifespan, while the size of the older adult population has been increasing over time. The proportion of Canadian adults over the age of 65 has increased from $13.7 \%$ in 2006 to $14.8 \%$ in 2011 , and this growth is expected to accelerate in the coming years as the baby boomer generation begins to reach age 65 (Statistics Canada, 2012). Three decades of research into cognitive aging have revealed several types of age-related changes in the domains of cognition and affect (Mather, 2006; Peters, Dieckmann, \& Weller, 2010), both of which are integral components in how we make decisions and are thus of significant importance to Canada's aging society.

Rarely does life provide us with explicit information about all possible options of a choice, the possible outcomes of those options, or even if those outcomes will occur with any certainty. In these situations we may be able to use experience gained in the past to help us make decisions in the present (Hertwig, Barron, Weber, \& Erev, 2004). On one hand, experience may be gained passively over long periods of time. If visiting a restaurant that serves a cuisine you are unfamiliar with you rely on your personal food preferences gained throughout life to select an entrée you will enjoy - the menu will not provide you with any explicit information about your potential enjoyment of any particular dish. On the other hand, situations exist in which you have no previous experience with the decision space. Imagine you have started a new job in 
a different city which requires a long commute either by bus or train; the bus is slower but more reliable while the train is faster but suffers from unforeseen delays. Before deciding between buying the yearly bus pass or yearly train ticket, you sample each route some number of times to get a sense for the average commute time for that route. In other words, you engage in an active, pre-decisional information search phase to acquire the knowledge necessary to make an informed decision. As will be described later, in studies of experience-based choice, older adults have been found to systematically search for and rely on less information than younger adults prior to making a decision; nevertheless, older adults do not display significant impairments to decision quality as a result (Mata \& Nunes, 2010; Mather, 2006; Yoon, Cole, \& Lee, 2009). The goal of this dissertation is to investigate this age-related decline in decisions requiring a period of active, pre-decisional information search. I have identified several factors that may play a role in this decline: (1) domain familiarity; (2) search patterns; (3) affect; and (4) risk.

Expertise gained from prior exposure to certain decision domains may be partially responsible for the decreased information search behaviour previously observed in older adults. By virtue of their advanced age, older adults have had more experience with various types of decisions and therefore need - or believe they need-less additional information prior to making a choice. For example, older adults tend to have greater exposure to and expertise with choices related to health, compared with younger adults, and this may help explain the lack of differences in decision quality between younger and older adults in studies involving healthcare choices (Meyer, Russo, \& Talbot, 1995; Zwahr, Park, \& Shifren, 1999), despite the fact that older adults will search for less information before making a decision. In this dissertation domain familiarity is defined as as any pre-existing knowledge of the particular choice domain 
used in the study that provides a participant with an informational advantage such that their need for information search decreases. For example, if a participant has substantial experience with home appliances then he or she may not require as much pre-decisional information search in a hypothetical refrigerator purchasing decision as someone who does not possess this knowledge.

Older adults may also search for information in different ways, compared to younger adults, with respect to the actual patterns used during search. When younger and older adults were presented with a set of four word search puzzles and asked to find as many words as possible in a set period of time, younger adults switched between the puzzles more often than older adults did (Chin et al., 2012). This suggests a shift to the approach in which we search for information with advancing age, possibly explaining the age-related decline previously observed in experience-based choice tasks.

As choice is often influenced by affective information the ability to successfully regulate one's emotions plays a vital role in human decision-making and evidence suggests that emotion regulation abilities improve with age. Bruine de Bruin, Parker, and Fischhoff (2010) showed that older adult choice performance did not differ from that of younger adults in interpersonal or affective choices; however younger and older adults do differ in their strategy selection in solving problems containing highly emotional content (Blanchard-Fields, Jahnke, \& Camp, 1995). These differences may be due to an age-related improvement in emotional regulation abilities. Carstensen, Pasupathi, Mayr, and Nesselroade (2000) found that older adults experience shorter periods of negative affect and are better at maintaining positive affect over time. As positive emotions tend to remain relatively constant across the lifespan little change in 
decision making is expected. Negative emotions tend to decrease with age (Carstensen et al., 2000) with different negative emotions impacting decision making in different ways. For example, fear increases risk aversion whereas anger decreases it (Lerner \& Keltner, 2001). Fear has also been found to increase the extent of information search in experience-based choices (Frey, Hertwig, \& Rieskamp, 2014). Similarly, expressions of fear have been associated with increased visual search, whereas expressions of disgust decrease search (Susskind et al., 2008).

Finally, there have been inconsistent findings on the interaction of age and affective information in choices involving risk. Compared with younger adults, older adults may place more weight on positive information (Weller, Levin, \& Denburg, 2010); place more (Weber, Shafir, \& Blais, 2004) or less (Mikels \& Reed, 2009) weight on negative information; or show a general increase in weighting of affective information, regardless of valence (Lauriola \& Levin, 2001). The lack of consistent results suggests that our understanding of the interaction of aging and affect experienced from valenced information is still incomplete.

When making a decision between uncertain options, our understanding of the probabilities with which outcomes occur, and our tolerance for those uncertainties, will drive the decisions we ultimately make. A risky choice is defined as a decision in which the possible outcomes of the choice are not certain (i.e., the outcomes of an option occur according some probability distribution; Glimcher, 2008). An option with a more variable outcome distribution (greater variance) can be said to be riskier than an option with a less variable probability distribution (lower variance). Given a set of decisions in which choice options have equal expected values but unequal levels of risk, a decision maker can be said to be risk averse if he shows a preference for the less risky option on average. While some people are comfortable 
with uncertain outcomes and are prone to risk-seeking behaviour, others may be highly risk averse and prefer to stick with more certain options when making a decision.

Risk preferences are highly sensitive to the framing and format of the choice. A classic finding in behavioural economics is that a loss of a certain amount feels twice as strong as an equivalent gain, giving rise to the idea that "losses loom larger than gains" (Kahneman \& Tversky, 1979, p. 279). This aversion to loss can also drive changes in risk preferences.

Individuals may display risk aversion when a risky decision results in a positive outcome, but become risk-seekers for the chance to avoid a negative outcome (Kahneman \& Tversky, 1979). Additionally, individuals tend to overweight the occurrence of rare events when all outcomes and their probabilities are explicitly provided-decisions from description-but underweight those same rare events if the information must first be learned-decisions from experience(Hertwig et al., 2004). A meta-analysis by Mata, Josef, Samanez-Larkin, and Hertwig (2011) revealed significant differences in how younger and older adults learn about and approach risk. The authors found no differences in risk-taking behaviour between age groups in decisions from description regardless of choice framing (positive outcomes versus negative outcomes). However, in experience-based decisions, risk-taking behaviour of older adults was dependent on the way in which information about the choice was learned, with different tasks requiring different approaches to learning risk, suggesting that the relationship between risky choice and experience-based information search is an important one when discussing age-related changes in decision-making.

In summary, the literature has shown that older adults generally do not suffer from decreased decision quality despite age-related reductions in information search in experience- 
based decision-making tasks. Several possible age-related differences exist which may contribute to observed declines in information search with age: (1) Older adults may rely on their greater familiarity with specific choice domains when making decisions from experience, lowering their need for further information search; (2) older adults may learn about and use information differently than younger adults, rendering additional information search unnecessary; (3) the improved emotion regulation abilities of older adults may allow them to make more effective use of the information they have during affective decisions; or (4) older adults may approach and understand risk differently than younger adults. In this dissertation, I investigated how these four different aspects of experience-based choice enable older adults to maintain decision quality, despite systematic decreases in information search behaviour. 


\section{LITERATURE REVIEW}

In this section, I present a review of the current state of the literature. First, studies on general age-related changes in cognitive processes involved in decision-making are reviewed. Second, the literature on how information search behaviour changes over the lifespan is examined, including what factors influence the extent of information search prior to choice and how search patterns may change with advancing age. Third, the role of emotion in the context of information search is described. Finally, age-related changes in risk propensity and information search in risky decisions are discussed.

\subsection{GENERAL CHANGES IN DECISION-RELATED COGNITIVE PROCESSES OVER THE LIFESPAN}

Two components of cognitive ability/general intelligence are crystallized intelligenceexperience, knowledge about the world - and fluid intelligence-abstract reasoning, logical thinking, novel problem solving - each of which undergo different trajectories of change over the lifespan (Horn \& Cattell, 1967). While crystallized intelligence tends to improve with age, fluid intelligence peaks in young adulthood and declines steadily afterwards as many of its component processes (e.g., working memory, inhibitory function) experience various levels of age-related decline (Baltes, Staudinger, \& Lindenberger, 1999). These declines in fluid intelligence may be responsible for differences between age groups in decision behaviour. A meta-analysis by Thornton and Dumke (2005) found that younger adults (18-35) outperformed older adults $\left(65^{+}\right)$in a variety of everyday problem-solving and decision-making tasks.

Finucane, Mertz, Slovic, and Schmidt (2005) found that older adults, compared to younger 
adults, showed less comprehension and less response consistency in decision tasks concerning health, nutrition, and finances, and that declines in fluid intelligence partially drove the observed differences. Age has also been associated with declines in feedback learning (Simon \& Gluck, 2013; Simon, Howard, \& Howard, 2010a; 2010b). Finally, there is evidence of age-related declines in basic numeracy (Peters, 2008), estimation of frequencies (Mutter \& Goedert, 1997; Spaniol \& Bayen, 2005), and the interpretation of numerical data (Hibbard, Slovic, Peters, Finucane, \& Tusler, 2001).

Differences in levels of fluid intelligence in individuals may be responsible for observed differences in the selection and application of appropriate cognitive strategies to tasks (Bröder, 2003). Lemaire, Arnaud, and Lecacheur (2004) asked younger and older adults to give estimates of the product of 2 -digit multiplication problems (e.g., $23 \times 67$ ). They found that older adults displayed poorer performance in the task compared to younger adults, were less successful in adapting their strategy selection according to the difficulty of the problem, and showed less consistency in their strategy selection. Geary and colleagues (1991; 1993) showed that in problems of addition and subtraction, older adults were more likely to select strategies that were cognitively less demanding. Given an arithmetic problem (e.g., 9+6) three strategies may be used to determine the solution: (1) retrieval, retrieving the solution from long-term memory; (2) decomposition, breaking down less familiar numbers into more easily processed ones $(9+6=9$ $+5+1=10+5=15$ ); or (3) verbal counting, repeatedly incrementing (or decrementing) the larger value a number of times equal to the smaller value. Geary and colleagues found that older adults relied more often on the simpler strategy of retrieval than younger adults did and when retrieval was unsuccessful were less likely to select a second strategy. Thus, age-related changes 
in fluid intelligence may be responsible for a shift towards solving problems using the least mentally-taxing strategy.

Outside the mathematical domain, Pachur, Mata, and Schooler (2009) found that older adults tended to misapply the recognition heuristic, suggesting difficulty in selecting and applying optimal cognitive strategies. The recognition heuristic predicts that when individuals are presented with two items, they tend to rely on the items' relative familiarity when making judgments about a multitude of features, such as the items' relative size or frequency. The authors presented participants with pairs of names of cities or names of infectious diseases and asked the participants to identify which had the greater population or higher rate of incidence, respectively. For example, given the names of two cities, Halifax and Coquitlam, a person using the recognition heuristic is more likely to recognize Halifax and conclude (correctly) that it has a greater population than Coquitlam, as larger cities tend to be more recognizable. However, simply recognizing the name of an infectious disease does not necessarily mean that that disease has a higher rate of incidence. Thus, applying the recognition heuristic to city cues is a more valid strategy than applying it to infectious disease cues. Pachur et al. (2009) found that older adults were more likely to rely on the recognition heuristic when presented low validity infectious disease cues, providing further evidence of age-related differences in cognitive strategy selection. The observed shift in strategy selection to the simpler end of the spectrum may come as a direct result of age-related declines in cognitive functioning; however, differences in strategy selection do not necessarily result in poorer performance in older adults. Geary and Wiley (1991) found that older adults' performance in addition problems was roughly equivalent to that of younger adults, despite their greater reliance on simpler strategies. 
Cognitive changes due to age may be responsible for the observed shift in how older adults approach decision-making and problem-solving tasks. Despite a greater reliance on simpler strategies, older adults are not always negatively affected by these changes.

Overall, age is associated with a decline in fluid intelligence and general cognitive abilities related to decision making. Declines in fluid intelligence are also responsible for reduction in abilities important to decision making, such as interpretation of numerical information and statistics. Finally, older adults have been found to have difficulties selecting the most appropriate strategies in choice tasks. All of these factors contribute to a general age-related decline in decision quality across the lifespan.

\subsection{INFORMATION SEARCH AND AGING}

The defining factor of experience-based choice is the need for information about choice outcomes and the probabilities with which those outcomes may occur. This information can be gained passively over long periods of time or from short, active periods of pre-decisional information search. For example, a decision about what to eat at an unfamiliar restaurant may be based on years of eating habits and food preferences (passive long-term information gain); in contrast, we are usually unable to sample every dish on the menu and then decide what to order for our meal (active pre-decisional information search). A number of reviews (Mather, 2006; Yoon et al., 2009) and meta-analyses (Mata \& Nunes, 2010) have revealed a small but significant age-related decline in pre-decisional information search across a range of choice domains including health care and medication, various consumer purchases, and political candidates. However, older adults were not found to have significant decreases in decision 
quality across these domains. It is these types of decisions, with periods of active pre-decisional information search, on which I focus this dissertation.

\subsubsection{FACTORS INFLUENCING INFORMATION SEARCH}

Information search can vary greatly based on a number of factors apart from age, such as task constraints, costs to search, and the types of cognitive strategies used. An early metaanalysis by Ford, Schmitt, Schechtman, Hults, and Doherty (1989) revealed that as task complexity and the amount of available information to search increased, individuals relied on less information and simpler cognitive strategies. Similarly, Hills, Noguchi, and Gibbert (2013) presented participants with risky choices with different numbers of options (set sizes of 2, 4, 8, 16, or 32 gambles). Participants experienced the choices with either increasing or decreasing set sizes, manipulated between subjects. While participants took more samples for larger set sizes, they sampled fewer gambles and fewer times per gamble. Rieskamp and Hoffrage (2008) reported similar decreases in information search when participants were presented with decisions under high levels of time pressure.

Information search is not always without its price and these costs can change the extent of pre-decisional search. Bröder (2000) examined how costs affected cognitive strategies and information search. Participants were tasked with acting as imaginary stockbrokers, selecting which of two hypothetical stocks would be the better investment. Correct selections resulted in rewards of a virtual currency that could also be used to purchase information about each stock to aid in subsequent stock predictions. Bröder found that when the costs of purchasing information were high (relative to the amount awarded for correct predictions) participants 
would buy less information and use simpler cognitive rules for making their stock predictions. Similarly, Newell and Shanks (2003) found that as the cost of information increased relative to the reward amount for a correct answer, information search declined and participants favoured the use of a "take-the-best" strategy, making their decisions based on a single piece of information from each option. Finally, Bröder and Schiffer (2003) showed that the cognitive effort required during search represented a type of search cost and that participants used less information if it had to be retrieved from memory versus provided in a format not dependent on memory. One group of participants was given a large set of information concerning 10 people suspected of being involved in a crime to be recalled from memory only, while a second group was provided the same information retrievable from a computer. Participants were then asked to make inferences about which of two presented suspects was more likely to have committed the crime. Participants who had to recall information from memory were significantly more likely to rely on fewer pieces of information and make their inferences based on more limited criteria. In other words, the cognitive effort of recalling the information was much more likely to cause participants to favour a simpler choice strategy (e.g., take-the-best) reliant on less information.

Finally, the stopping rule used to determine when to terminate search is an important factor. Pachur and Scheibehenne (2012) examined the endowment effect-the finding that people place more value on something simply because they own it-using a sampling paradigm. Participants were assigned to provide either the selling or buying price of monetary lotteries, the outcomes of which were learned through repeated sampling. The stopping rules for information search used by participants differed according to their role, with buyers 
stopping after experiencing low value outcomes and sellers stopping after experiencing high value outcomes, suggesting that the cognitive strategy that one selects - potentially determined by the type of decision being made-has a direct impact on the extent of information search.

Compared with younger adults, older adults have been observed to seek out less information during pre-decisional information search periods and this pattern of results has been observed across a variety of choice domains. Older adults will consider less information overall and review information from fewer sources when making choices about buying cereal (Cole \& Balasubramanian, 1993), diamonds (Mata, Schooler, \& Rieskamp, 2007), and cars (Johnson, 1990; Lambert-Pandraud, Laurent, \& Lapersonne, 2005), deciding which apartment to rent (Johnson, 1993; 1997), choosing which political candidates to support (Riggle \& Johnson, 1996), or selecting which over-the-counter medications (Johnson \& Drungle, 2000) or medical treatments (Meyer et al., 1995; Talbot, Meyer, \& Ranalli, 2007) to pursue. Similar findings of agerelated decline in information search have been observed in lab-based studies involving risky monetary choices (e.g., Spaniol \& Wegier, 2012). Despite this, decision quality was found to be roughly equivalent across age groups in these various studies.

In summary, apart from age, factors such as task constraints, search costs, and search strategy selection all appear to influence how we search for and use information before making decisions in a variety of lab-based tasks. Age has been shown to decrease information search in both experimental studies and real-world domains, such as renting an apartment or purchasing mediations. However, although older adults reliably search for less information, they do not suffer any declines in decision quality as a result. 


\subsubsection{DOMAIN FAMILIARITY}

A possible explanation for why older adults rely on less information in experience-based decisions compared to younger adults may be greater familiarity with certain choice domains (e.g., Johnson \& Drungle, 2000). Extensive pre-decisional information search may be unnecessary if one has pre-existing familiarity with a particular decision-making domain. For example, if tasked with making a decision about which of two refrigerators to buy, an individual with a large amount of pre-existing knowledge of refrigerators would need to engage in significantly less information search to reach the same level of expertise as someone who knows very little about refrigerators. ${ }^{1}$ By virtue of their advanced age, older adults have had greater exposure to a variety of domains and may require-or believe they require-less information search when asked to make a decision in one of these domains. In support of this, older adults have been observed to consider less nutritional information when purchasing cereal (Cole \& Balasubramanian, 1993), and to search fewer makes, models, and dealers of cars when looking to buy a new vehicle (Lambert-Pandraud et al., 2005). In both of these situations, older adults may have previously gained familiarity with the domain and therefore may not have needed to engage in as much pre-decisional information search.

One particularly salient domain may be health care decisions as advancing age brings with it a greater number of health issues. Thus, if presented with a medical decision-making

\footnotetext{
${ }^{1}$ Domain familiarity has thus far been defined very narrowly - as knowledge about the specific stimuli being presented that participants must learn about (marbles, refrigerators, prescription drugs, etc.). Domain could also be defined more broadly at a higher level of classification, such as familiarity with consumer purchases in general; or specific types of information presentation. For the purposes of this dissertation the narrow definition is used.
} 
task older adults may already be highly familiar with these kinds of decisions and require less information search before making a choice, compared with younger adults. Meyer, Russo, and Talbot (1995) studied information search and subsequent decision making in younger and older women diagnosed with breast cancer. While both age groups reached equivalent treatment decisions, older women engaged in less information search and made their choices faster than younger women. Zwahr, Park, and Shifren (1999) examined the decisions of woman aged 20 to 70 years old who had to make decisions about receiving estrogen replacement therapy. The authors found that women in their 40s, 50s, and 6os had the highest scores on a pre-test of prior knowledge about the therapy compared to women in the other age brackets, but after being given an information booklet during the session the women in their 6os rated the amount of information provided during the task as most sufficient. The older women were also more likely to proceed with the treatment suggested to them by a doctor while the younger women were more likely to seek a second opinion. Similarly, Johnson and Drungle (2000) observed that older adults searched for less information about over-the-counter pain relievers, compared to other drugs, possibly due to greater familiarity with pain management medications. These findings suggest that greater prior exposure to a specific choice domain may compensate - or even be responsible - for decreased pre-decisional information search in older adults.

Opposing findings were described by Mata and Nunes' (2010) meta-analysis, which found that across a range of studies age differences in pre-decisional information search were largely absent in choices from the health domain. The authors proposed that decisions in this domain did not become more familiar over the lifespan, but rather more relevant. Older adults are likely to find decisions about healthcare to be more relevant than younger adults do and this 
increased relevancy resulted in increased motivation to make the best possible choice, leading to greater pre-decisional information search.

Overall, older adults may benefit from choice domains with which they possess a greater familiarity. With age comes greater experience, manifesting as pre-existing knowledge in domains such as consumer products, nutrition, and healthcare. When asked to make an experience-based choice in such domains, older adults may be able to rely on their pre-existing knowledge, leading to decreased information search compared to younger adults, without a loss in subsequent decision quality. However, it is not clear if pre-existing knowledge simply compensates for the age-related decline in search or whether it is the cause of the decline.

\subsubsection{INFORMATION SEARCH PATTERNS}

One presently understudied dimension of decisions from experience which allow for selfdirected pre-decisional information search is the pattern used during the search period. If presented with a two-option forced-choice task in which outcomes and their probabilities of occurrence must be learned through sequential sampling, a decision maker can sample one option extensively before moving on and sampling the second option (comprehensive search), or continuously switch between the two options throughout the search phase (piecewise search). A meta-analysis by Hills and Hertwig (2010) found that across a number of studies using twooption risky gamble choice tasks, the frequency of switching during sampling was highly predictive of the final choice made in each trial. Participants using a piecewise search pattern were more prone to underweighting rare events, as piecewise search encourages the use of a decision strategy based on round-wise comparisons. As a result, participants selected the option 
that won the most rounds while discounting the magnitudes of the (rare) outcomes.

Comprehensive search resulted in better subjective judgments of expected value compared to piecewise search, leading to greater overall decision quality. To examine which search patterns were used by participants, Hills and Hertwig (2010) introduced a measure, switch ratio, where

$$
\text { switch ratio }=\frac{\text { number of switches }}{\text { number of possible switches }}=\frac{\text { number of switches }}{\text { number of samples }-1}
$$

and $0<$ switch ratio $\leq 1$. A switch ratio near o indicates a very low frequency of switching (comprehensive search) whereas a switch ratio near or at 1 indicates high switching frequency (piecewise search). Information search across all the studies was found to heavily favour a comprehensive search pattern with a median switch ratio of .16. The use of a piecewise pattern was also associated with decreased information search overall (see also Hills \& Hertwig, 2012; Rakow, Demes, \& Newell, 2008).

In contrast, Rottman (2014) found that the use of a piecewise pattern during sampling improved judgments of non-random sample data. Participants selected which of two painkillers to assign to patients in a mock drug-prescription task from which they sampled the influence of the selected drug on different baselines of pain. The baselines were temporally correlated - if pain was high at time $t$ then pain would be similarly high at times $t-1$ and $t+1$. The use of a piecewise pattern led to higher accuracy in the task. However, this was observed only if sample outcomes were temporally correlated, and no effect of search pattern was found if sample outcomes were random. However, sample sizes in this experiment were small and 
predetermined by the experimenter. This may have limited the amount of information available to participants, potentially affecting decision quality.

Chin et al. (2012) examined age differences in information search patterns in a wordsearch task. Participants were given a set of four word-search puzzles of differing difficulties and asked to find as many words as possible in 10 minutes. Participants were allowed to switch between puzzles whenever they wished. Results showed that younger adults switched more often than older adults did; switching frequency was correlated with the difficulty of the puzzle, with the greatest numbers of switches for the most difficult puzzles; and individuals with greater working memory capacity switched more often. However, switching behaviour in this task was not equivalent to that of Hills and Hertwig (2010), or Rottman (2014). In Chen et al.'s study, the probability of switching increased as it became more difficult for participants to find a word in the current puzzle. Therefore, switching to a different puzzle allowed participants to avoid further frustration with the current puzzle and to refocus their efforts, whereas in the other studies, switching between options provided no such relief.

The pattern with which one searches does appear to influence the extent of the search, with frequent switching associated with smaller sample sizes. As patterns of search used in experience-based choice appear to have a role in subsequent decision quality (Hills \& Hertwig, 2010), and pattern selection may be driven by such factors as working memory capacity and age, differences in the extent of information search may be due to differences in search pattern selection across age groups.

Across a wide range of choice domains including healthcare and consumer purchases, older adults have been found to search for less information, compared to younger adults, but do 
not suffer significant declines in decision quality (Mata \& Nunes, 2010; Mather, 2006; Yoon et al., 2009). A potential explanation lies with older adults' greater familiarity with various choice domains. Owing to their greater life experience, older adults may be able to use their preexisting knowledge when required to make a choice in a particular domain. However, whether pre-existing knowledge compensates for the decline in pre-decisional information search, or rather drives it, remains unknown. Additionally, older adults rely on differing search patterns when they do engage in information search. Possibly due to declines in fluid intelligence, older adults rely on simpler cognitive strategies, including less frequent switching in a word search task. Different search patterns have also been found to significantly affect subsequent decision quality, with piecewise search improving decision quality in one domain but decreasing it another.

\subsection{EMOTION, COGNITION, AND AGING}

With advancing age comes an increased ability in regulating one's emotional responses (Blanchard-Fields et al., 1995; Carstensen \& Mikels, 2005) and this increased emotional regulation may help older adults in decision making tasks that involve affective information. Thornton and Dumke (2005) presented a meta-analysis revealing differences between younger and older adults in performance on a wide range of everyday problem-solving and decisionmaking tasks and attributed these findings to age-related declines in cognitive processes. Older adults showed poorer performance on instrumental tasks - tasks requiring goals to be accomplished or skills to be improved. Age differences were significantly smaller when tasks were of an interpersonal nature, suggesting that the affect-rich quality of interpersonal tasks, 
compared to instrumental tasks, helped moderate age-related cognitive declines (Blanchard-

Fields et al., 1995; Blanchard-Fields, Chen, \& Norris, 1997). In a study by Bruine de Bruin et al.

(2010), younger and older adults completed a series of tasks to measure decision-making

competence on a number of dimensions: resistance to framing, applying decision rules,

consistence in risk perception, recognizing social norms, under- and over-confidence, and

resistance to sunk costs. The authors found that 'resistance to framing' and 'applying decision

rules' decreased as a function of age, 'consistency in risk perception' and 'recognizing social

norms' remained unchanged, and 'under- and over-confidence' and 'resistance to sunk costs'

improved with age. Put another way, in tasks of an interpersonal (recognizing social norms) or

affective (resistance to sunk cost) nature, older adult performance was on par with that of

younger adults. These findings suggest that older adults in some way compensate for cognitive

declines due to age through more effective use of the affective information components of

choice. The remainder of this section describes the role of emotion on cognition in general, how emotion regulation changes with age, and the moderating effect of emotion on information search.

\subsubsection{EMOTION AND COGNITION}

Emotion plays a significant role in choice, regardless of age. For example, people select options in a choice in order to minimize possible feelings of regret (Mellers, Schwartz, \& Ritov, 1999). In a study by Finucane, Alhakami, Slovic, and Johnson (2000), affect influenced how people perceived the risks and benefits of nuclear power. Positive information about its benefits improved individual affective state and reduced evaluations of the risks. Inversely, negative 
information increased evaluations of the risks of the technology. Similarly, positive affect can increase decision-making speed, increase efficiency of information search, and decrease the confusion experienced from large volumes of information (Isen, 2001). Periods of positive affect can also improve creative problem solving (Estrada, Isen, \& Young, 1997). Finally, anchoring (Estrada et al., 1997) and primacy effects (Lee \& Sternthal, 1999) are reduced by positive affect. On the other hand, negative affect can slow decision-making and increase information search behaviours (Luce, Bettman, \& Payne, 1997; Luce, Payne, \& Bettman, 2000).

The dual-process theory of information processing put forward by Stanovich and West (2000) and made more widely known by Kahneman $(2003 ; 2011)$ proposes that reasoning and decision-making are largely governed by the interplay of two cognitive systems, referred to as System 1 and System 2. System 1 represents the affective and experiential component driving judgment and decision making and is described as fast, automatic, effortless, intuitive, influenced by past experience and memory, and responsible for feelings and unconscious reasoning. System 2 represents deliberative processing, is analytical, slow, controlled, dependent on logic and evidence, and allows for more flexible reasoning. These systems may not be independent but rather two ends of a single continuum. Shiv and Fedorikhin (Shiv \& Fedorikhin, 1999) asked participants to memorize either a 2- or 7-digit number, walk down a hall to another room, and recite the number aloud. While participants moved from one room to the other an experimenter informed them that as a reward for participating in the study the participants could select one of two snacks: fruit salad or chocolate cake. The majority of participants who had to memorize the 7 -digit number selected chocolate cake whereas the majority of participants who had to memorize the 2-digit number selected fruit salad. The 
authors explained that the cognitive resources of the 7-digit group were depleted compared to the 2-digit group. As a result, the System 1 impulse of wanting the affect-rich option of chocolate cake could not be overridden. Along similar lines, Finucane et al. (2000) found that restricting participants' deliberation time increased their reliance on affective information in a choice task. Thus, decreasing or restricting the capabilities of System 2 increases the influence of System 1 on choice. The observed age-related decline in cognitive resources in older adults may contribute to the increased importance and focus on emotion regulation in later life.

\subsubsection{AGE-RELATED DIFFERENCES IN EMOTION REGULATION}

Older adults have been observed to be more effective and more interested in regulating their emotions compared to younger adults. Older adults are better at maintaining positive affect and avoiding negative affect (Carstensen et al., 2000), show a greater desire to avoid regret (Mellers \& McGraw, 2001), and work to maximize their satisfaction (Loewenstein, Hsee, Weber, \& Welch, 2001). Socioemotional selectivity theory (Carstensen, Isaacowitz, \& Charles, 1999) posits that as we get older we perceive the limitations of our time as being more salient and shift our priorities towards greater focus on emotion regulation. As a result, older adults focus more on their emotional state in order to optimize everyday experience. Two outcomes result from socioemotional selectivity theory: (1) increased age causes an increase in the amount of attention paid to affective components of choice that may help in regulating future emotional states; and (2) a positivity effect is observed in search and memory for information because older individuals focus more on positive information, less on negative information, or both. 
Mather and Carstensen (Mather \& Carstensen, 2003) presented participants with pairs of faces - one face was always neutral while the other was angry, sad, or happy - that were replaced by a single dot located where one of the faces had previously been. Participants were told to press a response key as quickly as possible upon seeing the dot. Older adults were found to respond faster to the dots presented behind positive or neutral faces than those presented behind negative faces, suggesting that older adults were more avoidant of negative stimuli. Blanchard-Fields, Chen, and Norris (1997) presented younger, middle-aged, and older adults with a selection of problems to be solved related to shopping, home management, and conflict resolution between friends. While older adults were found not to differ significantly from younger and middle-aged adults on how to solve problems related to shopping or the home, older adults showed more passive/avoidant strategies for interpersonal conflicts, suggesting avoidance of negative affect with age.

Age-related changes in emotional processing may also impact memory. In a study by Charles, Mather, and Carstensen (2003), participants were shown a series of positive, negative, and neutral images and then asked to recall as many as possible from a set of new and old images. The authors found that the number of negative images correctly recalled-compared to positive or neutral-decreased as age increased. Fung and Carstensen (2003) showed participants advertisements for a variety of products, each paired with a slogan. Slogans were either emotionally meaningful (e.g., "Take flight... your loved ones await”), knowledge-related (e.g., "Take flight... expand your horizons"), or neutral (no slogan). Older adults remembered more information from an advertisement if it contained emotionally meaningful material. 
Despite these results, a meta-analysis by Murphy and Isaacowitz (2008) found little in the way of age-related differences in emotional saliency or preferences for positive/negative information. Also, reasoning in social situations appears to be moderated by participants' cultural upbringing (Grossmann et al., 2012). Older Japanese adults do not display the same positivity effect found amongst older American adults (Grossmann, Karasawa, Kan, \& Kitayama, 2014). Recently, a negativity bias in older adults has been observed. When asked about their memories of a past event - the 2008 Presidential election - both younger and older adults showed memory enhancement if they felt negatively towards the results of the election. Such a bias was previously only reported in younger adults but not in older adults. Finally, as we will discuss later, there is contradictory evidence on how affective information is weighted across the lifespan (Holliday, 1988; Lauriola \& Levin, 2001; Mikels \& Reed, 2009; Weber et al., 2004; Weller et al., 2010), suggesting our understanding of the role of affective information is incomplete.

Overall, however, the evidence suggests that emotional goals are more salient to older adults than younger adults. Thus, older adults attend to, remember, and use affective information differently than their younger adult counterparts. As a result, information search may be biased towards affective information as one gets older.

\subsubsection{INFORMATION SEARCH AND EMOTION}

Older adults tend to prefer less variety in their choices (Novak \& Mather, 2007) and fewer options to select from (Reed, Mikels, \& Simon, 2008). This may be due to age-related declines in cognitive resources necessary for information search and complex decision-making (Finucane et 
al., 2005; Thornton \& Dumke, 2005); however, as significant differences in decision quality are not commonly observed, this is most likely not the case. Another possible-although not mutually exclusive-reason for older adults' decreased information search behaviour may be that older adults have different goals in choice compared to younger adults (Mata \& Nunes, 2010). Specifically, older adults may be more interested in regulating their emotions than in completing a comprehensive search of available information (Hanoch, Wood, \& Rice, 2007; Mather, 2006). Older adults have demonstrated biases towards positive information during predecisional information search, in line with predictions from socioemotional selectivity theory. Mather, Knight, and McCaffrey (2005) found that older adults spent more time examining positive information about an item than negative information in an item-comparison task. Löckenhoff and Carstensen $(2007 ; 2008)$ presented younger and older adults with a healthcare choice task requiring participants to search for and recall information about doctors and health plans. The authors found that older adults showed greater information search and better recall for positive-rather than negative or neutral-information compared to younger adults, suggesting that information search may be influenced by the need to regulate emotional responses. These findings suggest that age increases the desire to maintain one's emotional state and discourages exhaustive information search to avoid the experience of undesirable outcomes.

Emotional state also appears to play a role in regulating how one searches for information. Positive emotional states do not appear to change the extent of search, but search is mediated by negative emotions. Fear appears to increase the extent of information search in 
experience-based choices (Frey et al., 2014). Fear can also increase visual search, whereas disgust will decrease it (Susskind et al., 2008).

Overall, emotion regulation abilities improve with age (Blanchard-Fields, 2007; Blanchard-Fields et al., 1995; Carstensen \& Mikels, 2005), and this improvement may provide older adults with greater insight into variety of affective decision tasks, potentially explaining how older adults are able to match - or even surpass - the performance of younger adults (Thornton \& Dumke, 2005). However, the mechanism for this improvement is not clearly understood, as different studies find different patterns of results with regards to the valence of the affective information involved in a particular choice. Additionally, affective information and current emotional state appears to modulate information search behaviour in different ways. Thus, the role of affect in information search, and how that role changes over the lifespan, requires further study.

\subsection{RISK TAKING OVER THE LIFESPAN}

Whether or not someone decides to take a risk has been described as an interaction between who is taking the risk and when (Figner \& Weber, 2011). The who describes differences between individuals, such as gender or age, whereas the when describes aspects of the decision, such as the decision format or the affective nature of the choice.

\subsubsection{THE WHO}

Older adults represent the who being considered in this dissertation. Reduced risk-seeking behaviour is stereotypically held up as a side effect of aging (Okun, 1976). Findings from the 
Barratt Impulsiveness Scale (Barratt, 1959; Patton, Stanford, \& Barratt, 1995) revealed that older adults regularly report lower levels of impulsivity compared to younger adults (Spinella, 2007). However, while some studies have found evidence of decreased risk-taking behaviour in older adults, others have found that tolerance for risk remains unchanged-or even increases - with age (for a review see Mather, 2006).

\subsubsection{THE WHEN}

The affective nature of the choice will impact whether a risky option will be selected. The emotional responses during choice play a significant role in subsequent risk-taking, as proposed formally by Loewenstein et al. (2001) in their theory of risk-as-feelings. The decision one makes in a risky choice results from a cognitive appraisal of the possible outcomes of the choice and their subjective probabilities. Loewenstein et al. argued that in the past, emotional responses generated by the evaluation of outcomes and their probabilities were considered as a side effect that does not influence the final decision. Under their risk-as-feelings perspective, emotional responses are not only an indirect consequence of the cognitive appraisal, but also a direct result of the possible outcomes and do have an influence on the final decision behaviour. A possible positive outcome directly results in positive feelings, while a possible negative outcome directly results in negative feelings. These feelings would also be influenced by a variety of other factors, including the immediacy of the choice and prior mood, while also feeding back into the cognitive appraisal of the outcomes and their subjective probabilities. 


\subsubsection{THE INTERACTION OF WHO AND WHEN}

Inconsistences exist in regards to how emotional information affects risky choice.

Increased age has been linked to greater risk seeking for losses, suggesting greater weight put on negative outcomes (Weber et al., 2004); less risk seeking for losses, suggesting less weight on negative outcomes (Mikels \& Reed, 2009); and greater risk seeking for gains, suggesting greater weight on positive outcomes (Weller et al., 2010). Other studies have found no age differences in the effects of outcome valence on risky choice (Holliday, 1988) or greater weight placed on both positive and negative outcomes overall (Lauriola \& Levin, 2001).

As emotional state influences information search behaviour, it also shapes our behaviour in risky choice. While experiences of negative affect decline with increased age, different negative emotions influence risk-taking differently. Lerner and Keltner (2001) found that feelings of fear resulted in increased pessimism towards outcomes of risky choices and increased risk aversion, while feelings of anger in participants increased optimistic estimates of risk and increased risk-seeking behaviours. Frey, Hertwig, and Rieskamp (Frey et al., 2014) found that fear increases the degree to which people searched for information in decisions from experience, which modulated their experienced outcomes and final choices.

LEARNING ABOUT RISK. The statistical learning literature has demonstrated that humans appear well adapted to making intuitive statistical inferences about their environment (Fiser \& Aslin, 2001; 2002; Saffran, Aslin, \& Newport, 1996). However, the perception of probabilistic information may undergo different shifts with increased age across differing task formats. In a meta-analysis by Mata et al. (2011), older adults' risk taking in decisions from experience was found to differ significantly from that of younger adults as a function of the format in which 
choice information was learned. No age differences were found if choice information was learned through a pre-decisional information search period; however, if choice information was gained via feedback from repeatedly selecting options for the same choice then age differences were present. Two of the tasks included in the meta-analysis in which younger and older adults differed are the Iowa Gambling Task (IGT) - in which older adults were more risk-seeking than younger adults - and the Balloon Analogue Risk Task (BART) - in which older adults were less risk-seeking. In the IGT, participants are presented with four desks of cards-two "good" decks and two "bad" decks - and draw cards from whichever deck they wish. Printed on the cards are positive and negative values of points that participants gain or lose points based on what is printed on the cards when they are drawn. The good decks are designed so that initial gains are small but grow over time, while the bad decks appear to be good at first but progressively get worse over time. To do well in this task, one must draw cards to first determine which of the decks are good decks while drawing as few cards as possible from the bad decks. Risk-seeking behaviour in this task is operationalized by drawing more cards from the bad decks. Thus, one starts by randomly drawing cards from each deck - highly risky behaviour - followed by focusing in on only drawing cards from the good decks - progressively more risk-avoidant behaviour ${ }^{2}$. In the BART, participants must pump air into a virtual balloon, each pump increasing a pot of money to be won. If the balloon pops from overinflating the amount in the pot is lost, but if the participant elects to stop before the balloon pops then they receive the amount of money in the pot. Optimal behaviour in the BART is to start with only a few pumps

\footnotetext{
${ }^{2}$ Search pattern usage in tasks such as the IGT has not yet been examined.
} 
into the balloon and gradually increasing the amount of air on successive trials. Therefore, one starts with risk-avoidant behaviour that becomes increasingly risk seeking through subsequent trials. The authors found that older adults were more risk seeking in the IGT, but less risk seeking in the BART, compared to younger adults, suggesting that age somehow amplifies the necessary behaviours in a more (or less) risk-seeking direction, possibly resulting in suboptimal performance. No differences were found between age groups in decisions from description.

CHOICE OUTCOMES. In a series of experiments with younger and older adults, Mather et al. (Mather et al., 2012) found age differences in attitudes towards risk in choice problems that included an option with a certain outcome. Participants were presented with a series of decisions from description regarding probabilistic monetary outcomes (e.g., \$10 for sure or a $10 \%$ chance of getting $\$ 100)$. Choice problems consisted of pairs of options with equal or unequal expected values; one option was risky and the other certain or both options were risky. The combinations of these conditions yielded four sets of choice problems. Older adults were found to display a strong preference for certain-but-small over risky-but-large gain options, compared to younger adults. If options involved losses, older adults were more risk seeking and avoided the certain loss more often than younger adults did. No age differences were found if both options in a choice were risky. Thus, Mather et al. concluded older adults exhibited a certainty effect, weighing certainty more than greater expected value if a certain option was present (selecting certain gains and avoiding certain losses). However, these findings were restricted to decisions from description where the probabilities were explicitly provided to participants. The study included no decisions from experience, which involve periods of pre-decisional information search. 
Overall, risk seeking has not been found to reliably change with age. Contradictory evidence has been found regarding how information valence interacts with age to affect risky choice behaviour. However, the format in which information is learned in a choice task does seem to interact with age more clearly, revealing a possible amplifying effect in older adults. 



\section{OVERVIEW OF EXPERIMENTS}

Age has been associated with a decline in information search behaviour-regarding both the extent of search (Mata \& Nunes, 2010; Mather, 2006; Yoon et al., 2009) and search patterns used (Chin et al., 2012) - however; older adults generally do not suffer from decreased decision quality despite age-related reductions in information search in experience-based decision-making tasks. Several possible explanations for this have been presented: (1) Domain familiarity - older adults rely on greater familiarity with specific choice domains when making decisions from experience, either by lowering their need for more information or compensate for the decline in information search; (2) Search patterns-possibly due to declines in fluid intelligence, older adults display a preference for simpler cognitive strategies in decision tasks, and may therefore learn about and use information differently than younger adults, rendering additional information search unnecessary; (3) Emotion regulation - with increased age comes improved emotion regulation abilities that may allow older adults to make more effective use of information during affective decision making; and (4) Risk-older adults approach and understand risk differently than younger adults and these differences may lead to declines in information search.

In this dissertation, I investigated how different aspects of experience-based choice enable older adults to maintain decision quality, despite systematic decreases in information search behaviour. The next four chapters describe a series of experiments that systematically investigate the aspects of information search patterns, emotion, and risk in the domain of experience-based choices. As defined previously, domain familiarity here refers to choices in 
which participants may possibility possess some prior knowledge, such as information about refrigerators in a task requiring decisions about appliance purchases. Domain familiarity was not explicitly manipulated in any of the four experiments as many past studies have reported findings using real-world decision tasks (Cole \& Balasubramanian, 1993; Johnson, 1990; 1993;

1997; Johnson \& Drungle, 2000; Lambert-Pandraud et al., 2005; Mata et al., 2007; Mata \& Nunes, 2010; Mata, Helversen, \& Rieskamp, 2010; Mata, Wilke, \& Czienskowski, 2013; Meyer et al., 1995; Riggle \& Johnson, 1996; Talbot et al., 2007; Zwahr et al., 1999).

\subsection{EXPERIMENT 1}

Experiment 1 examined how the extent of information search and search pattern selection change with age, using a paradigm designed to minimize three of the four factors previously identified - domain familiarity, affect, and risk - that may contribute to older adults' decreased information search behaviour, compared to younger adults. We used a novel paradigm in which participants completed an experience-based proportion judgment task in which they were presented with two bags of virtual marbles and asked to determine which bag contained the greater proportion of marbles of a given target colour. With such a paradigm, domain familiarity was minimized as there was no way that a participant could enter the study with pre-existing knowledge of the proportions of marbles in any of the bags. The impact of affect was minimized as coloured marbles are not particularly affective and no post-trial performance feedback was provided to limit any potential positive (negative) feelings resulting from correct (incorrect) responses. Finally, differences in risk propensity were minimized as the task involved no risky choice, but was rather an experience-based proportion judgment task. With 
such a task, the potential confounds of domain familiarity, affect, and risk, were minimized to allow for the study of age-related changes to pre-decisional information search. Search patterns were left unrestricted such that participants could search using whichever pattern they desired.

Experiment 1 had two goals: (1) to determine whether or not older adults would search for less information than younger adults in a paradigm where the possible confounding factors from previous studies were minimized; and (2) whether there existed an age-related shift in preferences for search patterns. I found that older adults searched for more information, compared to younger adults, in this new paradigm, suggesting that previously observed agerelated declines in information search may have been due to other confounding factors such as domain familiarity, affect, and risk. Additionally, I observed younger adults were roughly split between the two search patterns but older adults showed an overall preference for comprehensive search. Finally, no differences due to age were found for judgment accuracy, but regardless of age, more frequent switching during search was correlated with higher judgment accuracy. The results demonstrated that past studies of age-related changes in pre-decisional information search may have been due to several confounding factors, including a shift in search pattern selection across the lifespan.

\subsection{EXPERIMENT 2}

Experiment 2 was designed to further investigate the role of search patterns on predecisional information search and subsequent decision quality. Experiment 1 found evidence for an age-related preference shift in search patterns in decisions made from experience. Additionally, more frequent switching during search was associated with higher overall 
judgment accuracy, suggesting that search patterns may be highly relevant to decision quality in experience-based choice. However, due to the design of Experiment 1, search patterns were left under the control of participants and were not experimentally manipulated.

The goal of Experiment 2 was to test the possibility of a causal influence of search patterns on accuracy. The marbles task from Experiment 1 was modified to allow search patterns to be enforced and manipulated within participants. As frequency of switching during search was found to be positively correlated with subsequent judgment accuracy in Experiment 1, I predicted that an enforced pattern of piecewise search would result in significantly higher accuracy than comprehensive search. This prediction was confirmed by the results; I found that accuracy was significantly higher when participants used a strictly piecewise search pattern than when they used a strictly comprehensive search pattern, across both younger and older age groups. The results demonstrate that the appropriate selection of information search strategies - specifically the search patterns used-plays an important role in decision quality in experience-based choice.

\section{$3 \cdot 3$ EXPERIMENT 3}

Feedback-based learning and generalization abilities are important skills that unfortunately decline with age (Simon \& Gluck, 2013; Simon, Howard, \& Howard, 2010a; 2010b). This decline may be mediated through the use of affect-rich feedback. Gorlick et al. (2013) presented younger and older adults with a task involving rule-based learning and found that the presentation of affect-rich feedback (happy and angry faces) was able to attenuate age- 
related declines in learning. However, similar effects of feedback on information search in experience-based choice have received insufficient attention.

The goal of Experiment 3 was to examine the interaction of age and affective feedback on subsequent information search and decision quality. Participants completed a modified version of the marbles task used in Experiments 1 and 2 that included post-trial performance feedback - whether they had answered the previous trial correctly or incorrectly. Feedback was either affect-rich (happy or angry faces) or affect-poor (the words "CORRECT" and "INCORRECT"). I predicted that feedback in general would result in decreased information search following correct responses and increased information search following incorrect responses, and that these effects would be amplified in older adults as they are more susceptible to endorsing "hot hand" effects (Castel, Rossi, \& McGillivray, 2012). Both the extent of information search and search pattern selection were unaffected by participant age group or the post-trial feedback provided. However, judgment accuracy was modulated by the interaction of age group and feedback type, with greater accuracy for younger adults when provided affectpoor feedback than affect-rich, but no difference due to feedback in older adults. These results add to the growing literature on how the processing of affective information changes across the lifespan and the role of feedback in experience-based choice tasks.

\section{$3 \cdot 4$ EXPERIMENT 4}

Studies examining age-related changes in risk taking have produced inconsistent results (e.g., Holliday, 1988; Lauriola \& Levin, 2001; Mikels \& Reed, 2009; Weber et al., 2004; Weller et al., 2010). One common experience-based paradigm for investigating risk taking behaviour 
presents participants with a choice between a smaller reward with low (or zero) outcome variance and a larger reward with high outcome variance. Outcome information is learned via experiential sampling. As both outcomes are usually equated in their expected values, selection of the high variance outcome is interpreted as risk-seeking behaviour. Recently, a certainty effect has been observed in description-based choice, with older adults preferring certain-butsmall gains over risky-but-large ones, to a greater extent than younger adults, suggesting older adults play greater weight on certain outcomes and discount larger uncertain outcomes (Mather et al., 2012).

The goal of Experiment 4 was two-fold. Firstly, I sought to determine if older adults are able to correctly identify the option which has the higher expected value, to the same degree as younger adults, when controlling for risk. Age-related declines in fluid intelligence (Baltes et al., 1999; Horn \& Cattell, 1967) and strategy selection (Horn, Pachur, \& Mata, 2015; Pachur et al., 2009), specifically in arithmetic problems (Lemaire et al., 2004), may result in poorer performance in older adults. While past age-differences in risk taking may have been the result of changes to risk tolerance over the lifespan, another possibility is past results have been confounded by cognitive decline that prevented the proper identification of the higher value option. Results showed both age groups were similarly able to correctly identify the option with the higher expected value, with no difference in information search behaviour, suggesting past differences in risk taking may due to other factors.

The second goal of Experiment 4 was to determine if the certainty effect found by Mather et al. (2012) manifests in experience-based choice and, if so, whether it is due to older adults' desire to avoid risk (variance) or to avoid options that result in zero dollar outcomes. No 
evidence for a certainty effect was found, suggesting it may be an artifact of the descriptionbased paradigm used by Mather et al. 



\section{EXPERIMENT 1}

Past research has revealed several possible confounding factors that may impact predecisional information search behaviour. First, older adults may have greater domain familiarity with certain choices - such as hypothetical consumer purchases (e.g., Mata et al., 2007) - potentially modulating the extent of information search engaged in by older adults. Second, older adults have been shown to prioritize positive information - relative to neutral or negative information - to a greater extent than younger adults (Löckenhoff \& Carstensen, 2007; 2008; Mather et al., 2005), this may lead to potential differences in search if outcome information is affective. Finally, an interaction of age and the format in which probabilistic information was learned during various experience-based choice tasks has been found, which appears to guide subsequent risk-taking behaviour (Mata et al., 2011). Older adults displayed greater riskaversion, compared to younger adults, if learning during the task encouraged increasingly greater risk-seeking, but greater risk-seeking behaviour if learning encouraged increasingly greater risk-averse behaviour.

To avoid these potential confounds a new experience-based choice task was implemented. Participants completed an experience-based proportion judgment task in which they were presented with two bags of virtual marbles and asked to determine which bag contained the greater proportion of marbles of a given target colour. Thus, participants could not have had any familiarity with the task domain; the task contained no affective information, nor any elements of risk. With such a task, the potential confounds of domain familiarity, affect, 
and risk, were minimized to allow for the study of age-related changes to pre-decisional information search.

In this experiment I first sought to determine whether previously observed declines in older adults' information search may have been driven by several confounding factors, and whether there exists an age-related preference shift in the search patterns used during predecisional information search. First, I predicted that age differences in the extent of information search would decrease, or disappear altogether, when the confounding factors were minimized. Second, as piecewise search may be cognitively less demanding - it does not require the explicit sample tracking that may be necessary in comprehensive search-and older adults have been shown to rely on simpler cognitive strategies across a variety of tasks (Geary et al., 1993; Geary \& Wiley, 1991; Lemaire et al., 2004; Pachur et al., 2009), I predicted that older adults would rely more heavily on piecewise search than younger adults.

\subsection{METHOD}

\subsection{PARTICIPANTS}

All participants provided written consent to participate in the study, which was approved by the Research Ethics Board at Ryerson University. Participants included 40 younger adults (20 female) and 39 older adults (20 female). Three additional participants (two younger and one older) were recruited but excluded for not following experimental instructions. Both groups were recruited from the community and received 10 Canadian dollars (CAD) per hour for their participation. Participants had the opportunity to win an additional cash bonus for each correct answer given. Characteristics for the final sample are shown in Table 1. Compared 
with younger adults, older adults had significantly higher levels of education, $t(77)=3 \cdot 32$, $p=.001, d=.76$, and lower Corsi spans, $t(77)=6.88, p<.001, d=1.57$. Other measures showed no significant age differences.

\subsubsection{PROCEDURE}

Participants completed the marbles task, an experience-based proportion judgment task (Figure 1). Participants were presented with two virtual bags of coloured marbles and asked to determine which of the bags contained the greater proportion of marbles of a specific target colour. To learn how colours were distributed within the bags participants could sample marbles one by one from either of the two bags, via key presses, as many times as they wished. Sample outcomes were drawn from randomly generated probability distributions for each bag. The probability distributions were generated in the following way: One bag was randomly assigned to have the greater proportion $p$ of marbles of the target colour (i.e., this bag was the correct answer for that trial), where $p$ was a randomly selected value between 0.20 and 0.90 , inclusive. The second bag was then assigned a random proportion between 0.10 and $p-0.10$, inclusive. Thus, if the "correct" bag contained a proportion of 0.50 of the target colour, the "incorrect" bag could contain any proportion between 0.10 and 0.40 of marbles of the target colour. The smaller the difference in target-colour proportions between the two bags, the higher the task difficulty. Difficulty has been shown to be positively correlated with switching frequency during search (Chin et al., 2012) and was therefore a variable of potential interest.

Each bag contained marbles in two colours: the target colour and a distractor colour. Six colours were used in the task - red, yellow, magenta, green, blue, and cyan. The target colour 
and the distractor colours were randomly assigned in each trial with the restrictions that each was unique within a trial, each of the six target colours appeared an equal number of times throughout the experiment, and the distractor colours differed between bags. To learn about how colours were distributed between the two bags, participants sampled sequentially from each of the two bags via keystrokes; participants pressed the $C$ key to sample from the left bag and the M key to sample from the right bag. The result of each sample was displayed on screen for 750 ms. Participants were allowed to sample as many marbles as they felt necessary, using whatever pattern of search they wished. Once participants felt they knew which bag contained the greatest proportion of marbles of the target colour they pressed the $\mathrm{Q}$ key to answer. Correct answers were awarded 1o points, which were converted to cash upon completion of the study at a rate of 1 point $=\$ 0.01$ CAD. No post-trial feedback was provided .

To present the stimuli and collect responses, we used MATLAB version R2011B (The MathWorks Inc.) with the Psychophysics Toolbox extension (Brainard, 1997) version 3.0.9, running on an Intel Core 2 Quad 2.40 GHz 32-bit Windows Vista desktop computer with 4GB of RAM and a 23-inch LCD display. All text appeared in a black 53-point typeface on a white background.

Participants were tested individually in a quiet testing room. After signing the consent form, participants received task instructions and completed a three-trial practice version of the marbles task. Participants then completed the experimental version of the task consisting of 48 randomly-generated trials. After every 12 trials participants were given a self-paced break. After the marbles task participants completed the Need for Cognition scale (Cacioppo, Petty, \& Kao, 1984), an 18-item questionnaire measuring enjoyment of effortful cognition; the Lipkus 
Numeracy scale (Lipkus, Samsa, \& Rimer, 2001), an 11-item questionnaire measuring mathematical proficiency pertaining to concepts such as fractions, decimals, percentages, and proportions; a forward digit span task; and a computerized version of Corsi's block tapping task (Berch, Krikorian, \& Huha, 1998; Kessels, van Zandvoort, Postma, Kappelle, \& de Haan, 2000).

\subsection{RESULTS}

The analyses focused on three aspects of task performance: (1) accuracy, operationalized as the proportion of correct responses based on participants' experienced sample histories;

(2) extent of information search, operationalized as the total number of marbles drawn per trial; and (3) search patterns. To examine search patterns, we calculated the switch ratio (Hills \& Hertwig, 2010) for each participant as the ratio of the number of switches and number of possible switches (number of samples -1 ). Thus, switch ratio is a value greater than o and less than or equal to 1 , with values nearer o indicating the use of a more comprehensive search pattern, and values nearer 1 indicating the use of a more piecewise search pattern. Given the aforementioned finding of a link between difficulty and switch frequency (Chin et al., 2012), I binned trials into three difficult levels ( $N$ representing the number of trials per difficulty level, across participants): easy $(N=1264)$ was a difference above $\cdot 31$, moderate difficulty $(N=1273)$ was a difference between .18 and .31 , and hard difficulty $(N=1255)$ was a difference between .10 and .18. 


\subsubsection{ACCURACY}

A 2 (age group: younger vs. older) $\times 3$ (difficulty: easy, moderate, hard) analysis of variance (ANOVA) on accuracy was conducted. There was no significant main effect of age group on accuracy, $p=.863$, with younger adults, $M=.93,95 \% \mathrm{CI}[.91, .95]$, and older adults, $M$ $=.93,[.91, .95]$, showing similar levels of accuracy. The main effect of difficulty was significant, $F(2,154)=12.65, p<.001$, partial $\eta^{2}=.14$. Planned linear contrasts revealed that as difficulty increased, accuracy decreased, $F(1,77)=12.17, p<.001$, partial $\eta^{2}=.22$, with accuracy being highest for easy trials, $M=.96,[.95, .97]$, followed by moderate trials, $M=.92,[.91, .94]$, and hard trials, $M=.91,[.88, .93]$. The Age Group $\times$ Difficulty interaction was not significant, $p=.141$. To test for potential ceiling effects, we collapsed across age groups and examined overall accuracy. Although 10 of the 79 participants answered correctly on each trial, overall accuracy was significantly below ceiling for each level of difficulty: easy, $t\left(7^{8}\right)=6.00, p<$. oo1; moderate, $t\left(7^{8}\right)$ $=8.11, p<.001 ;$ and hard $, t(78)=8.47, p<.001$.

\subsubsection{EXTENT OF INFORMATION SEARCH}

A 2 (age group) $\times 3$ (difficulty) ANOVA on the number of marbles sampled was conducted. The main effect of age group was significant, $F(1,77)=4.19, p=.044$, partial $\eta^{2}=.05$, with older adults, $M=40.6$, $[34.6,46.6]$, sampling more than younger adults, $M=31.9$, [25.9, 37.8]. The main effect of difficulty was also significant, $F(2,154)=67.26, p<.001$, partial $\eta^{2}=.47$. Planned linear contrasts revealed that as difficulty increased, sampling also increased, $F(1,77)=$ 80.50, $p<.001$, partial $\eta^{2}=.51$, with sampling being lowest for easy trials, $M=28.6,[25.4,31.8]$, followed by moderate trials, $M=36.6$, [32.2, 41.0], and hard trials, $M=43.5,[38.0,49.1]$. The Age 
Group $\times$ Difficulty interaction was not significant, $p=789$. Finally, sample size correlated significantly with accuracy for younger adults, $r=.40, p=.011$, but not for older adults, $r=.22$, $p=.171$.

\subsubsection{SEARCH PATTERNS}

A 2 (age group) $\times 3$ (difficulty) ANOVA was conducted on switch ratios as a measure of search pattern used during sampling. The main effect of age group was significant, $F(1,77)=$ $4.53, p=.037$, partial $\eta^{2}=.06$, with younger adults, $M=.43,[.32, .55]$, switching more often than

older adults, $M=.25,[.13, .37]$. The main effect of difficulty was not significant, $p=.421$, nor was the Age Group $\times$ Difficulty interaction, $p=.704$. Switch ratio did not correlate significantly with degree of information searched for either younger adults, $r=.03, p=.843$, nor older adults, $r=$ $.13, p=.419$.

To examine the age-related shift in search pattern selection, Figure 2 presents a kernel density plot of switch ratios without collapsing across trials, for both younger and older adults. While this plot does not average switch ratios across trials and thus the individual as a level of analysis is lost, it does demonstrate that older adults more strongly favour comprehensive search over piecewise search, compared to younger adults.

Lastly, to examine the link between search pattern and accuracy, I conducted a median split on switch ratio to divide participants into frequent and infrequent switchers. There was a significant group difference, $F(1,77)=6.40, p=.013$, partial $\eta^{2}=.08$, with higher accuracy in the frequent-switch group, $M=.95,[.93, .96]$, than in the infrequent-switch group, $M=.91,[.90, .93]$. Of note, sample size did not differ significantly between the frequent-switch group, $M=34.8$, 
[28.6, 40.9], and the infrequent-switch group, $M=37.6$, [31.5, 43.6]. Finally, frequent and infrequent switchers showed no significant differences on any of the cognitive measures listed in Table 1 . These results suggest that the observed differences in accuracy between the two groups may have largely been the result of the differing search patterns each had employed.

\subsubsection{BACKGROUND MEASURES}

Only a significant correlation of numeracy and switch ratio was found in younger adults, $r=.43, p=.006$, such that individuals with higher numeracy scores switched less frequently during search. All other correlations for both age groups were not significant.

\section{$4 \cdot 3$ DISCUSSION}

In this experiment, younger and older adults completed an experience-based proportion judgment task in which they sampled to determine which of two virtual bags contained a greater proportion of marbles of a target colour. Both age groups achieved a high level of accuracy $(M=.93)$, with average performance being below ceiling. Older adults sampled more than younger adults, contrary to previous findings in the literature (e.g., Mata \& Nunes, 2010; Spaniol \& Wegier, 2012). One reason for this discrepancy may be that the marbles task was designed to minimize the possible effects of domain familiarity, affect, and risk. These factors may have given rise to age differences in information search in previous studies. Furthermore, the marbles task is an experience-based proportion judgment task, whereas previous studies have examined more complex types of decisions, usually involving preference-based choices. A direct comparison with previous studies of decisions from experience may therefore not be 
warranted. However, this difference in sampling may not be of significant consequence as the extent of information search was correlated with accuracy in younger adults but not in older adults, suggesting that older adults may have been oversampling. Despite greater information search, there was no significant increase in accuracy in the older adults. This lack of a difference may have been due to the two age groups relying in different patterns during search.

The major novel finding in Experiment 1 was that older adults tended to switch between options less frequently than younger adults. The finding of a significant correlation between switch ratio and decision accuracy suggests that older adults may have employed a less effective search pattern in this task. The lack of difference in accuracy between the age groups may be explained by the greater extent of information search in the older adult sample. Had the extent of sampling been manipulated to higher levels - perhaps through a set minimum level of sampling - I believe that piecewise search would still remain the better strategy as the cognitive demands of both strategies would remain roughly in line with one another. Alternatively, for very large sample sizes, an explicit comprehensive strategy would become more difficult to apply and make the accuracy difference between the two strategies even greater.

One potential problem in examining search behaviour in the way done here is that switch ratio is a coarse measure of search pattern, as it distils a highly variable behaviour into a single value. Consider the following example: One participant employs a strictly comprehensive search pattern (switches between options only once per trial) during the first half of experimental trials, then uses a strictly piecewise pattern (constantly switching between options 
after each sample) for the remainder of trials ${ }^{3}$. This would result in a switch ratio of $0.5 . \mathrm{A}$ second participant also achieves a switch ratio of 0.5 but does so by switching options after every other sample on each trial. The switch ratio measure would not capture the behavioural difference between the two individuals. Thus, the kernel density plot of switch ratios in Figure 2 shows, without collapsing across trials, that older adults more strongly favour comprehensive search over piecewise search, compared to younger adults. It should also be noted that this behaviour in older adults is counter to what I initially predicted. Prior literature provides evidence for an age-related shift towards the use of simpler strategies in choice (Geary et al., 1993; Geary \& Wiley, 1991; Lemaire et al., 2004; Pachur et al., 2009). I had conjectured that piecewise search represents a less cognitively demanding strategy than comprehensive search, and therefore expected that older adults would favour the former. However, it may be that piecewise search is less intuitive than comprehensive search, and that older adults' increased reliance on comprehensive search represents a metacognitive failure.

Experiment 1 provided evidence of age-related differences in pre-decisional information search behaviour in an experience-based task. While older adults sampled more than younger adults before making their judgments, there was no age difference in accuracy. Accuracy decreased and the extent of information increased as trial difficulty increased; however, there was no interaction of difficulty with age in either. With regards to search patterns, I found

\footnotetext{
${ }^{3}$ To help rule out the possibility of systematic changes in search behaviour over the course of the experiment, I divided trials into quartiles and performed a 2 (age group) $\times 4$ (quartile) mixed design ANOVA. This analysis yielded no significant main effect of quartile and no Age Group $\times$ Quartile interaction, both $p>.135$.
} 
evidence for an age-related shift towards the use of comprehensive search. Overall, increased switching was associated with higher accuracy. However, as sample size and search pattern were only measured but not manipulated, we conducted Experiment 2 to investigate the causal effect of specific patterns on subsequent decision quality by manipulating search patterns explicitly. 



\section{EXPERIMENT 2}

Experiment 1 was designed to investigate the extent of information search and subsequent decision quality when the confounding factors of domain familiarity, affect, and risk were minimized. Results revealed frequent switching (piecewise search) was correlated with higher judgment accuracy, compared with infrequent switching (comprehensive search). Additionally, there was evidence of an age-related shift in preference for search patterns, with older adults showing a greater preference for comprehensive search than for piecewise search; however, search patterns were not manipulated experimentally. As previous studies addressing patterns of search have also used unrestricted sampling but been correlational in nature (Frey et al., 2014; Hills \& Hertwig, 2010), or have enforced search patterns but with restricted sample sizes and non-random sample outcomes (Rottman, 2014), I sought to systematically investigate the effect of experimentally-manipulated search patterns with random sample outcomes and an unrestricted degree of sampling. I was interested in what impact search patterns would have on the extent of information search and the quality of the subsequent decision when patterns were enforced and how enforced patterns would interact with age. Hills and Hertwig (2010) suggested that the application of a piecewise search pattern results in the use of a round-wise decision rule in choice. Rottman (2014) found the use of enforced piecewise search improved decision quality; however, this was the case only when outcomes were autocorrelated and not random. Thus enforcing the use of a piecewise pattern may not result in the performance improvement seen in Experiment 1. However, since past findings have been so mixed-with 
piecewise search improving decision quality in one domain (Rottman, 2014) but decreasing it in another (Hills \& Hertwig, 2010) - this was an issue that warranted further investigation.

The design of Experiment 2 was identical to that of Experiment 1, with the following exceptions. First, search patterns were enforced rather than left under participants' control. Each participant completed a set of trials once using a strictly comprehensive pattern (could only switch options once per trial) and again using a strictly piecewise pattern (were required to switch options after each sample). The order of the search patterns was counterbalanced across participants. To compare the effectiveness of both search patterns directly trials were no longer randomly generated; instead, the same set of trials was used for both search patterns. This also allowed me to systematically manipulate the difficulty of the trials (i.e., the relative difference in proportions between the two options). Additionally, the task was designed to be more difficult than in Experiment 1 due to concerns regarding possible ceiling effects. Finally, participants provided ratings of confidence in their answers after each trial, allowing me to examine subjective confidence in the use of both search patterns. Based on evidence from the previous experiment, I expected that the use of piecewise search would result in greater accuracy than the use of comprehensive search. With trials of greater difficulty, I expected overall accuracy to decrease and the extent of information search to increase, but I had no hypothesis regarding how specific search patterns would interact with the increased difficulty of trials. 


\subsection{METHOD}

\subsubsection{PARTICIPANTS}

All participants gave written consent for the study, which was approved by the Research Ethics Board at Ryerson University. Participants included 40 younger adults (19 female) and 40 older adults ( 24 female). An additional seven participants (four younger and three older) were recruited but excluded for not following experimental instructions or a history of self-reported health problems. Both groups were recruited from the community and received \$10 CAD per hour for their participation. Participants had the opportunity to win an additional cash bonus for each correct answer given. Characteristics for the final sample are shown in Table 2. Compared with younger adults, older adults had significantly higher levels of education, $t(78)=2.07, p=.042, d=.47$; lower levels of numeracy, $t(77)=2.72, p=.008, d=.62$; lower Corsi spans, $t(76)=4.83, p<.001, d=1.11$; and lower digit spans, $t(76)=3.04, p=.003, d=$ .69. Other measures showed no significant age differences.

\subsubsection{PROCEDURE}

All participants completed the same 12 choice problems (Table 3) four times, twice using piecewise search and twice using comprehensive search, giving a total of 48 trials. The order of the two 24-trial blocks (comprehensive vs. piecewise search) was counterbalanced across participants in each age group. The correct answer for each trial appeared once on the left and once on the right in each block. On each trial, following the choice, participants provided confidence ratings on a scale from $50 \%$ to $100 \%$, in 10 percentage point increments. During the comprehensive search block, participants could begin sampling by pressing either the $\mathrm{C}$ or $\mathrm{M}$ 
keys (left and right bag, respectively). The results of each sample were displayed on screen for $750 \mathrm{~ms}$. Once they had sampled the initial side to their satisfaction they pressed the P key to signal that they wished to switch sides, and were allowed to begin sampling from the opposite side. When they were ready to make their final decision participants pressed the Q key. During the piecewise search block, participants began by sampling from whichever option they wished and then had to switch options after each sample by pressing the $\mathrm{C}$ and $\mathrm{M}$ keys in alternation. Pressing either the $\mathrm{C}$ or $\mathrm{M}$ key more than once in a row did nothing. Once participants had sampled to their satisfaction they pressed the Q key to answer.

\subsection{RESULTS}

\subsubsection{ACCURACY}

A 2 (age group: younger vs. older) $\times 2$ (search pattern: comprehensive vs. piecewise) $\times 3$

(difficulty: moderate, hard, very hard) ANOVA on accuracy was conducted. The main effect of age group was not significant, $p=.926$. The main effect of search pattern was significant, $F(1,78)$ $=53.46, p<.001$, partial $\eta^{2}=.41$ (Figure 3 ), with higher accuracy for piecewise search, $M=.90$, $95 \%$ CI $[.88, .92]$, than for comprehensive search, $M=.80,[.77, .82]$. This effect was qualified by a significant Age Group $\times$ Search Pattern interaction, $F(1,78)=4.08, p=.047$, partial $\eta^{2}=.05$. Posthoc tests revealed a significant difference for younger adults, $F(1,39)=47.69, p<.001$, partial $\eta^{2}$ $=.55$, who were more accurate during piecewise, $M=.92$, $[.89, .94]$, than comprehensive search, $M=.78,[.74, .82]$. The effect was larger in younger adults than older adults, $F(1,39)=12.88, p=$ .001 , partial $\eta^{2}=.25$, who were more accurate using piecewise, $M=.89$, $[.86, .91]$, than comprehensive search, $M=.81,[.78, .84]$. The main effect of difficulty was also significant, $F(2$, 
156) $=24.34, p<.001$, partial $\eta^{2}=.24$. Planned linear contrasts revealed that as difficulty increased, accuracy decreased, $F(1,78)=42.67, p<.001$, partial $\eta^{2}=.35$, with accuracy being greatest for moderate trials, $M=.90,[.88, .92]$, followed by hard trials, $M=.84,[.82, .86]$, and very hard trials, $M=.80,[.78, .83]$. The interactions of Age Group $\times$ Difficulty, $p=.429$, Search Pattern $\times$ Difficulty, $p=.158$, and Age Group $\times$ Search Pattern $\times$ Difficulty, $p=.930$, were all nonsignificant.

\subsubsection{EXTENT OF INFORMATION SEARCH}

A 2 (age group) $\times 2$ (search pattern $) \times 3$ (difficulty) ANOVA on sample sizes was conducted. The main effects of age group, $p=.086$; and search pattern, $p=.673$, were not significant. The main effect of difficulty was significant, $F(2,156)=28.24, p<.001$, partial $\eta^{2}=.27$. This effect was qualified by a significant Search Pattern $\times$ Difficulty interaction, $F(2,156)=15.65$, $p<.001$, partial $\eta^{2}=.17$, reflecting the fact that the difficulty-related increase in sampling was greater for piecewise search, $F(1,79)=43.99, p<.001$, partial $\eta^{2}=.36$, than for comprehensive search, $F(1,79)=4.15, p=.045$, partial $\eta^{2}=.05$, though the effect was significant for both search patterns (Figure 4). The interactions of Age Group $\times$ Pattern, $p=.974$, Age Group $\times$ Difficulty, $p$ $=.306$, and Age Group $\times$ Pattern $\times$ Difficulty, $p=.654$, were all nonsignificant. Additionally, I found that accuracy was significantly correlated with the number of samples made for comprehensive search, $r=.24, p=.029$, but not for piecewise search, $r=.18, p=.120$. 


\section{$5 \cdot 2 \cdot 3$ CONFIDENCE}

Finally, a 2 (age group) $\times 2$ (search pattern) $\times 3$ (difficulty) ANOVA on post-trial confidence ratings was conducted. Only the main effect of difficulty was significant, $F(2,156)=$ 34.26, $p<.001$, partial $\eta^{2}=.30$, with confidence ratings decreasing as difficulty increased.

\subsubsection{BACKGROUND MEASURES}

Several interesting correlations were observed (Table 4). In younger adults, the extent of information search was found to be strongly correlated with Corsi span. Due to the design of the marbles task - with sampled information from the two bags appearing on different sides of the screen-greater visuospatial working memory would allow for more successful tracking of sample outcomes and therefore greater information search. However, no correlation between sample size and judgment accuracy was found, suggesting that the additional sampling did not lead to improvements on judgment accuracy, and none of the measures of fluid intelligence appeared to have any effect on judgment accuracy for younger adults. In older adults, higher levels across all four measures of fluid intelligence were correlated with increased accuracy when using comprehensive search. For piecewise search, only Corsi span was positively correlated with judgment accuracy.

\section{$5 \cdot 3$ DISCUSSION}

In this experiment I sought to investigate the effect of pre-decisional information search patterns on accuracy, using the previously developed marbles task. Several novel observations regarding patterns of information search behaviour were made. Firstly, when search pattern use 
was enforced both age groups made more accurate judgments when using the piecewise pattern than the comprehensive pattern. Accuracy for younger adults increased from $78 \%$ to $92 \%$ correct, whereas older adults' accuracy increased from $81 \%$ to $89 \%$ correct. One possible explanation for the observed increase in performance may be that a piecewise search pattern is cognitively less demanding than a comprehensive one. When using explicitly comprehensive search to make a judgment one must keep track of four different counts - the number of samples drawn from each option and the number of times the target colour was seen during each of those samples - then use those counts to calculate two proportions and make a final comparison between the two prior to answering. One also could eschew explicit tracking for a more passive approach to frequency tracking by letting samples simply "wash over" them; however, it is not possible to discern which approach participants actually used given the experimental design used here. If using a piecewise pattern, one needs only keep a single difference score in memory (e.g., +1 to a counter if the target was seen in one option, -1 if the target was seen in the other option, $\mathrm{o}$ if seen in both or neither) and then make their decision based on the final difference score. However, it remains unclear whether participants explicitly used a difference score approach when engaged in piecewise search. Such an explicit pattern may also be less intuitive, despite being cognitively less demanding than comprehensive search, and, as such, older adults displayed a preference for comprehensive search over piecewise search.

The absence of age differences is important here. Older adults were able to achieve similar levels of decision accuracy, compared to younger adults, despite declines in numeracy and working memory. With search patterns enforced, older adults also showed a boost in 
performance for piecewise search, suggesting that appropriate search pattern selection may help compensate for age-related cognitive decline (e.g., the observed age-differences in numeracy, Corsi span, and digit span of our older adult sample). However, the two age groups benefitted to different degrees, with younger adults showing a greater increase in accuracy than older adults. This difference in the amount of improvement between age groups may have been driven by older adults' slightly greater sampling, compared to younger adults, as increased information search was correlated with improved performance for comprehensive search, but not in piecewise search.

As in Experiment 1, I observed that older adults engaged in a greater degree of search in contrast to several recent studies (e.g., Mata \& Nunes, 2010; Spaniol \& Wegier, 2012). This may possibly be explained by the fact that our marbles task was designed to control for the confounding factors of domain familiarity, affect, and risk. It may also be the case that the task was simply too dissimilar to past studies of experience-based choice, which are often based on financial gambles (Hau, Pleskac, \& Hertwig, 2010; Hau, Pleskac, Kiefer, \& Hertwig, 2008; Hertwig et al., 2004; Hills \& Hertwig, 2010), to allow for meaningful comparison. We found no difference in participants' confidence in their answers when using each of the two patterns as a function of age group or search pattern. Finally, as expected, the difficulty manipulation decreased accuracy, increased the extent of information search, and decreased participants' confidence in their responses.

One limitation was that sample sizes were not experimentally manipulated in Experiment 2. This was done to investigate whether the two different patterns of search would modulate the degree of information search. Although I did observe a Pattern $\times$ Difficulty 
interaction in the number of samples, this was most likely not directly due to the specific search patterns. As difficulty increases it is easy to modulate search when using a piecewise search pattern; however, if restricted to the use of a comprehensive pattern, one would not be able to make a judgment regarding the difficulty of the trial until after switching options - as difficulty is defined as the relative difference between the two options. Restricting both search patterns and the number of samples available could prove to be an interesting direction of further study.

Overall, the results of Experiment 2 show the importance of search pattern selectionthe same participants, completing the same set of trials, with the same amount of information, were able to improve their performance by over 10 percentage points on average, just by using a piecewise search pattern. Older adults have been observed to show roughly equivalent decision quality, compared to younger adults, across a variety of tasks. Results from Experiment 1 found that older adults relied on less effective search strategies (i.e., comprehensive search) in experience-based choice tasks. It is possible that older adults may be able to outperform younger adults in such choice tasks had they used taken advantage of piecewise search patterns during pre-decisional information search. 



\section{EXPERIMENT 3}

Age is associated with deficits in learning across a wide variety of tasks (Simon \& Gluck, 2013; Simon, Howard, \& Howard, 2010a; 2010b). It has also been shown that this decline may be mediated using emotionally-valenced feedback in a task relying on rule learning and set shifting (Gorlick et al., 2013). However, the effect of post-trial feedback on information search and decision quality in experience-based choice has received insufficient attention. My goal for Experiment 3 was to examine the interaction of age and post-trial feedback on subsequent information search and decision quality. Two forms of feedback were used: Affect-rich (consisting of pictures of a young woman smiling or frowning), and affect-poor (consisting only of the words "CORRECT" and "INCORRECT").

Firstly, I was interested in the role of feedback on the extent of information search and subsequent accuracy, specifically if feedback results in participants modulating information search behaviour on subsequent trials, and if so, how the type of feedback (affect-rich or affectpoor) may interact with age. I hypothesised that feedback in general would result in decreased information search following correct responses and increased information search following incorrect responses, and that any observed effect would be stronger in older adults than in younger adults, as older adults have been found to be more susceptible to endorsing "hot hand" effects during runs (Castel et al., 2012).

Secondly, I was interested in the role of feedback on search patterns. As the previous experiments have demonstrated, older adults select different search patterns in experiencebased choice when given the opportunity and both age groups gain a boost in accuracy when 
using a piecewise search pattern over a comprehensive search pattern. However, as the role of feedback in general has received so little attention in this literature I had no specific hypothesis about how it might influence the information search patterns employed in this task.

Several manipulations could have been used to fill the role of examining affect on information search behaviour, such as the design used by Frey, Hertwig, and Rieskamp (2014). I initially used a design that was more in line with the method used by Frey et al. but I was not able to successfully manipulate the affective state of participants during pilot testing. As I was also interested in the role of performance feedback on information search, a procedure based on Gorlick et al.(2013) was used instead.

\section{I METHOD}

\subsubsection{PARTICIPANTS}

All participants provided written consent for the study, which was approved by the Research Ethics Board at Ryerson University. Participants included 64 younger adults (44 female) and 64 older adults (45 female). An additional four participants (three younger and one older) were recruited but excluded for not following experimental instructions or a history of self-reported health problems. Both groups were recruited from the community and received \$10 CAD per hour for their participation. Participants had the opportunity to win an additional cash bonus for each correct answer given. Characteristics for the final sample are shown in Table 5 . Half of the participants in each age group were assigned to the affect-rich feedback condition and the other half was assigned to the affect-poor feedback condition. Assignment to feedback groups was random. In the affect-rich feedback condition, older adults had 
significantly higher scores of positive affect, $t(62)=2.40, p=.019, d=.61$; lower scores of negative affect, $t(54.5)=2.40, p=.020, d=.65$; higher need for cognition, $t(62)=3.03, p=.004, d=.77$; and lower Corsi spans, $t(61)=4.06, p<.001, d=1.04$; compared to younger adults. In the affect-poor condition, older adults had significantly higher levels of education, $t(62)=2.68, p=.009, d=.68$; higher scores of positive affect, $t(62)=2.16, p=.034, d=.55$; lower scores of negative affect, $t(39.5)=3.84, p<.001, d=1.22 ;$ lower levels of numeracy, $t(60.1)=2.45, p=.017, d=.63 ;$ and lower Corsi spans, $t(62)=3.91, p<.001, d=.99$; compared to younger adults. Other measures showed no significant age differences. No differences were found between feedback groups on any of the characteristics.

\subsubsection{PROCEDURE}

Participants first completed the Positive And Negative Affect Schedule (Watson, Clark, \& Tellegen, 1988). Participants then completed a variant of the marbles task as described in Experiment 1. Seventeen problems (Table 6) appeared twice, once with the correct answer on the left and once with the correct answer on the right. The resulting 34 trials were presented in random order. An additional randomly-generated problem was used as the first trial. To examine the effect of feedback on information search and decision quality we focused on the pre-programmed 34 trials and discarded the randomly generated initial trial (as there was no feedback immediately preceding its presentation).

To learn about how colours were distributed between the two bags, participants sampled sequentially from each of the two bags using the $C$ and $M$ keys. The results of the sample were displayed on screen for $750 \mathrm{~ms}$. The number of samples drawn and patterns of 
search used were entirely self-determined by the participants. Once they felt they knew which bag contained the greatest proportion of marbles of the target colour, they pressed the Q key to answer. Correct answers were awarded \$0.20 CAD.

Unlike in Experiments 1 and 2, participants received post-trial feedback in this experiment. This allowed me to examine how feedback modulated information search and subsequent decision quality in younger and older adults. Two forms of feedback were used: affect-rich (consisting of pictures of a young woman smiling or frowning), and affect-poor (consisting only of the words "CORRECT" and "INCORRECT"); however, validations of the levels of affect resulting from the two feedback types were not gathered from participants. The pictures used for the affect-rich feedback condition (Appendix X) were drawn from the SuMo Face Database (Sugden \& Moulson, 2013) - a large database of photographs of individuals posing a variety of emotional expressions. The particular individual was chosen after consultation with one of the database's creators who identified her as providing an especially expressive set of images. Only a single individual was used to avoid potential confounds of gender and age. The images were of a 20 year old white female, born in Russia but raised in Canada from age 4. She has blue eyes, brown hair, two visible earrings, and low makeup. Ratings of the intensities of her expressions were provided by 10 validators and are found in Table 7. The original images were cropped to include only the head and shoulders of the subject and scaled to $650 \times 600$ pixels for display on screen. Feedback for both conditions was presented in isolation and centered on the screen.

To present the stimuli and collect responses, I used MATLAB version R2011B (The MathWorks Inc.) with the Psychophysics Toolbox extension (Brainard, 1997) version 3.0.9, 
running on an Intel Core 2 Quad 2.40 GHz 32-bit Windows Vista desktop computer with 4GB of RAM and a 23-inch LCD display. All text appeared in a black 53-point typeface on a white background.

Participants were tested individually in a quiet testing room. After signing the consent form, participants received task instructions and completed a three-trial practice version of the marbles task. Participants then completed the experimental version of the task consisting of 35 trials. After 18 trials participants were given a self-paced break. After the marbles task, participants completed the Need for Cognition scale (Cacioppo et al., 1984), an 18-item questionnaire measuring enjoyment of effortful cognition; the Numeracy scale (Lipkus et al., 2001), an 11-item questionnaire measuring mathematical proficiency pertaining to concepts such as fractions, decimals, percentages, and proportions; a forward digit span task; and a computerized version of Corsi's block tapping task (Berch et al., 1998; Kessels et al., 2000).

\subsection{RESULTS}

Three dependent measures were analyzed: accuracy, extent of information search, and search patterns used. For the analysis of accuracy, only age group and feedback conditions were considered. For the analyses of extent of information search and search patterns, both the differences between age group and feedback conditions and also the outcome of the previous result (excluding the first trial for each participant from analysis).

Faces have been found to be processed more strongly than words (Beall \& Herbert, 2008). To ensure that the different feedback types were sufficiently affective, we elicited ratings of valence and intensity from a subset of 26 older adult participants ( 13 per feedback type) 
recruited for the study. The positive feedback provided for correct answers was rated as much more positive than the feedback for incorrect answers, $F(1,24)=224.53, p<.001$, partial $\eta^{2}=.90$. The effect of feedback type was not significant, $p=.300$. However, I did not gather ratings from the younger adult sample and thus are based entirely on the older adult sample.

\subsubsection{ACCURACY}

A 2 (age group: younger vs. older) $\times 2$ (feedback type: affect-rich vs. affect-poor) ANOVA was conducted on accuracy. The main effects of age group, $p=.282$, and feedback type, $p=.282$, were not significant. The Age Group $\times$ Feedback Type interaction was significant, $F(1$, $124)=10.50, p=.002$, partial $\eta^{2}=.08,($ Figure 5$)$. Post-hoc tests revealed a significant difference for younger adults, $F(1,62)=11.02, p=.002$, partial $\eta^{2}=.15$, who were more accurate when provided affect-poor feedback, $M=.91,[.89, .94]$, than when provided affect-rich feedback, $M=$ $.86,[.83, .88]$. In contrast, older adults showed the reverse pattern of results but this difference failed to reach significance, $F(1,62)=2.02, p=.160$.

\subsubsection{EXTENT OF INFORMATION SEARCH}

To examine the modulating effect of feedback on the extent of information search, a 2 (age group) $\times 2$ (feedback type $) \times 3$ (previous answer: correct vs. incorrect) ANOVA on the number of marbles sampled was conducted. The main effects of age, $p=.129$, feedback type, $p=$ .595 , and previous answer, $p=.197$, were all nonsignificant. Younger adults, $M=46.2$, [39.8, 52.6], and older adults, $M=53.2,[46.8,59.5]$, both sampled a similar number of marbles. Affectrich, $M=48.4,[42.1,54.8]$, and affect-poor, $M=50.9,[44.5,57 \cdot 3]$, feedback did not differ in terms of the extent of sampling they elicited. Finally, whether the previous trial was answered 
correctly $-M=48.7,[44.7,52.7]-$ or incorrectly $-M=50.6,[45 \cdot 3,56.0]-$ also did not modulate information search behaviour. All interactions were nonsignificant.

\subsubsection{SEARCH PATTERNS}

A 2 (age group) $\times 2$ (feedback type $) \times 3$ (previous answer) ANOVA on participants' switch ratios was conducted to examine the impact of feedback on search patterns used during pre-decisional search. No age-related shift in search pattern preference was observed, $p=.496$, as in Experiment 1 . Younger adults, $M=.36,[.26, .46]$, and older adults, $M=.31,[.21, .41]$, searched similarly in this task. Feedback type also had no effect on patterns of search, $p=.674$, with affect-rich feedback, $M=.35,[.25, .48]$, eliciting the same search patterns as affect-poor feedback, $M=.32,[.22, .42]$. Finally, the correctness of the previous answer did not change search patterns used, $p=.695$, as switch ratio did not differ following correct, $M=.34,[.27, .41]$, and incorrect, $M=.33,[.26, .40]$, answers. All interactions were nonsignificant.

\subsubsection{BACKGROUND MEASURES}

In the affect-rich feedback condition (Table 8a), a negative correlation of switch ratio and sample size was found for younger adults, $r=-.44, p=.012$, with fewer samples being drawn when a piecewise search pattern was used. A similar correlation was observed in Experiment 1 and in past literature (Hills \& Hertwig, 2010; Rakow et al., 2008). For older adults, switch ratio was positively correlated with judgment accuracy, $r=.60, p<.001$, with more frequent switching resulting in greater accuracy. Additionally, greater numeracy was associated with more accurate judgments, $r=.42, p=.017$, and greater digit spans with less sampling, $r=-.36$, $p=.050$. 
In the affect-poor feedback condition (Table $8 \mathrm{~b}$ ), switch ratio was positively correlated with judgment accuracy for younger adults, $r=.38, p=.032$, with more frequent switching resulting in greater accuracy. Additionally for younger adults, numeracy was negatively correlated with switch ratio, $r=.42, p=.017$, with more numerate participants switching less often during search, similar to Experiment 1 . For older adults, education, $r=.39, p=.027$, and numeracy, $r=.52, p=.002$, were both associated with greater judgment accuracy.

\subsection{DISCUSSION}

In Experiment 3 I examined the effect of affect-rich and affect-poor post-trial feedback on information search and subsequent decision quality. Past studies have demonstrated agerelated deficits in learning across a wide variety of tasks (Simon \& Gluck, 2013; Simon, Howard, \& Howard, 2010a; 2010b); however, the use of emotionally-valenced feedback has been shown to mediate this decline in certain types of learning tasks (Gorlick et al., 2013). To investigate the role of post-trial feedback, participants completed a version of the marbles task that included two types of feedback: Affect-rich (consisting of pictures of a young woman smiling or frowning) and affect-poor (consisting only of the words "CORRECT" and "INCORRECT").

Feedback type had no impact on search behaviour - neither extent of search nor search patterns used-nor did it interact with age group or whether the previous trial was answered correctly or incorrectly. This suggests that information search behaviour may be resilient to both affect-rich and affect-poor performance feedback in experience-based choice tasks. However, other forms of feedback may still have a modulating effect on search behaviour and should be considered in future research. 
Critically, a significant interaction of age group and feedback type on judgment accuracy was found. Younger adults achieved higher accuracy when provided affect-poor feedback than when provided affect-rich feedback, whereas older adults showed a trend in the opposite direction. As there was no difference in information search between age or feedback groups, this suggests that specific types of post-trial feedback - affect-poor (words) for younger adultsmay enhance memory for previously sampled information, leading to more accurate judgments in the experience-based proportion judgment task. Alternatively, affect-rich feedback may negatively impact younger adults, possibly having a distracting effect, leading to a decline in decision quality. In older adults, this decline is not seen, possibly as a result of their increased emotion regulation abilities. However, due to the design of the current experiment, I was not able to investigate the cause of this difference.

A possible explanation for the nonsignificant difference in older adults' judgment accuracy between feedback types is that affect-rich feedback was not age-matched. All participants in the affect-rich condition, regardless of age or gender, were shown the same young female face. This was done as my goal was not to investigate what role age congruent and incongruent feedback played in information search. However, evidence for an other age effect has been reported in the literature (Anastasi \& Rhodes, 2006; Hills \& Lewis, 2011; Kuefner, Macchi Cassia, Picozzi, \& Bricolo, 2008; Wiese, Kachel, \& Schweinberger, 2013)— similar to the more widely known other race effect-suggesting individuals in one age group are better at processing faces in their own age group than the faces of members from other age groups. Older adults may be less able to process the faces of the young woman used for the post-trial feedback in the affect-rich condition, specifically the emotional meaning expressed by 
the faces, and therefore the effect is not as large as within the younger adult group (where the age group of the participants and the woman in the feedback images is congruent). Future research on the use of facial feedback as a performance measure should address this potential confound.

The age-related shift in search pattern preference I had observed in Experiment 1 did not manifest here. Compared to the previous results, younger adults switched less often than in Experiment 1 while older adults switched more often, with groups' search pattern preferences converging towards one another. This converging of patterns may be due to the presence of post-trial feedback - participants had a sense for how they were doing during the experiment and could adjust their performance throughout the duration of the task. Similarly, feedback may have motivated participants to test various search patterns (e.g., changing from comprehensive to piecewise and back) but these changes in pattern would be obscured when switch ratios were calculated. Any further research in this area should explicitly manipulate patterns - similar to the design of Experiment 2-to control for potential shifts in search pattern selection throughout the duration of the study.

Overall, Experiment 3 revealed several novel findings. Information search - both in terms of extent of information searched and search patterns used - was largely unaffected by age, feedback type, or correctness of the previous trial. This suggests that information search behaviour is resistant to outcome feedback. Additionally, the use of feedback may have allowed participants to modulate their search behaviour in a way that was not possible in Experiments 1 and 2, resulting in the previously observed age-related shift in search pattern preference to no longer be present. The main effects of age group, feedback type, and the correctness of the 
previous answer did not impact judgment accuracy. However, a significant interaction of age group and feedback type was found, with younger adults being more accurate when provided affect-poor than affect-rich feedback; older adults showed a trend for the reverse pattern, suggesting that feedback type may enhance memory for previously sampled information, leading to more accurate judgments in the experience-based proportion judgment task used. However, due to the design of the current experiment, additional research is required to further investigate this result and identify the mechanisms involved. 



\section{EXPERIMENT 4}

The current state of the literature provides a mixed picture of differences in risk taking over the lifespan. A risky choice as defined in economic terms is a decision with outcomes that do not occur with certainty, but rather according to a probability distribution (Glimcher, 2008). An option with greater outcome variance (a more variable probability distribution) is said to be riskier than an option with lower variance (a less variable probability distribution). One common paradigm in decisions from experience research has been the risky choice format used by many studies (e.g., Hau et al., 2008; 2010; Hertwig et al., 2004; Spaniol \& Wegier, 2012). Participants are presented with a choice between a smaller reward with low (or zero) outcome variance and a larger reward with high outcome variance (e.g., “Would you prefer \$3.0o for sure or an $80 \%$ of winning $\$ 4.00$, else nothing?"). Participants learn the outcomes through a sequential sampling procedure prior to selecting one of the options. An understudied aspect of this paradigm is the role of risk (outcome variance). As older adults sometimes display a preference for certain (zero variance) options in description-based choice (Mather et al., 2012), it is possible that past observations of experience-based risky choice behaviour in younger and older adults may have been confounded by age-related differences in attitudes towards risk.

The goal of Experiment 4 was to add risk and numerical outcomes to the paradigm used in the previous experiments to investigate two aspects of the role of risk in differences in experience-based choice between younger and older adults. Firstly, I sought to establish whether older adults are able to identify which of two given options had the higher expected value, when controlling for risk, to the same degree as younger adults. There has been no 
previous direct test of this. If explicit mental arithmetic is involved in determining which option has the higher expected value, there may be no difference between age groups as both are as efficient in the necessary arithmetic, despite older adults relying on simpler cognitive strategies (Geary et al., 1993; Geary \& Wiley, 1991). However, it is not clear whether individuals make such explicit calculations in risky choice. The literature investigating age-related changes in risk taking has found inconsistent results (Holliday, 1988; Lauriola \& Levin, 2001; Mikels \& Reed, 2009; Weber et al., 2004; Weller et al., 2010) while studies in which younger and older adults make monetary gambles have used choice problems with equal expected values (e.g., Spaniol \& Wegier, 2012). These factors make it difficult to say whether age differences in risky choice are due to differences in attitudes towards risk taking, or due age-related cognitive decline in fluid intelligence that makes identifying the higher value outcome more difficult.

Secondly, I was interested in whether the certainty effect (Mather et al., 2012) exists in decisions from experience, and if so, whether it is the result of older adults' desire to avoid variance (risk) or rather a desire to avoid zero-reward outcomes. Mather et al. (2012) found older adults showed a greater preference for certain-but-small gains over risky-but-large ones compared to younger adults. This certainty effect was explained as a greater weighting of certainty in older adults. However, a possible confound exists: Is this preference due to older adults' desire to avoid variance (risk) or a desire to avoid zero value outcomes?

To address these two questions, an experience-based risky choice paradigm was used, similar to past studies (e.g., Hau et al., 2008; 2010; Hertwig et al., 2004; Spaniol \& Wegier, 2012). Five sets of choice problems were designed. The first set aimed to establish whether older adults were able to identify which of two options had the higher expected value when controlling for 
risk, and the other four sets attempt a replication of Mather et al.'s (2012) certainty effect but using an experience-based choice paradigm and investigate whether the certainty effect is the result of older adults' desire to avoid options with high variance or rather avoid zero value outcomes.

\subsection{METHOD}

\subsubsection{PARTICIPANTS}

Participants provided written consent for the study which was approved by the Research Ethics Board at Ryerson University. Participants included 40 younger adults (22 female) and 40 older adults (22 female). Three additional older adult participants were recruited but excluded for not following experimental instructions. Both groups were recruited from the community and received \$10 CAD per hour for their participation. Participants had the opportunity to win an additional cash bonus based on their choices during the risky choice task. Characteristics for the final sample are shown in Table 9. Compared with younger adults, older adults had significantly higher levels of education, $t(77)=3.96, p<.001, d=.89$, and lower Corsi spans, $t(77)=5.86, p<.001, d=1.31$. Other measures showed no significant age differences.

\subsubsection{STIMULI}

The five choice sets can be found in Table 10. Choice Set 1 consisted of choices between two risky options, with one option always having an expected value that was $\$ 1$.oo greater than the other option. The variances of the outcomes for each of the options were held constant at 
\$9.00, meaning both options were equally risky ${ }^{4}$. This allowed me to control for any age-related differences in participants' risk propensity. As one option had an objectively greater expected value than the other ${ }^{5}$ and there was no difference in the riskiness of each choice, this meant that each choice problem had a "correct" answer (i.e., the option with the higher expected value). Using this design, I was able to investigate whether age-related declines in fluid cognitive abilities hindered older adults from identifying which of the two options had the higher expected value.

Choice Sets 2 and 3 were subsets of the choice problems used by Mather et al. (2012). Problems were selected based on the largest reported differences between younger and older

${ }^{4}$ Given an option with two outcomes, variance, $V A R$, is calculated in the following manner:

$$
V A R=p_{1} \times\left(m_{1}-E V\right)^{2}+p_{2} \times\left(m_{2}-E V\right)^{2}
$$

where:

$p_{1}$ is the probability of outcome 1 occurring

$p_{2}$ is the probability of outcome 2 occurring

$m_{1}$ is the magnitude of outcome 1

$m_{2}$ is the magnitude of outcome 2

$E V$ is the overall expected value of the option

For example, an option in which you have a 50\% chance of winning \$40; otherwise \$o, the expected value and variance would be calculated as:

and

$$
E V=(0.5 \times \$ 40)+(0.5 \times \$ 0)=\$ 20
$$

$$
\begin{gathered}
V A R=\left[0.5 \times(40-20)^{2}\right]+\left[0.5 \times(0-20)^{2}\right] \\
V A R=\left[0.5 \times(20)^{2}\right]+\left[0.5 \times(-20)^{2}\right] \\
V A R=(0.5 \times 400)+(0.5 \times 400) \\
V A R=200+200=400
\end{gathered}
$$

${ }^{5}$ In a study conducted previously - but the results of which are not reported here-the difference of $\$ 1.00$ in expected values between options was found to be large enough for participants to reliably identify which option had the greater expected value. 
adults. The problems contained a certain-but-small option and a risky-but-large option, where the risky option resulted in a large monetary win (larger than the certain option yielded) with some probability $p$, or an outcome of zero dollars with probability 1-p. These two choice sets were used to determine whether the certainty effect holds in decisions from experience. For choice sets 4 and 5 I modified sets 2 and 3 by replacing the zero outcome with a monetary value equal to $10 \%$ of the risky-but-large reward (smaller than the reward given by the certain option), and reducing the probabilities at which the risky-but-larger reward was encountered so as to leave the expected values for each problem unchanged. This yielded a total 24 choice problems across the five sets, all framed as monetary gains. Loss framed choice problems were then created by multiplying each outcome amount by -1 to give 24 loss choice problems, resulting in the 48 choice problems described in Table 10.

\subsubsection{PROCEDURE}

Participants completed an experience-based risky choice task based on designs previously used in the literature (Hau et al., 2010; e.g., Hertwig et al., 2004). Participants were presented with two probabilistic gambles and asked to select which of the gambles they would prefer to play. To learn about the possible outcomes and their probabilities of occurrence participants sequentially sampled each of the gambles one by one via key presses, as many times as they wished. Participants pressed the C key to sample from the left option and the M key to sample from the right option. Participants were allowed to sample as many times as they wished, using whatever search pattern they preferred. Once they felt ready to make a decision they pressed the $Q$ key to select one of the risky gambles to play. No post-trial feedback was 
provided on the outcome of the chosen gamble or the outcome of the forgone gamble.

To present the gamble options and collect responses, MATLAB version R2011B (The MathWorks Inc.) was used, in conjunction with the Psychophysics Toolbox extension (Brainard, 1997) version 3.0.9, running on an Intel Core 2 Quad 2.40 GHz 32-bit Windows Vista desktop computer with $4 \mathrm{~GB}$ of RAM and a 23-inch LCD display. All text appeared in a black 53-point typeface on a white background.

Participants were tested individually in a quiet testing room. After signing the consent form, participants received task instructions and completed a four-trial practice version of the risky gambles task. Participants then completed the experimental version of the task consisting of the 48 choice problems. After 24 trials participants were given a self-paced break. After the risky choice task, participants completed the Need for Cognition scale (Cacioppo et al., 1984), an 18-item questionnaire measuring enjoyment of effortful cognition; the Lipkus Numeracy scale (Lipkus et al., 2001), an 11-item questionnaire measuring mathematical proficiency pertaining to concepts such as fractions, decimals, percentages, and proportions; a forward digit span task; and a computerized version of Corsi's block tapping task (Berch et al., 1998; Kessels et al., 2000).

\section{$7 \cdot 2$ RESULTS}

Descriptive statistics for all five choice sets are presented in Table 11.

\subsubsection{CHOICE SET 1}

ACCURACY. A 2 (age group: younger vs. older) × 2 (choice framing: gain vs. loss) ANOVA was conducted on accuracy - whether or not the option with the higher expected 
value was selected. Neither the main effects of age group, $p=.958$, or choice framing, $p=.087$, were significant. The Age Group $\times$ Choice Framing interaction, $p=.945$, was also not significant EXTENT OF INFORMATION SEARCH. A 2 (age group) $\times 2$ (choice framing) ANOVA on the number of samples made prior to choice revealed neither the main effects of age group, $p=.856$, or choice framing, $p=.895$, nor their interaction, $p=.694$, were significant.

SEARCH PATTERNS. A 2 (age group) $\times 2$ (choice framing) ANOVA was conducted on participants' search patterns, operationalized as the switch ratio. As with the extent of information search, neither the main effects of age group, $p=.461$, or choice framing, $p=.130$, nor their interaction, $p=.375$, were significant.

\subsubsection{CHOICE SET 2}

RISK TAKING. A 2 (age group) × 2 (choice framing) ANOVA was conducted on the proportion of risky options selected. The main effect of age group was not significant, $p=.258$. The main effect of choice framing was significant, $F(1,78)=4.96, p=.029$, partial $\eta^{2}=.06$, with greater risk seeking for loss trials, $M=.54,[.48, .60]$, than for gain trials, $M=.45,[.38, .52]$. The Age Group $\times$ Choice Framing interaction was not significant, $p=.874$.

EXTENT OF INFORMATION SEARCH. A 2 (age group) $\times 2$ (choice framing) ANOVA on the number of samples made prior to choice was conducted and neither the main effects of age group, $p=.982$, or choice framing, $p=.297$, nor their interaction, $p=.333$, were significant. SEARCH PATTERNS. A 2 (age group) $\times 2$ (choice framing) ANOVA was conducted on participants' search patterns, operationalized by their switch ratios. As with the extent of 
information search, neither the main effects of age group, $p=.461$, or choice framing, $p=.130$, nor their interaction, $p=.375$, were significant.

\subsubsection{CHOICE SET 3}

RISK TAKING. A 2 (age group) × 2 (choice framing) ANOVA on the proportion of risky options selected was conducted. The main effect of age group was not significant, $p=.475$. The main effect of choice framing was significant, $F(1,78)=23.72, p<.001$, partial $\eta^{2}=.23$, with greater risk seeking in gain trials, $M=.62$, [.56, .69], than in loss trials, $M=.42,[.36, .48]$. This was qualified by a significant Age Group $\times$ Choice Framing interaction $F(1,78)=4.72, p=.033$, partial $\eta^{2}=.06$. Post-hoc tests revealed a significant difference of choice framing for younger adults, $F(1,39)=27.69, p<.001$, partial $\eta^{2}=.42$, who were more risk seeking for gains, $M=.65$, $[.56, .74]$, than for losses, $M=.36,[.27, .44]$. For older adults the effect was marginally nonsignificant, $F(1,39)=3.29, p=.077$, partial $\eta^{2}=.08$, with more risk seeking for gains, $M=.59$, $[.50, .69]$, than for losses, $M=.48,[.39, .57]$.

EXTENT OF INFORMATION SEARCH. A 2 (age group) $\times 2$ (choice framing) ANOVA was conducted on the number of samples made prior to choice. Neither the main effects of age group, $p=.553$, or choice framing, $p=.112$, nor their interaction, $p=.082$, were significant.

SEARCH PATTERNS. A 2 (age group) $\times 2$ (choice framing) ANOVA on participants' search patterns was conducted, operationalized by their switch ratios. The main effect of age group was not significant, $p=.509$. The main effect of choice framing was significant, $F(1,78)=5.83, p=$ .018 , partial $\eta^{2}=.07$, with more switch during loss trials, $M=.43,[.38, .52]$, than in gain trials, $M$ $=.40,[.32, .49]$. The Age Group $\times$ Choice Framing interaction, $p=.332$, was also not significant. 


\subsubsection{CHOICE SETS 4 \& 5}

As no evidence for the certainty effect was found in Choice Sets 2 and 3, I do not report a detailed breakdown of results for Choice Sets 4 and 5 as these were designed to disentangle the potential confound of outcome variance in the certainty effect. However, I will note that for both choice sets no main effect of age group nor an Age Group $\times$ Choice Framing interaction was found for risk taking, the extent of information search, or search patterns.

\subsubsection{BACKGROUND MEASURES}

Correlations with background measures are presented in Table 12. In Choice Set 1, a significant negative correlation between switch ratio and sample size was found for younger adults, $r=-.42, p=.007$, echoing findings from Experiments 1 and 3 and in past literature (Hills \& Hertwig, 2010; Rakow et al., 2008). For older adults, Corsi span was correlated with extent of information search, $r=.35, p=.026$, and more years of education was correlated with a decrease in switching during search, $r=-.40, p=011$. For Choice Sets $2-5$ the same pattern of results emerged for younger adults as in Choice Set 1, with switch ratio and sample size being negatively correlated, $r=-.33, p=.039$. Interestingly, for older adults, a significant positive correlation between switch ratio and risk taking was found, $r=.34, p=.032$, suggesting that the use of a piecewise search pattern may increase risk seeking behaviour in older adults.

\section{$7 \cdot 3$ DISCUSSION}

The goal of Experiment 4 was to add risk and numerical outcomes to the paradigm used in the previous experiments. This allowed for the investigation of two aspects of the role of risk 
on choice behaviour differences between younger and older adults. Firstly, I tested whether older adults were able to identify which of two choice options had the higher expected value when controlling for risk (operationalized by the outcome variance of the option). I found no main effects of age group on participants' ability to correctly identify which option had the higher expected value when risk was controlled for, and both younger and older adults sampled similarly, both in terms of the extent of information search and the search patterns used. Despite past evidence of age-related declines in decision-making performance (Finucane et al., 2002; Thornton \& Dumke, 2005), older adults' sensitivity to expected values remains intact. This suggests that past findings of age differences in risk taking may stem from other factors, such as learning of choice information or differences in tolerance for risk.

Secondly, I was interested in whether the certainty effect (Mather et al., 2012) exists in decisions from experience, and if so, whether it would be due to older adults' desire to avoid outcomes with high variance (risk) or rather a desire to avoid zero value outcomes. Critically, in choice sets 2 and 3 I found no evidence of an age-related certainty effect-no main effects of age group on risk taking were found in either choice set. As there were no age group differences in neither the extent of information search nor the search patterns used, the lack of a certainty effect could not have been due to age differences in information search behaviour-both age groups had essentially equivalent information, learned using the same search patterns, and made similar choices. This suggests that the certainty effect may only manifest in decisions from description, the format used by Mather et al. (2012), while being modulated in decisions from experience. Behavioural differences due to decision format are well documented - the literature has found individuals overweight the impact of rare events in description-based choice but 
underweight their impact in experience-based choice (Hertwig, 2009; Hertwig et al., 2004).

Finally, as the certainty effect does not appear to manifest in experience-based choice tasks, the results of choice sets 4 and 5 were not of particular interest. No main effects of age group, or Age Group $\times$ Choice Framing interactions, were found for any of the dependent variables of interest. Overall, it appears that the certainty effect reported by Mather et al. (2012) is confined to description-based choice-learning choice outcomes through experience modulates the effect and results in no age-related differences in behaviour. 



\section{GENERAL DISCUSSION}

Past research on experience-based choice-decisions in which all options, their outcomes, and the probabilities of occurrence of those outcomes must be learned prior to the final decision - has revealed an age-related decline in the extent of pre-decisional information search. Despite this, older adults do not seem to suffer from significant declines in decision quality as a result. In this dissertation, I have suggested several possible age-related differences which may be responsible for the observed decline in information search with advancing age: (1) Domain familiarity - older adults may rely on past familiarity with specific choice domains when making decisions from experience, and therefore do not need, or believe they do not need, to search for further information; (2) Search patterns-older adults may search for information differently than younger adults, rendering additional information search unnecessary; (3) Affect-the improved emotion regulation abilities that come with advanced age may allow older adults to make more effective use of affective information during choice,

reducing the need for further search; or (4) Risk - older adults may learn about and understand risk differently than younger adults causing the observed reduction in information search. Each of these factors may contribute to the age-related decline in information search behaviour reported in the literature (Mata \& Nunes, 2010; Mather, 2006; Yoon et al., 2009); however, the role of each factor has not been systematically investigated. Thus the goal of this dissertation was to examine how each of these factors changes the extent of information search, and subsequent decision quality, across the lifespan. 
As domain familiarity has been included in various past experience-based choice studies (Cole \& Balasubramanian, 1993; Johnson, 1990; 1993; 1997; Johnson \& Drungle, 2000; LambertPandraud et al., 2005; Mata et al., 2007; 2010; 2013; Mata \& Nunes, 2010; Meyer et al., 1995; Riggle \& Johnson, 1996; Talbot et al., 2007; Zwahr et al., 1999) I did not explicitly manipulate this factor here. Rather, I designed a paradigm in which the impact of the remaining three factors - patterns of search, emotion, and risk - could be minimized and then systematically reintroduced to examine their role in modulating information search behaviour in both younger and older adults. For Experiment 1, the novel marbles task was designed to minimize the possible confounding factors. First, the task was on in which no participant would have any applicable pre-existing knowledge of the possible outcomes of the task (i.e., no one was aware of the distributions of the marbles in each of the bags). This allowed me to minimize the role of domain familiarity. Second, the task provided no performance feedback and contained no affective qualities, minimizing the role of affect and removing any influence of differences in emotional regulation. Third, as the task was primarily focused on experience-based judgments rather than choices between financial gambles, there was no element of risk, minimizing any influence of differences in participants' risk propensities. In Experiment 2, I manipulated information search patterns, thus reintroducing the factor of search patterns to the task. In Experiment 3, affect was reintroduced in the form of affective performance feedback provided to participants. Finally, in Experiment 4, the marbles task was modified to more closing resemble a risky choice paradigm, thus reintroducing the factor of risk. 


\subsection{INFORMATION SEARCH}

In Experiment 1 participants completed the marbles task - an experience-based proportion judgment task. Participants were presented with two virtual bags of coloured marbles and were asked to determine which of the two bags contained the greater proportion of marbles of a specified target colour. The distributions of the colours were learned via experiential sampling of the two options. No post-trial feedback was provided to participants. This design was used in order to minimize the influence of domain familiarity, participants could not have any pre-existing knowledge of the colour distributions coming into the experiment; affect, proportion judgments of coloured marbles are not particularly affective and participants were provided no post-trial feedback which may have influenced their emotional state; and risk, no aspect of the task contained risky choices. With these factors minimized, I expected that the gap in information search behaviour between younger and older adults would close. Additionally, I was interested in determining if there existed an age-related shift in search strategy selection. Past research (Hills \& Hertwig, 2010; Rottman, 2014) had revealed that search strategy selection impacted subsequent decision quality and age may shift preferences for search patterns in experience-based choice tasks (Chin et al., 2012). The results of Experiment 1 not only showed that the gap in information search between age groups had closed, but it had reversed-older adults searched for more information than their younger adult counterparts. Second, older adults switched less often during pre-decisional information search, preferring the use of a comprehensive search strategy. In contrast, younger adults' search pattern preferences were more evenly divided between the two strategies. Collapsing across age groups and splitting the sample based on switch ratios revealed that the use of a 
frequent-switch (piecewise) search pattern resulted in greater accuracy than an infrequentswitch (comprehensive) search pattern. This demonstrated that the use of a piecewise search pattern could lead to greater decision quality, contrasting with previous findings (Hills \& Hertwig, 2010); however, search patterns were not explicitly manipulated in this experiment and further work was necessary to determine if this was the case.

Experiment 2 was designed as a continuation of the first experiment-younger and older adult participants completed the marbles task but search patterns were restricted to being either a strictly comprehensive pattern allowing participants to switch options only once per trial, or a strictly piecewise pattern requiring constant switching between the two options. The results revealed that piecewise search was associated with significantly higher accuracy, about 10 percentage points on average, for both younger and older adults, and with no differences in the extent of information search. This showed the importance of search pattern selection in experience-based choice tasks - the same participants, completing the same set of trials, with the same amount of information, were significantly more accurate due to the use of a frequentswitching piecewise search pattern.

Taken together these two experiments make several novel contributions to the experience-based choice literature. First, the age-related gap in extent of pre-decisional information search was investigated using the marbles task with no significant decline in information search found for older adults. Actually, older adults engaged in a greater degree of search, compared to younger adults, in contrast to past findings (Mata \& Nunes, 2010; Mather, 2006; Yoon et al., 2009). This may possibly be explained by the fact that the marbles task was designed to control for the confounding factors of domain familiarity, affect, and risk. Older 
adults had no pre-existing information about the choice domain prior to beginning the study, no additional information could be derived by older adults from the affective content of the choices as the design contained no emotional information, and differences in leaning about risk were not a factor as participants were only providing relative judgments of proportion and not preferences with regards to risky choice. These findings suggest that past evidence of an agerelated decline in information search was driven by the confounding factors of domain familiarity, affect, and risk, and thus older adults will search for the same amount of - or even more-information than younger adults in paradigms in which those factors are controlled.

It is possible that the marbles task was simply too dissimilar to past studies of experience-based choice - which are often based on financial gambles (e.g., Hau et al., 2008; 2010; Hertwig et al., 2004; Hills \& Hertwig, 2010) - to allow for meaningful comparison. Despite increased sampling, older adults were not found to be more accurate in the task than younger adults - although sample size may not necessarily be strongly linked to choice (Hau et al., 2008). Also, due to the factors being investigated, the design of the marbles task was not particularly ecologically valid - rarely in life does one care about marbles. It is possible that due to the low ecological validity, participants may not be motivated to search for information to the same extent as they may have had I used a different paradigm.

The second contribution of Experiments 1 and 2 is the novel finding of an age-related shift in search pattern preferences. Older adults displayed a greater preference for the comprehensive pattern while younger adults were roughly split between the two. As Experiment 2 showed no effect of search pattern on response confidence as a function of age, this observed shift in pattern preference was not due to older adults being less confident in their 
use of a piecewise pattern. To the extent that this age difference is reliable it may suggest an age-related decline in metacognitive skills (Finucane et al., 2005; Thornton \& Dumke, 2005). The effectiveness of piecewise search is not immediately obvious without someone applying it themselves and represents a less intuitive and more novel approach to the problem. Older adults have been found to select less appropriate strategies in arithmetic tasks (Lemaire et al., 2004) and misapply heuristics (Horn et al., 2015; Pachur et al., 2009) in other domains, so while piecewise search may be more effective older adults may not even consider to employ this less intuitive pattern during information search.

The age-related differences in information search behaviour observed in Experiments 1 and 2 were not found in Experiments 3 and 4 . I had hypothesized that the previously observed age-related declines in pre-decisional information search (Mata \& Nunes, 2010; Mather, 2006; Yoon et al., 2009) were driven by experimental confounds such as domain familiarity, search patterns, affect, and risk. When these factors were all controlled for (Experiment 1 ), older adults were observed to search for more information than younger adults, and showed preferences for different search patterns than their younger adult counterparts. However, when affect (Experiment 3) and risk (Experiment 4) were reintroduced, older adults still searched for as much information as younger adults did-no statistically significant difference between the two age groups was observed in Experiments 3 and 4 on the extent of information search.

Several explanations for this exist. First, information search behaviour may be resilient to the influence of affective choice feedback overall. Such an explanation lines up with several findings of no age-related differences in preferences for emotionally salient information (Grossmann et al., 2012). Another possibility is the way in which I reintroduced these two 
factors to the experience-based choice task was sufficiently different from past research (Mata \& Nunes, 2010; Mather, 2006; Yoon et al., 2009) for an age-related decline in information search to manifest. It may be the case that affect and risk do depress information search in older adults but only in certain conditions - when the content of a choice is highly affective rather than just the feedback, or in risky choices with equal expected values. Finally, it may be the case that the presence of affect or risk in an experience-based choice task does not decrease information search in older adults at all as I had hypothesized. Rather, age-related decline in information search may be primarily - or even solely - driven by the one factor not explicitly manipulated here: domain familiarity. Participants with increased familiarity with a choice domain may need, or feel they need, less information, and it is this familiarity that has primarily been responsible for the age-related decline in information search. However, this remains difficult to test as it would require a paradigm in which familiarity with the domain could be manipulated but all other factors - search patterns, affect, and risk - remain unchanged, and thus I can only speculate here.

Age-differences in search pattern preference were also minimized in Experiments 3 and 4, compared to the findings in the first half of the dissertation. In Experiment 3, younger adults switched less often and older adults switched more often, compared with their behaviour in Experiment 1 (but older adults did not switch more often than younger adults overall, just in relation to their behaviour in Experiment 1). The age-related shift in search pattern selection from Experiment 1 was no longer observed, possibly due to feedback allowing participants to modulate their search behaviour to a degree not possible in Experiment 1 . The addition of posttrial feedback provided participants with a measure of their performance which may have 
encouraged them to change their search pattern selection. Also, if participants were doing poorly, the addition of feedback may have motivated them to try out different search patterns. In Experiment 4, no difference in search pattern selection was found between age groups. Interestingly, overall switch ratios in Experiment 4 were greater than in Experiment 1, with older adults in Experiment 4 switching more often than younger adults did in Experiment 1. This may be due to the differing nature of the tasks used in each of the experiments; Experiment 1 used the proportion judgment marbles task while Experiment 4 used a risky choice preference task. Gathering information to make a relative judgment may require different search patterns and extents of information search compared to gathering information to develop a preference. The latter may require less information as the individual's own risk propensity would partially inform the decision and decrease the amount of information required. Thus, search pattern selection shifts not only with age but also with task demands. Additionally, the interaction of age and task demands is key, with older adults shifting their strategies to a greater degree across the different experimental paradigms, while younger adults appear to be more stable. Whether this more adaptive search pattern selection in older adults is beneficial in these tasks is not evident - the two age groups did not differ in judgment accuracy - but additional confounds (affective feedback and risk) were present in those paradigms and may have obscured any age differences.

Shifts in search pattern selection may have been driven by differences in the extent of information search - both age groups searched significantly less in Experiment 4 than in Experiment 1 . Differences in search pattern preference may only become stable with larger sample sizes. The decline in information search between Experiments 1 and 4 may have been a 
result of the differences in task instructions. As participants in Experiment 4 were instructed to select which gamble they would prefer, they may have been able to establish a stable preference for risky choice with less information than what was needed to identify the correct response in the proportion judgments of Experiment 1. Participant preferences may also have been driven by individual risk propensities - each participant was aware of what level of risk they were comfortable with and did not need to establish this during search, thus needing less information prior to terminating search. Therefore, age differences in the extent of information search manifest differently across different tasks, and a preference for increased sampling in older adults may only be observed in tasks that require more exhaustive information search (e.g., the marbles task).

\subsection{DECISION QUALITY}

The results of Experiments 1 and 2 demonstrated the importance of search pattern strategy selection, with piecewise search resulting in significantly greater accuracy compared to comprehensive search. In Experiment 1, more frequent switching during search led to significantly higher judgment accuracy, regardless of participant age. When search patterns were enforced in Experiment 2, both younger and older adults' performance improved significantly when information search was carried out using a piecewise search compared to comprehensive search. As with the nature of the age-related search pattern preference shift, the cause of this performance improvement is unknown. I presented one explanation previously, that piecewise search was cognitively less demanding than comprehensive search, leading to the boost in judgment accuracy. However, participants would need to be applying these search 
patterns explicitly for this to be the case, which may not be the approach taken by participants. The design of the two experiments as presented is unable to account for the boost in performance from the application of a piecewise search pattern and further research is needed. It may be the case that piecewise search allows for easier comparisons of proportion, or memory for sampled information may be more accurate when frequently switching during search. A possible explanation lies in fuzzy-trace theory (Reyna, 2004; Reyna \& Brainerd, 1995), which posits that memories of past experiences are either explicit verbatim representations or more implicit gist representations. In paradigms such as the ones used in this dissertation, participants rely on gist representations of the experienced outcomes - there is simply too much information that was experienced for explicit representations to be used. Thus it may be the case that piecewise search allows for more accurate gist representations to be formed during the sampling process, explaining the significant improvements in accuracy seen in Experiments 1 and 2. Additionally, The marbles task is particularly suited to reasoning with gist as such representations are often encoded in more categorical terms (e.g., "some" versus "none"). Regardless of the cause of the performance increase, appropriate search pattern selection is a vital component in experience-based choice tasks and deserves careful consideration when one is presented with such a decision.

Experiment 3 reintroduced affect into experienced-based choice, manipulated through the use of affect-rich and affect-poor post-trial feedback. Participants completed a modified version of the marbles task from Experiment 1 but were provided with post-trial performance feedback, presented as either affect-rich or affect-poor-pictures of a young woman smiling or frowning, or the words CORRECT and INCORRECT, respectively. Search patterns were left 
unrestricted. Age has been associated with deficits in feedback-based learning and generalization skills (Simon \& Gluck, 2013; Simon, Howard, \& Howard, 2010a; 2010b) and the use of emotionally-valenced feedback has been shown to mediate this decline in a task involving rule-based learning, where affect-rich face feedback attenuated declines in learning in older adults (Gorlick et al., 2013). Similarly, the results of Experiment 3 showed an interaction of age group and feedback type on judgment accuracy. Younger adults were more accurate when given affect-poor feedback (words) than when given affect-rich feedback (faces) while older adults showed a trend in the reverse direction. These findings were not due to any no agerelated differences in general information search behaviour both younger and older adults sampled to the same extent and regardless of correctness of the previous answer, for both affectrich and affect-poor feedback. The work of Carstensen and colleagues (1999; 2000; 2003) has found age-related improvements in emotion regulation over the lifespan. The older adults in Experiment 3 may thus be better at regulating their emotional response to the affective feedback. The difference amongst the younger adult sample would then be caused by the younger adults' inability to regulate their responses to the affect-rich feedback - it may be distracting to be provided with such affect-rich feedback in an experience-based choiceexplaining the decline in performance between feedback conditions in the younger adults. Additionally, improvements to memory for emotional information has been associated with increased age (Charles et al., 2003; Fung \& Carstensen, 2003), suggesting that older adults may have benefitted from more accurate memories of sampled information, while younger adults in the affect-rich condition suffered. 
Older adults may have even been more accurate than younger adults had the affect-rich feedback been matched to participants' age groups. Evidence for an other age effect has been reported in the literature (Anastasi \& Rhodes, 2006; Hills \& Lewis, 2011; Kuefner et al., 2008; Wiese et al., 2013), suggesting that older adults in the affect-rich condition may have been less able to process the faces of the young woman used for the post-trial feedback. Overall, these finding suggests that the type affective feedback used may enhance memory for information gained through experiential sampling, leading to more accurate judgments in the experiencebased proportion judgment task used.

Experiment 4 added in risk-operationalized as outcome variance-which was not considered in the previous experiments due to the limitations of the marbles task. To investigate the role of risk on information search behaviour I used a risky choice paradigm more commonly used in the literature. The goal of Experiment 4 was two-fold: To determine whether older adults could identity which of two gambles had the higher expected value when controlling for risk, to the same degree as younger adults; and whether the certainty effect (Mather et al., 2012) was present in experience-based choice tasks. First, no age difference in participants' ability to correctly identify which option had the higher expected value was found. Although age-related declines in decision quality have been previously observed (Finucane et al., 2002; Thornton \& Dumke, 2005), sensitivity to expected values appears to remain intact across the lifespan. This suggests that past findings of age differences in risky choice may be due to other factors, such as age-related shift in risk tolerance, or differences in the learning of outcome information due to task format. 
Second, no evidence of a certainty effect was found when gamble outcomes had to be learned via experiential sampling, suggesting that age differences in risk-taking are modulated by the way in which choice outcomes are learned - via explicit presentation or during periods of pre-decisional information search. Also, the certainty effect only appears to manifest in description-based choice tasks - an asymmetry that should be investigated further. As the certainty effect was not observed when decision outcomes had to be learned in an experiential sampling paradigm, I could not determine whether the effect was due to older adults' desire to avoid outcomes with high variance (risk) or rather a desire to avoid zero-value outcomes. Taken together, these results add to the already well documented findings that risk propensity is a function of the format in which choices are presented (Hertwig et al., 2004).

Overall, the findings of this dissertation made several novel contributions to the literature. Through the minimization and systematic manipulation of several potential confounding factors, I have shown that the age-related decline in information search is mediated in different types of decisions. For example, in judgments of proportion (Experiment 1 ) older adults engaged in greater information than younger adults. This may have been due to the fact that the task minimized the confounding factor of domain familiarity. Thus, when the playing field regarding pre-existing knowledge is leveled between age groups, the often reported speed-accuracy trade-off (Geary \& Wiley, 1991; Salthouse, 1979; Starns \& Ratcliff, 2010) - in which older adults will sacrifice speed to avoid errors and maintain accuracy - is observed. However, the difference in information search (with older adults sampling more than younger adults) disappears in choices involving affective feedback (Experiment 3) or risk (Experiment 4). 
Adding to past findings of an age-related decline the ability to identify and select the most appropriate strategy (Bröder, 2003; Geary et al., 1993; Geary \& Wiley, 1991; Lemaire et al., 2004; Pachur et al., 2009), Experiment 1 found that older adults selected the poorer of the two search patterns by relying more greatly on comprehensive search. However, when search pattern selection was manipulated in Experiment 2, both age groups' accuracy increased significantly when using piecewise search. The exact mechanism driving this difference remains unknown but it may be that piecewise search is cognitively less demanding, or results in better gist representations in memory as per fuzzy trace theory (Reyna, 2004; Reyna \& Brainerd, 1995).

Finally, when affective feedback was introduced, younger adults suffered from a decline in performance when presented affect-rich feedback compared to when presented affect-poor feedback. However, this difference was not observed in the older adult sample. In line with predictions from socioemotional selectivity theory (Carstensen et al., 1999) of greater emotion regulation with age, older adults' performance was unaffected by the two types of post-trial feedback presented.

\subsection{LIMITATIONS AND FUTURE DIRECTIONS}

Due to the type of questions this dissertation was aiming to help answer, the design of the experiments did not allow for deep investigation of each of the factors-domain familiarity, search patterns, affect, and risk. As a result, several limitations to this work exist.

First, the design of the marbles task used throughout the dissertation was artificial in nature; this was necessary in order to achieve the systematic manipulation required. However, this, combined with the fact that domain familiarity was not manipulated, reduces the 
ecological validity of the studies - very rarely in life are we concerned with counting coloured marbles. Rather, any future studies of the factors discussed in this dissertation should strongly consider the use of tasks that are more often encountered in the real world. For example, if one is investigating the impact of search patterns then a task should be chosen to mimic real life decisions - such as the consumer purchasing tasks seen previously (e.g., Mata et al., 2007) - and information search be searchable in a way similar to what may be seen by consumer (e.g., features presented in a grid which can be search product-wise or feature-wise).

The findings here could also prove useful when applied to the area of decision aids. The field of medical decision making has begun to use experience-based decision aids to help patients learn about treatment options. Some of the findings presented here could applied to such aids and tailor them to specific age groups. For example, if a decision aid required patients to learn about their treatment options through a period of self-directed pre-decisional information search, older adults may be nudged (or even required) to use a piecewise search pattern as I found that older adults will often rely on the less effective comprehensive search pattern. Such a manipulation may thus result in increased decision quality in older adults compared to what they may have achieved otherwise.

None of the four experiments explicitly manipulated the extent of information search. This was done to investigate whether the two different search patterns would modulate the extent of information search engaged in by participants. The lack of an age difference in judgment accuracy in Experiment 1, despite significant differences in search pattern selection, may have been due to the unequal amount of information searched between age groups. Had the two groups sampled to the same extent, an age-related decline in decision quality may have 
been observed. Restricting both search patterns and the number of samples available could prove to be an interesting direction of further study.

Along similar lines, further research is needed to examine the role of task difficulty on information search behaviour. In Experiment 1, information search increased as difficulty increased. Also, while we did observe a Pattern $\times$ Difficulty interaction in the degree of information search in Experiment 2, this was most likely not directly due to the specific enforced search patterns. As difficulty increases, it is easy to modulate search when using a piecewise search pattern; however, if restricted to the use of a comprehensive pattern, one would not be able to make a judgment regarding the difficulty of the trial until after switching options - as difficulty is defined as the relative difference between the two options. The degree of difficulty in the marbles task could be increased, reducing the gap between the colour proportions of the two bags even further. This may be an interesting direction to examine the stability of the finding that piecewise search results in greater accuracy - this may only be the case when cognitive load is low. However, when cognitive load is high it may be untenable to use piecewise search. To investigate the role of task difficulty further a modified paradigm to the marbles task used here is required, such that participants were aware of problem difficulty - prior to switching in comprehensive search - and could thus modulated their degree of information search.

Judgment accuracy in the marbles task was modulated by the interaction of age and the affect richness of post-trail feedback. However, the facial feedback used in the affect-rich condition was not age-matched across participants, allowing for the possibility of a confound due to the other age group effect (Anastasi \& Rhodes, 2006; Hills \& Lewis, 2011; Kuefner et al., 
2008; Wiese et al., 2013). Thus, the lack of a difference between feedback types in the older adult sample may have been driven by this other age effect, such that older adults were not able to process the younger adult faces in the affect feedback condition as well as they may have if the faces were of older adults. The feedback itself could be made more relevant for the two groups, such as the use of tailored images for the affect-rich feedback (i.e., pictures of individuals who have a meaningful connection to the participant, such as loved ones). Additionally, Experiment 3 relied on affective feedback rather than the manipulation of affective state through other means. As current emotional state has been shown to modulate information search behaviour (Frey et al., 2014; Susskind et al., 2008), the use of other forms of affective manipulation could prove to me an interesting avenue of study. Future work should control for this and consider the inclusion of types of affective feedback beyond pictures of emotionally expressive faces.

While I found that the type of experience-based choice task used modulated information search, none of the experiments were designed to experimentally manipulate the type of experience-based choice task being used. Participants sampled significantly less when presented with the risky choice task in Experiment 4 than the proportion judgment task used in the other studies, suggesting that nature of the task to be a factor in participants' information search behaviour. Additional investigations are needed to establish how difference types of choice tasks change information search and role those changes may have on subsequent decision quality.

Finally, there are several methodological issues that future work should address as well. First, the older adult participant pool at Ryerson is known to be very highly educated and perhaps not the most accurate reflection of the average older adult in Canada today. This may 
partially explain the lack of an age-related decline in search behaviour. Using a more representative sample, possible by recruitment from other sources or through stricter selection criteria, may be important in future work. Additionally, the measures used to assess working memory - a forward digit span task and Corsi's block tapping task (Berch et al., 1998; Kessels et al., 2000) - should be augmented with a working memory updating measure. Working memory updating, which is highly relevant to the type of experiential sampling tasks used in this dissertation, has been found to decline with age (Chen \& Li, 2007; Hartman, Dumas, \& Nielsen, 2001; Xin, Lai, Li, \& Maes, 2014); however, I included no measure to assess working memory updating in study participants.

\subsection{CONCLUSIONS}

In this dissertation, I investigated potential causes of age-related decline in the extent of information search in experience-based choice. I identified four potential confounds present in past research that considered age differences in information search: (1) domain familiarity; (2) search patterns; (3) affect; and (4) risk. As domain familiarity was a dimension often present in other research, I did not experimentally manipulate here. I presented the results of four studies that systematically considered the role of the other three factors. To conduct these studies, I introduced a novel experience-based proportion judgment task - the marbles task. Across the four experiments, no significant decline in the extent of information search was found. However, each experiment resulted in novel findings, adding to our understanding of how decisions from experience change over the lifespan. 
Experiment 1 found evidence of an age-related shift in search pattern selection in experience-based choice. Older adults showed a preference for the use of a comprehensive search pattern during search, switching less often than their younger counterparts. Experiment 2 demonstrated the significant impact that search patterns can have on decision quality then those patterns are strictly applied. The use of a piecewise search pattern resulted in a significant improvement in performance, relative to comprehensive search for both younger adults and older adults who had declines in fluid intelligence. Experiment 3 revealed a significant interaction of age and affective feedback on decision quality. Younger adults' performance was greater when they were provided with affect-poor performance feedback, whereas older adults showed a similar pattern when provided affect-rich feedback. Finally, Experiment 4 used the risky choice paradigm common in other studies of experience-based choice and found older adults to be no less efficient in identifying higher value outcomes than younger adults.

Taken together, this dissertation presents several firsts in this field of research. Critically, it highlights the importance of information search patterns on decision quality in younger and older adults. Most importantly however, I have shown that older adults - despite stereotypes and evidence of cognitive decline-are no less effective in their decisions, and the findings here could even be used to craft decision aids to further improve upon that performance. 

TABLE 1. Experiment 1: Participant characteristics

\begin{tabular}{lccc}
\hline \multicolumn{1}{c}{ CHARACTERISTIC } & YOUNGER & OLDER & $p^{1}$ \\
\hline$N$ & 40 & 39 & \\
$n$ female & 20 & 20 & \\
Age (years) & $22.0(3.6)$ & $72.6(6.9)$ & $<.001$ \\
Age range & $18-33$ & $61-94$ & \\
Education (years) & $14.9(1.5)$ & $16.3(2.1)$ & .001 \\
Numeracy & $8.9(1.9)$ & $8.2(2.6)$ & .178 \\
Need for Cognition & $12.7(3.5)$ & $12.1(4.8)$ & .508 \\
Corsi span & $6.4(1.0)$ & $4.9(1.0)$ & $<.001$ \\
Digit span & $6.5(1.3)$ & $7.0(1.3)$ & .106 \\
\hline
\end{tabular}

${ }^{1}$ Indicates difference between younger and older adult groups within experiments. 
TABLE 2. Experiment 2: Participant characteristics ${ }^{1}$

\begin{tabular}{lccc}
\hline \multicolumn{1}{c}{ CHARACTERISTIC } & YOUNGER & OLDER & $p^{2}$ \\
\hline$N$ & 40 & 40 & \\
$n$ female & 19 & 24 & \\
Age (years) & $22.8(3.6)$ & $66.8(5.9)$ & $<.001$ \\
Age range & $18-34$ & $60-82$ & \\
Education (years) & $15.2(1.6)$ & $16.2(2.6)$ & .042 \\
Numeracy & $9.8(1.6)$ & $8.6(2.2)$ & .008 \\
Need for Cognition & $11.7(4.3)$ & $12.2(4.3)$ & .569 \\
Corsi span & $6.3(0.9)$ & $5.5(0.7)$ & $<.001$ \\
Digit span & $7.9(1.4)$ & $6.9(1.6)$ & .003 \\
\hline
\end{tabular}

${ }^{1}$ Due to experimenter error, the Corsi spans for two participants and the Digit span for one participant were not recorded.

${ }^{2}$ Indicates difference between younger and older adult groups within experiments. 
TABLE 3. Experiment 2: Problem list

\begin{tabular}{cccc}
\hline \multirow{2}{*}{ Item } & \multicolumn{2}{c}{ Target colour proportions } & Difficulty \\
\cline { 2 - 3 } & High & Low & \\
\hline 1 & .90 & .85 & Very Hard \\
2 & .70 & .65 & Very Hard \\
3 & .50 & .45 & Very Hard \\
4 & .30 & .25 & Very Hard \\
5 & .90 & .80 & Hard \\
6 & .70 & .60 & Hard \\
7 & .50 & .40 & Hard \\
8 & .30 & .20 & Hard \\
9 & .90 & .70 & Moderate \\
10 & .70 & .50 & Moderate \\
11 & .50 & .30 & Moderate \\
12 & .30 & .10 & Moderate \\
\hline
\end{tabular}

${ }^{1}$ Difficulty was defined by the difference in target colour proportions between the two bags.

The greater the difference in proportions, the less difficult the trial. Very Hard difficulty was a difference of .05, Hard a difference of .10, and Moderate a difference of .20. 
TABLE 4. Experiment 2: Correlations with background measures

\begin{tabular}{|c|c|c|c|c|c|c|c|c|}
\hline & 1 & 2 & 3 & 4 & 5 & 6 & 7 & 8 \\
\hline \multicolumn{9}{|l|}{ YOUNGER ADULTS } \\
\hline \multicolumn{9}{|l|}{ 1. Accuracy (Comprehensive) } \\
\hline 2. Accuracy (Piecewise) & .30 & & & & & & & \\
\hline 3. Samples (Comprehensive) & .21 & - & & & & & & \\
\hline 4. Samples (Piecewise) & - & .19 & $.59^{* *}$ & & & & & \\
\hline 5. Education (years) & .14 & -.17 & -.07 & -.05 & & & & \\
\hline 6. Numeracy & .09 & .04 & -.14 & -.01 & .16 & & & \\
\hline 7. Need for Cognition & .04 & .05 & .07 & .17 & -.05 & .04 & & \\
\hline 8. Corsi span & .09 & .03 & $.47^{* *}$ & $.47^{* *}$ & -.07 & $.35^{*}$ & .17 & \\
\hline 9. Digit span & .09 & .20 & -.10 & -.31 & -.10 & .26 & -.14 & .20 \\
\hline \multicolumn{9}{|l|}{ OLDER ADULTS } \\
\hline \multicolumn{9}{|l|}{ 1. Accuracy (Comprehensive) } \\
\hline 2. Accuracy (Piecewise) & .09 & & & & & & & \\
\hline 3. Samples (Comprehensive) & .26 & - & & & & & & \\
\hline 4. Samples (Piecewise) & - & .22 & $.58^{* *}$ & & & & & \\
\hline 5. Education (years) & .04 & .02 & -.20 & -.04 & & & & \\
\hline 6. Numeracy & $\cdot 34^{*}$ & .00 & -.05 & -.14 & $.32^{*}$ & & & \\
\hline 7. Need for Cognition & $.33^{*}$ & .02 & .09 & .16 & .19 & .29 & & \\
\hline 8. Corsi span & $.44^{*}$ & $.47^{* *}$ & $.33^{*}$ & .23 & .20 & $.33^{*}$ & .16 & \\
\hline 9. Digit span & $.36^{*}$ & .25 & .13 & .21 & .01 & .25 & .27 & $.39^{*}$ \\
\hline
\end{tabular}


TABLE 5. Experiment 3: Participant characteristics

\begin{tabular}{lcccccc}
\hline \multirow{2}{*}{ Characteristic } & \multicolumn{3}{c}{ Affect-rich feedback } & \multicolumn{3}{c}{ Affect-poor feedback } \\
\cline { 2 - 6 } & Younger & Older & $p^{1}$ & Younger & Older & $p^{1}$ \\
\hline$N$ & 32 & 32 & & 32 & 32 & \\
$n$ female & 24 & 22 & & 20 & 23 & \\
Age (years) & $24.1(5.4)$ & $66.9(6.8)$ & $<.001$ & $22.4(3.6)$ & $68.3(7.0)$ & $<.001$ \\
Age range & $19-35$ & $60-83$ & & $18-34$ & $61-84$ & \\
Education (years) & $15.8(2.0)$ & $16.3(2.0)$ & .395 & $15.0(1.6)$ & $16.2(1.9)$ & .009 \\
Positive affect & $31.5(7.0)$ & $36.0(8.0)$ & .019 & $30.5(6.4)$ & $34.5(8.4)$ & .034 \\
Negative affect & $12.6(2.7)$ & $11.2(1.9)$ & .019 & $13.3(3.6)$ & $10.7(1.4)$ & $<.001$ \\
Numeracy & $9.1(1.5)$ & $8.2(2.3)$ & .068 & $9.0(1.8)$ & $7.8(2.2)$ & .017 \\
Need for Cognition & $11.3(4.4)$ & $14.2(3.1)$ & .004 & $12.2(4.8)$ & $12.8(3.9)$ & .653 \\
Corsi span & $6.4(1.0)$ & $5.4(1.0)$ & $<.001$ & $6.2(1.0)$ & $5.3(0.8)$ & $<.001$ \\
Digit span & $6.6(1.2)$ & $6.9(1.3)$ & .273 & $6.6(1.4)$ & $6.9(1.5)$ & .432 \\
\hline
\end{tabular}

${ }^{1}$ Indicates difference between younger and older adult groups within feedback conditions. 
TABLE 6. Experiment 3: Problem list

\begin{tabular}{ccc}
\hline \multirow{2}{*}{ ITEM } & \multicolumn{2}{c}{ TARGET COLOUR PROPORTIONS } \\
\cline { 2 - 3 } & HIGH & LOW \\
\hline 1 & .95 & .85 \\
2 & .90 & .80 \\
3 & .85 & .75 \\
4 & .80 & .70 \\
5 & .75 & .65 \\
6 & .70 & .60 \\
7 & .65 & .55 \\
8 & .60 & .50 \\
9 & .55 & .45 \\
10 & .50 & .40 \\
11 & .45 & .35 \\
12 & .40 & .30 \\
13 & .35 & .25 \\
14 & .30 & .20 \\
15 & .25 & .15 \\
16 & .20 & .10 \\
17 & .15 & .05 \\
\hline
\end{tabular}


TABLE 7. Experiment 3: Rating scores of affect-rich feedback images

\begin{tabular}{lcccc}
\hline \multirow{2}{*}{ RATING $^{1}$} & \multicolumn{3}{c}{ PICTURES } & \multirow{2}{*}{$p^{4}$} \\
\cline { 2 - 3 } & OVERALL & HAPPY & ANGRY & \\
\hline Attractiveness (/10) & $7.1(1.7)$ & & & \\
Distinctiveness (/5) & $3.4(0.7)$ & 10 & 10 & \\
Valence $^{2}$ & & 10 & 10 & \\
Congruency $^{3}$ & & $4.5(0.8)$ & $3.8(1.6)$ & .184 \\
Genuineness $(/ 5)_{\text {Intensity }(/ 10)}$ & & $6.4(0.5)$ & $6.4(0.5)$ & 1.000 \\
Arousal $(/ 10)$ & $6.2(2.7)$ & $6.0(2.7)$ & .870 \\
\hline
\end{tabular}

${ }^{1}$ Ten validators ( 6 female; mean age $=22.6, \mathrm{SD}=4.6$ ) provided the associated ratings. Higher scores indicate greater agreement with the rating (i.e., higher ratings of attractiveness mean validators found the face to be more attractive).

${ }^{2}$ Number of validators that rated the images as expressing the appropriate valence (positive for the happy image and negative for the angry image).

${ }^{3}$ Number of validators that rated the images as expressing the appropriate emotion (happy for the happy image and angry for the angry image).

${ }_{4}$ Difference between the ratings of the Happy and Angry images. 
TABLE 8A. Experiment 3: Correlations with background measures, affect-rich condition

\begin{tabular}{|c|c|c|c|c|c|c|c|c|c|}
\hline & 1 & 2 & 3 & 4 & 5 & 6 & 7 & 8 & 9 \\
\hline \multicolumn{10}{|l|}{ YOUNGER ADULTS } \\
\hline 1. Accuracy & & & & & & & & & \\
\hline 2. Samples & -.03 & & & & & & & & \\
\hline 3. Switch ratio & -.02 & $-.44^{*}$ & & & & & & & \\
\hline 4. Positive affect & -.27 & .26 & -.20 & & & & & & \\
\hline 5. Negative affect & .17 & .34 & -.31 & -.16 & & & & & \\
\hline 6. Education (years) & .13 & .09 & -.17 & .28 & -.23 & & & & \\
\hline 7. Numeracy & .20 & .26 & -.34 & -.07 & .22 & .26 & & & \\
\hline 8. Need for Cognition & .08 & .30 & -.33 & .20 & .22 & -.03 & .32 & & \\
\hline 9. Corsi span & .24 & .06 & -.31 & -.24 & .14 & .13 & .32 & .06 & \\
\hline 10. Digit span & .14 & .25 & -.04 & -.18 & .22 & -.11 & .31 & .18 & .02 \\
\hline \multicolumn{10}{|l|}{ OLDER ADULTS } \\
\hline 1. Accuracy & & & & & & & & & \\
\hline 2. Samples & -.10 & & & & & & & & \\
\hline 3. Switch ratio & $.60^{* *}$ & .09 & & & & & & & \\
\hline 4. Positive affect & .06 & -.12 &.- .08 & & & & & & \\
\hline 5. Negative affect & .13 & -.29 & .05 & -.15 & & & & & \\
\hline 6. Education (years) & .16 & .08 & .33 & -.18 & .13 & & & & \\
\hline 7. Numeracy & $.42^{*}$ & .08 & .06 & -.16 & .04 & .17 & & & \\
\hline 8. Need for Cognition & .10 & .19 & .12 & -.07 & -.04 & .07 & .11 & & \\
\hline 9. Corsi span & .04 & -.05 & .09 & -.07 & -.07 & .24 & .20 & -.04 & \\
\hline 10. Digit span & -.15 & $-.36^{*}$ & .05 & -.06 & .13 & -.11 & -.01 & -.35 & .24 \\
\hline
\end{tabular}


TABLE 8B. Experiment 3: Correlations with background measures, affect-poor feedback

\begin{tabular}{|c|c|c|c|c|c|c|c|c|c|}
\hline & 1 & 2 & 3 & 4 & 5 & 6 & 7 & 8 & 9 \\
\hline \multicolumn{10}{|l|}{ YOUNGER ADULTS } \\
\hline 1. Accuracy & & & & & & & & & \\
\hline 2. Samples & .21 & & & & & & & & \\
\hline 3. Switch ratio & $.38^{*}$ & -.14 & & & & & & & \\
\hline 4. Positive affect & -.18 & -.05 & -.01 & & & & & & \\
\hline 5. Negative affect & -.27 & -.01 & -.20 & .01 & & & & & \\
\hline 6. Education (years) & .09 & -.24 & -.40 & .06 & -.06 & & & & \\
\hline 7. Numeracy & .19 & -.06 & $-.37^{*}$ & -.28 & -.07 & $.36^{*}$ & & & \\
\hline 8. Need for Cognition & .04 & -.09 & -.03 & $\cdot 5 \mathrm{O}^{* *}$ & -.21 & .26 & .18 & & \\
\hline 9. Corsi span & .01 & -.30 & .25 & .18 & -.22 & -.15 & $<.01$ & .03 & \\
\hline 10. Digit span & -.18 & .18 & .06 & -.32 & .10 & -.10 & $<-.01$ & -.05 & -.30 \\
\hline \multicolumn{10}{|l|}{ OLDER ADULTS } \\
\hline 1. Accuracy & & & & & & & & & \\
\hline 2. Samples & -.18 & & & & & & & & \\
\hline 3. Switch ratio & .17 & -.10 & & & & & & & \\
\hline 4. Positive affect & -.14 & -.11 & -.16 & & & & & & \\
\hline 5. Negative affect & -.28 & -.27 & .27 & -.04 & & & & & \\
\hline 6. Education (years) & $.39^{*}$ & .01 & .28 & -.01 & $-.38^{*}$ & & & & \\
\hline 7. Numeracy & $.52^{* *}$ &.- .08 & .11 & -.02 & -.35 & $.44^{*}$ & & & \\
\hline 8. Need for Cognition & .17 & .03 & -.25 & .16 & -.32 & .31 & $.43^{*}$ & & \\
\hline 9. Corsi span & .30 & -.09 & .04 & .10 & -.19 & $.46^{* *}$ & $.40^{*}$ & .18 & \\
\hline 10. Digit span & .17 & .03 & -.06 & -.01 & -.10 & -.11 & .09 & -.14 & -.20 \\
\hline
\end{tabular}


TABLE 9. Experiment 4: Participant characteristics

\begin{tabular}{lccc}
\hline \multicolumn{1}{c}{ CHARACTERISTIC } & YOUNGER & OLDER & $p^{1}$ \\
\hline$N$ & 40 & 40 & \\
$n$ female & 22 & 22 & \\
Age (years) & $20.8(2.9)$ & $68.3(6.7)$ & $<.001$ \\
Age range & $18-29$ & $60-83$ & \\
Education (years) & $14.6(1.7)$ & $17.4(4.0)$ & $<.001$ \\
Numeracy & $9.3(1.8)$ & $8.7(2.3)$ & .165 \\
Need for Cognition & $12.5(3.5)$ & $12.6(4.6)$ & .891 \\
Corsi span & $6.6(1.0)$ & $5.3(0.9)$ & $<.001$ \\
Digit span & $7.0(1.3)$ & $7.2(1.4)$ & .688 \\
\hline
\end{tabular}

${ }^{1}$ Indicates difference between younger and older adult groups within experiments. 
TABLE 10. Experiment 4: Choice problem sets

\begin{tabular}{|c|c|c|c|c|c|c|c|c|c|c|c|c|}
\hline \multirow{2}{*}{ ITEM } & \multicolumn{6}{|c|}{ OPTION A } & \multicolumn{6}{|c|}{ OPTION B } \\
\hline & $P_{1}$ & $\mathrm{O}_{1}$ & $\mathrm{P}_{2}$ & $\mathrm{O}_{2}$ & $\mathrm{E}[\mathrm{A}]$ & $\operatorname{VAR}[\mathrm{A}]$ & $\mathrm{P}_{1}$ & $\mathrm{O}_{1}$ & $\mathrm{P}_{2}$ & $\mathrm{O}_{2}$ & $\mathrm{E}[\mathrm{B}]$ & $\operatorname{VAR}[\mathrm{B}]$ \\
\hline \multicolumn{13}{|c|}{ SET 1 —EQUAL VARS, DIFFERENCE IN EV } \\
\hline 1 & $45 \%$ & $\$ 7 \cdot 32$ & $55 \%$ & $\$ 1.29$ & $\$ 4.00$ & $\$ 9.00$ & $29 \%$ & $\$ 9.69$ & $71 \%$ & $\$ 3.08$ & $\$ 5.00$ & $\$ 9.00$ \\
\hline 2 & $31 \%$ & $\$ 8.62$ & $69 \%$ & $\$ 2.13$ & $\$ 4.14$ & $\$ 9.01$ & $74 \%$ & $\$ 6.92$ & $26 \%$ & \$0.08 & $\$ 5.14$ & $\$ 9.00$ \\
\hline 3 & $67 \%$ & $\$ 6.40$ & $33 \%$ & $\$ 0.02$ & $\$ 4.29$ & $\$ 9.00$ & $53 \%$ & $\$ 8.11$ & $47 \%$ & $\$ 2.10$ & $\$ 5.29$ & $\$ 9.00$ \\
\hline 4 & $64 \%$ & $\$ 6.68$ & $36 \%$ & $\$ 0.43$ & $\$ 4.43$ & $\$ 9.00$ & $59 \%$ & $\$ 7.93$ & $41 \%$ & $\$ 1.83$ & $\$ 5.43$ & $\$ 9.00$ \\
\hline 5 & $33 \%$ & $\$ 8.84$ & $67 \%$ & $\$ 2.46$ & $\$ 4.57$ & $\$ 9.00$ & $67 \%$ & $\$ 7.68$ & $33 \%$ & $\$ 1.30$ & $\$ 5.57$ & $\$ 9.00$ \\
\hline 6 & $50 \%$ & $\$ 7.71$ & $50 \%$ & $\$ 1.71$ & $\$ 4.71$ & $\$ 9.00$ & $75 \%$ & $\$ 7.44$ & $25 \%$ & $\$ 0.51$ & $\$ 5.71$ & $\$ 9.00$ \\
\hline 7 & $28 \%$ & $\$ 9.67$ & $72 \%$ & $\$ 2.99$ & $\$ 4.86$ & $\$ 9.00$ & $38 \%$ & $\$ 9.69$ & $62 \%$ & $\$ 3.51$ & $\$ 5.86$ & $\$ 9.00$ \\
\hline 8 & $36 \%$ & $\$ 9.00$ & $64 \%$ & $\$ 2.75$ & $\$ 5.00$ & $\$ 9.00$ & $49 \%$ & $\$ 9.06$ & $51 \%$ & $\$ 3.06$ & $\$ 6.00$ & $\$ 9.00$ \\
\hline 9 & $45 \%$ & $-\$ 7.32$ & $55 \%$ & $-\$ 1.29$ & $-\$ 4.00$ & $\$ 9.00$ & $29 \%$ & $-\$ 9.69$ & $71 \%$ & $-\$ 3.08$ & $-\$ 5.00$ & $\$ 9.00$ \\
\hline 10 & $31 \%$ & $-\$ 8.62$ & $69 \%$ & $-\$ 2.13$ & $-\$ 4.14$ & $\$ 9.01$ & $74 \%$ & $-\$ 6.92$ & $26 \%$ & $-\$ 0.08$ & $-\$ 5.14$ & $\$ 9.00$ \\
\hline 11 & $67 \%$ & $-\$ 6.40$ & $33 \%$ & $-\$ 0.02$ & $-\$ 4.29$ & $\$ 9.00$ & $53 \%$ & $-\$ 8.11$ & $47 \%$ & $-\$ 2.10$ & $-\$ 5.29$ & $\$ 9.00$ \\
\hline 12 & $64 \%$ & $-\$ 6.68$ & $36 \%$ & $-\$ 0.43$ & $-\$ 4.43$ & $\$ 9.00$ & $59 \%$ & $-\$ 7.93$ & $41 \%$ & $-\$ 1.83$ & $-\$ 5.43$ & $\$ 9.00$ \\
\hline 13 & $33 \%$ & $-\$ 8.84$ & $67 \%$ & $-\$ 2.46$ & $-\$ 4.57$ & $\$ 9.00$ & $67 \%$ & $-\$ 7.68$ & $33 \%$ & $-\$ 1.30$ & $-\$ 5.57$ & $\$ 9.00$ \\
\hline 14 & $50 \%$ & $-\$ 7.71$ & $50 \%$ & $-\$ 1.71$ & $-\$ 4.71$ & $\$ 9.00$ & $75 \%$ & $-\$ 7.44$ & $25 \%$ & $-\$ 0.51$ & $-\$ 5.71$ & $\$ 9.00$ \\
\hline 15 & $28 \%$ & $-\$ 9.67$ & $72 \%$ & $-\$ 2.99$ & $-\$ 4.86$ & $\$ 9.00$ & $38 \%$ & $-\$ 9.69$ & $62 \%$ & $-\$ 3.51$ & $-\$ 5.86$ & $\$ 9.00$ \\
\hline 16 & $36 \%$ & $-\$ 9.00$ & $64 \%$ & $-\$ 2.75$ & $-\$ 5.00$ & $\$ 9.00$ & $49 \%$ & $-\$ 9.06$ & $51 \%$ & $-\$ 3.06$ & $-\$ 6.00$ & $\$ 9.00$ \\
\hline \multicolumn{13}{|c|}{ SET 2-CERTAINTY EFFECT REPLICATION, EQUAL EV } \\
\hline 17 & $100 \%$ & $\$ 10.00$ & $0 \%$ & $\$ 0.00$ & $\$ 10.00$ & $\$ 0.00$ & $20 \%$ & $\$ 50.00$ & $80 \%$ & $\$ 0.00$ & $\$ 10.00$ & $\$ 400.00$ \\
\hline 18 & $100 \%$ & $\$ 10.00$ & $0 \%$ & $\$ 0.00$ & $\$ 10.00$ & $\$ 0.00$ & $40 \%$ & $\$ 25.00$ & $60 \%$ & $\$ 0.00$ & $\$ 10.00$ & $\$ 150.00$ \\
\hline 19 & $100 \%$ & $\$ 10.00$ & $0 \%$ & $\$ 0.00$ & $\$ 10.00$ & $\$ 0.00$ & $60 \%$ & $\$ 16.67$ & $40 \%$ & $\$ 0.00$ & $\$ 10.00$ & $\$ 66.69$ \\
\hline 20 & $100 \%$ & \$10.00 & $0 \%$ & $\$ 0.00$ & \$10.00 & $\$ 0.00$ & $80 \%$ & $\$ 12.50$ & $20 \%$ & $\$ 0.00$ & \$10.00 & $\$ 25.00$ \\
\hline
\end{tabular}




\begin{tabular}{|c|c|c|c|c|c|c|c|c|c|c|c|c|}
\hline \multirow{2}{*}{ ITEM } & \multicolumn{6}{|c|}{ OPTION A } & \multicolumn{6}{|c|}{ OPTION B } \\
\hline & $P_{1}$ & $\mathrm{O}_{1}$ & $\mathrm{P}_{2}$ & $\mathrm{O}_{2}$ & $\mathrm{E}[\mathrm{A}]$ & VAR[A] & $\mathrm{P}_{1}$ & $\mathrm{O}_{1}$ & $\mathrm{P}_{2}$ & $\mathrm{O}_{2}$ & $\mathrm{E}[\mathrm{B}]$ & $\mathrm{VAR}[\mathrm{B}]$ \\
\hline 21 & $100 \%$ & $-\$ 10.00$ & $\mathrm{O} \%$ & $\$ 0.00$ & $-\$ 10.00$ & $\$ 0.00$ & $20 \%$ & $-\$ 50.00$ & $80 \%$ & $\$ 0.00$ & $-\$ 10.00$ & $\$ 400.00$ \\
\hline 22 & $100 \%$ & $-\$ 10.00$ & $0 \%$ & $\$ 0.00$ & $-\$ 10.00$ & $\$ 0.00$ & $40 \%$ & $-\$ 25.00$ & $60 \%$ & $\$ 0.00$ & $-\$ 10.00$ & $\$ 150.00$ \\
\hline 23 & $100 \%$ & $-\$ 10.00$ & $0 \%$ & $\$ 0.00$ & $-\$ 10.00$ & $\$ 0.00$ & $60 \%$ & $-\$ 16.67$ & $40 \%$ & $\$ 0.00$ & $-\$ 10.00$ & $\$ 66.69$ \\
\hline 24 & $100 \%$ & $-\$ 10.00$ & $0 \%$ & $\$ 0.00$ & $-\$ 10.00$ & $\$ 0.00$ & $80 \%$ & $-\$ 12.50$ & $20 \%$ & $\$ 0.00$ & $-\$ 10.00$ & $\$ 25.00$ \\
\hline \multicolumn{13}{|c|}{ SET 3-CERTAINTY EFFECT REPLICATION, UNEQUAL EV } \\
\hline 25 & $100 \%$ & $\$ 10.00$ & $0 \%$ & $\$ 0.00$ & $\$ 10.00$ & $\$ 0.00$ & $20 \%$ & $\$ 62.50$ & $80 \%$ & $\$ 0.00$ & $\$ 12.50$ & $\$ 625.00$ \\
\hline 26 & $100 \%$ & $\$ 10.00$ & $0 \%$ & $\$ 0.00$ & $\$ 10.00$ & $\$ 0.00$ & $40 \%$ & $\$ 31.25$ & $60 \%$ & $\$ 0.00$ & $\$ 12.50$ & $\$ 234.38$ \\
\hline 27 & $100 \%$ & $\$ 10.00$ & $0 \%$ & $\$ 0.00$ & $\$ 10.00$ & $\$ 0.00$ & $60 \%$ & $\$ 20.83$ & $40 \%$ & $\$ 0.00$ & $\$ 12.50$ & $\$ 104.13$ \\
\hline 28 & $100 \%$ & $\$ 10.00$ & $0 \%$ & $\$ 0.00$ & $\$ 10.00$ & $\$ 0.00$ & $80 \%$ & $\$ 15.63$ & $20 \%$ & $\$ 0.00$ & $\$ 12.50$ & $\$ 39.09$ \\
\hline 29 & $100 \%$ & $-\$ 10.00$ & $0 \%$ & $\$ 0.00$ & $-\$ 10.00$ & $\$ 0.00$ & $20 \%$ & $-\$ 62.50$ & $80 \%$ & $\$ 0.00$ & $-\$ 12.50$ & $\$ 625.00$ \\
\hline 30 & $100 \%$ & $-\$ 10.00$ & $\mathrm{O} \%$ & $\$ 0.00$ & $-\$ 10.00$ & $\$ 0.00$ & $40 \%$ & $-\$ 31.25$ & $60 \%$ & $\$ 0.00$ & $-\$ 12.50$ & $\$ 234.38$ \\
\hline 31 & $100 \%$ & $-\$ 10.00$ & $0 \%$ & $\$ 0.00$ & $-\$ 10.00$ & $\$ 0.00$ & $60 \%$ & $-\$ 20.83$ & $40 \%$ & $\$ 0.00$ & $-\$ 12.50$ & $\$ 104.13$ \\
\hline 32 & $100 \%$ & $-\$ 10.00$ & $0 \%$ & $\$ 0.00$ & $-\$ 10.00$ & $\$ 0.00$ & $80 \%$ & $-\$ 15.63$ & $20 \%$ & $\$ 0.00$ & $-\$ 12.50$ & $\$ 39.09$ \\
\hline \multicolumn{13}{|c|}{ SET 4-DISENTANGLING THE CERTAINTY EFFECT, EQUAL EV } \\
\hline 33 & $100 \%$ & $\$ 10.00$ & O\% & $\$ 0.00$ & $\$ 10.00$ & $\$ 0.00$ & $11 \%$ & $\$ 50.00$ & $89 \%$ & $\$ 5.00$ & $\$ 10.00$ & $\$ 200.00$ \\
\hline 34 & $100 \%$ & $\$ 10.00$ & $\mathrm{O} \%$ & $\$ 0.00$ & $\$ 10.00$ & $\$ 0.00$ & $33 \%$ & $\$ 25.00$ & $67 \%$ & $\$ 2.50$ & $\$ 10.00$ & $\$ 112.50$ \\
\hline 35 & $100 \%$ & $\$ 10.00$ & $\mathrm{O} \%$ & $\$ 0.00$ & $\$ 10.00$ & $\$ 0.00$ & $56 \%$ & $\$ 16.67$ & $44 \%$ & $\$ 1.67$ & $\$ 10.00$ & $\$ 55.56$ \\
\hline 36 & $100 \%$ & $\$ 10.00$ & $0 \%$ & $\$ 0.00$ & $\$ 10.00$ & $\$ 0.00$ & $78 \%$ & $\$ 12.50$ & $22 \%$ & $\$ 1.25$ & $\$ 10.00$ & $\$ 21.88$ \\
\hline 37 & $100 \%$ & $-\$ 10.00$ & $\mathrm{O} \%$ & $\$ 0.00$ & $-\$ 10.00$ & $\$ 0.00$ & $11 \%$ & $-\$ 50.00$ & $89 \%$ & $\$ 5.00$ & $-\$ 10.00$ & $\$ 200.00$ \\
\hline 38 & $100 \%$ & $-\$ 10.00$ & $0 \%$ & $\$ 0.00$ & $-\$ 10.00$ & $\$ 0.00$ & $33 \%$ & $-\$ 25.00$ & $67 \%$ & $\$ 2.50$ & $-\$ 10.00$ & $\$ 112.50$ \\
\hline 39 & $100 \%$ & $-\$ 10.00$ & $\mathrm{O} \%$ & $\$ 0.00$ & $-\$ 10.00$ & $\$ 0.00$ & $56 \%$ & $-\$ 16.67$ & $44 \%$ & $\$ 1.67$ & $-\$ 10.00$ & $\$ 55.56$ \\
\hline 40 & $100 \%$ & $-\$ 10.00$ & $0 \%$ & $\$ 0.00$ & $-\$ 10.00$ & $\$ 0.00$ & $78 \%$ & $-\$ 12.50$ & $22 \%$ & $\$ 1.25$ & $-\$ 10.00$ & $\$ 21.88$ \\
\hline
\end{tabular}




\begin{tabular}{|c|c|c|c|c|c|c|c|c|c|c|c|c|}
\hline \multirow{2}{*}{ ITEM } & \multicolumn{6}{|c|}{ OPTION A } & \multicolumn{6}{|c|}{ OPTION B } \\
\hline & $\mathrm{P}_{1}$ & $\mathrm{O}_{1}$ & $\mathrm{P}_{2}$ & $\mathrm{O}_{2}$ & $\mathrm{E}[\mathrm{A}]$ & VAR[A] & $\mathrm{P}_{1}$ & $\mathrm{O}_{1}$ & $\mathrm{P}_{2}$ & $\mathrm{O}_{2}$ & $\mathrm{E}[\mathrm{B}]$ & $\operatorname{VAR}[\mathrm{B}]$ \\
\hline \multicolumn{13}{|c|}{ SET 5－DISENTANGLING THE CERTAINTY EFFECT, UNEQUAL EV } \\
\hline 41 & $100 \%$ & $\$ 10.00$ & $0 \%$ & $\$ 0.00$ & $\$ 10.00$ & $\$ 0.00$ & $11 \%$ & $\$ 62.50$ & $89 \%$ & $\$ 6.25$ & $\$ 12.50$ & $\$ 312.50$ \\
\hline 42 & $100 \%$ & $\$ 10.00$ & $\mathrm{O} \%$ & $\$ 0.00$ & $\$ 10.00$ & $\$ 0.00$ & $33 \%$ & $\$ 31.25$ & $67 \%$ & $\$ 3.12$ & $\$ 12.50$ & $\$ 175.84$ \\
\hline 43 & $100 \%$ & $\$ 10.00$ & $0 \%$ & $\$ 0.00$ & $\$ 10.00$ & $\$ 0.00$ & $56 \%$ & $\$ 20.83$ & $44 \%$ & $\$ 2.08$ & $\$ 12.50$ & $\$ 86.81$ \\
\hline 44 & $100 \%$ & $\$ 10.00$ & O\% & $\$ 0.00$ & $\$ 10.00$ & $\$ 0.00$ & $78 \%$ & $\$ 15.63$ & $22 \%$ & $\$ 1.56$ & $\$ 12.50$ & $\$ 34.22$ \\
\hline 45 & $100 \%$ & $-\$ 10.00$ & O\% & $\$ 0.00$ & $-\$ 10.00$ & $\$ 0.00$ & $11 \%$ & $-\$ 62.50$ & $89 \%$ & $\$ 6.25$ & $-\$ 12.50$ & $\$ 312.50$ \\
\hline 46 & $100 \%$ & $-\$ 10.00$ & O\% & $\$ 0.00$ & $-\$ 10.00$ & $\$ 0.00$ & $33 \%$ & $-\$ 31.25$ & $67 \%$ & $\$ 3.12$ & $-\$ 12.50$ & $\$ 175.84$ \\
\hline 47 & $100 \%$ & $-\$ 10.00$ & o\% & $\$ 0.00$ & $-\$ 10.00$ & $\$ 0.00$ & $56 \%$ & $-\$ 20.83$ & $44 \%$ & $\$ 2.08$ & $-\$ 12.50$ & $\$ 86.81$ \\
\hline 48 & $100 \%$ & $-\$ 10.00$ & $0 \%$ & $\$ 0.00$ & $-\$ 10.00$ & $\$ 0.00$ & $78 \%$ & $-\$ 15.63$ & $22 \%$ & $\$ 1.56$ & $-\$ 12.50$ & $\$ 34.22$ \\
\hline
\end{tabular}


TABLE 11. Experiment 4: Descriptive statistics

\begin{tabular}{|c|c|c|c|c|c|c|}
\hline \multirow{2}{*}{ CHOICE SET } & \multicolumn{3}{|c|}{ AGE GROUP } & \multicolumn{3}{|c|}{ CHOICE FRAMING } \\
\hline & YOUNGER & OLDER & $p$ & GAIN & LOSS & $p$ \\
\hline \multicolumn{7}{|l|}{ SET 1} \\
\hline Accuracy & $.77[.73, .81]$ & $.77[.72, .81]$ & .958 & $.75[.71, .79]$ & $.79[.75, .82]$ & .087 \\
\hline Extent of information search & $21.9[18.2,25.5]$ & $22.3[18.7,26.0]$ & .856 & $22.0[19.3,24.8]$ & $22.2[19.5,24.8]$ & .895 \\
\hline Search patterns & $.40[.28, .52]$ & $.46[.34, .58]$ & .461 & $.42[.34, .51]$ & $.44[.35, .52]$ & .130 \\
\hline \multicolumn{7}{|l|}{ SET 2} \\
\hline Risk taking & $.47[.40, .54]$ & $.52[.45, .59]$ & .258 & $.45[.38, .52]$ & $.54[.48,60]$ & .029 \\
\hline Extent of information search & $20.5[17.3,23.6]$ & $20.4[17.3,23.6]$ & .982 & $21.0[18.4,23.6]$ & $19.9[17.6,22.2]$ & .297 \\
\hline Search patterns & $.36[.24, .48]$ & $.47[.35, .58]$ & .228 & $.40[.32, .49]$ & $.42[.34, .51]$ & .137 \\
\hline \multicolumn{7}{|l|}{ SET 3} \\
\hline Risk taking & $.50[.44, .57]$ & $.54[.47, .60]$ & .475 & $.62[.56, .69]$ & $.42[.36, .48]$ & $<.001$ \\
\hline Extent of information search & $19.6[15.9,23.2]$ & $21.1[17.4,24.8]$ & .553 & $21.3[18.0,24.6]$ & $19.4[17.2,21.7]$ & .112 \\
\hline Search patterns & $.39[.27, .51]$ & $.45[.33, .57]$ & .509 & $.40[.32, .49]$ & $.43[.35, .52]$ & .018 \\
\hline \multicolumn{7}{|l|}{ SET 4} \\
\hline Risk taking & $.50[.43, .57]$ & $.47[.40, .54]$ & .518 & $.42[.36, .48]$ & $.55,[.48, .62]$ & .003 \\
\hline Extent of information search & $21.0[17 \cdot 3,24.7]$ & $19.8[16.1,23.5]$ & 645 & $20.5[17.5,23.6]$ & $20.3[17.7,22.8]$ & .796 \\
\hline Search patterns & $.36[.24, .48]$ & $.46[.34, .58]$ & .257 & $.40[.32, .49]$ & $.42,[.33, .50]$ & .395 \\
\hline \multicolumn{7}{|l|}{ SET 5} \\
\hline Risk taking & $.49[.42, .55]$ & $.52[.46, .59]$ & .464 & $.61[.55, .67]$ & $.40[.33, .46]$ & $<.001$ \\
\hline Extent of information search & $19.7[16.9,22.5]$ & $19.0[16.2,21.8]$ & .717 & $19.6[17.4,21.9]$ & $19.1[17.1,21.2]$ & .557 \\
\hline Search patterns & $.36[.24, .48]$ & $.47[.35, .59]$ & .208 & $.40[.31, .48]$ & $.43[.35, .52]$ & .024 \\
\hline
\end{tabular}


TABLE 12. Experiment 4: Correlations with background measures across choice sets

\begin{tabular}{|c|c|c|c|c|c|c|c|c|c|c|c|c|c|c|}
\hline & \multicolumn{7}{|c|}{ YOUNGER ADULTS } & \multicolumn{7}{|c|}{ OLDER ADULTS } \\
\hline & 1 & 2 & 3 & 4 & 5 & 6 & 7 & 1 & 2 & 3 & 4 & 5 & 6 & 7 \\
\hline \multicolumn{15}{|l|}{ CHOICE SET 1} \\
\hline \multicolumn{15}{|l|}{ 1. Accuracy } \\
\hline 2. Samples & .21 & & & & & & & $<.01$ & & & & & & \\
\hline 3. Switch ratio & -.04 & $-.42^{* *}$ & & & & & & -.04 & -.26 & & & & & \\
\hline 4. Education (years) & $<.01$ & -.18 & .10 & & & & & .20 & .25 & $-.40^{*}$ & & & & \\
\hline 5. Numeracy & .04 & .14 & -.16 & -.12 & & & & -.06 & .04 & -.13 & $.33^{*}$ & & & \\
\hline 6. Need for Cognition & .08 & .03 & -.16 & -.29 & .18 & & & .20 & .11 & .07 & $\cdot 31$ & $36^{*}$ & & \\
\hline 7. Corsi span & -.14 & -.02 & -.24 & -.11 & .23 & .27 & & -.19 & $.35^{*}$ & .06 & .09 & .22 & $.40^{*}$ & \\
\hline 8. Digit span & .10 & .16 & .10 & -.08 & .26 & .15 & -.28 & .15 & -.25 & .07 & .05 & -.09 & $.32^{*}$ & .20 \\
\hline \multicolumn{15}{|l|}{ CHOICE SETS 2-5 } \\
\hline \multicolumn{15}{|l|}{ 1. Risk taking } \\
\hline 2. Samples & .05 & & & & & & & -.23 & & & & & & \\
\hline 3. Switch ratio & -.04 & $-.33^{*}$ & & & & & & $\cdot 34^{*}$ & -.23 & & & & & \\
\hline 4. Education (years) & .08 & -.09 & .07 & & & & & $-.36^{*}$ & .17 & $-.40^{*}$ & & & & \\
\hline 5. Numeracy & -.21 & .10 & -.21 & -.12 & & & & .08 & .04 & -.14 & $.33^{*}$ & & & \\
\hline 6. Need for Cognition & .13 & .04 & -.14 & -.29 & .18 & & & .09 & .11 & .07 & .31 & $.36^{*}$ & & \\
\hline 7. Corsi span & -.10 & -.23 & -.23 & -.11 & .23 & .27 & & .12 & $\cdot 33^{*}$ & .10 & .09 & .22 & $.40^{*}$ & \\
\hline 8. Digit span & -.01 & .16 & -.09 & -.08 & .26 & .15 & -.28 & .20 & -.27 & .08 & .05 & -.09 & $.32^{*}$ & .20 \\
\hline
\end{tabular}





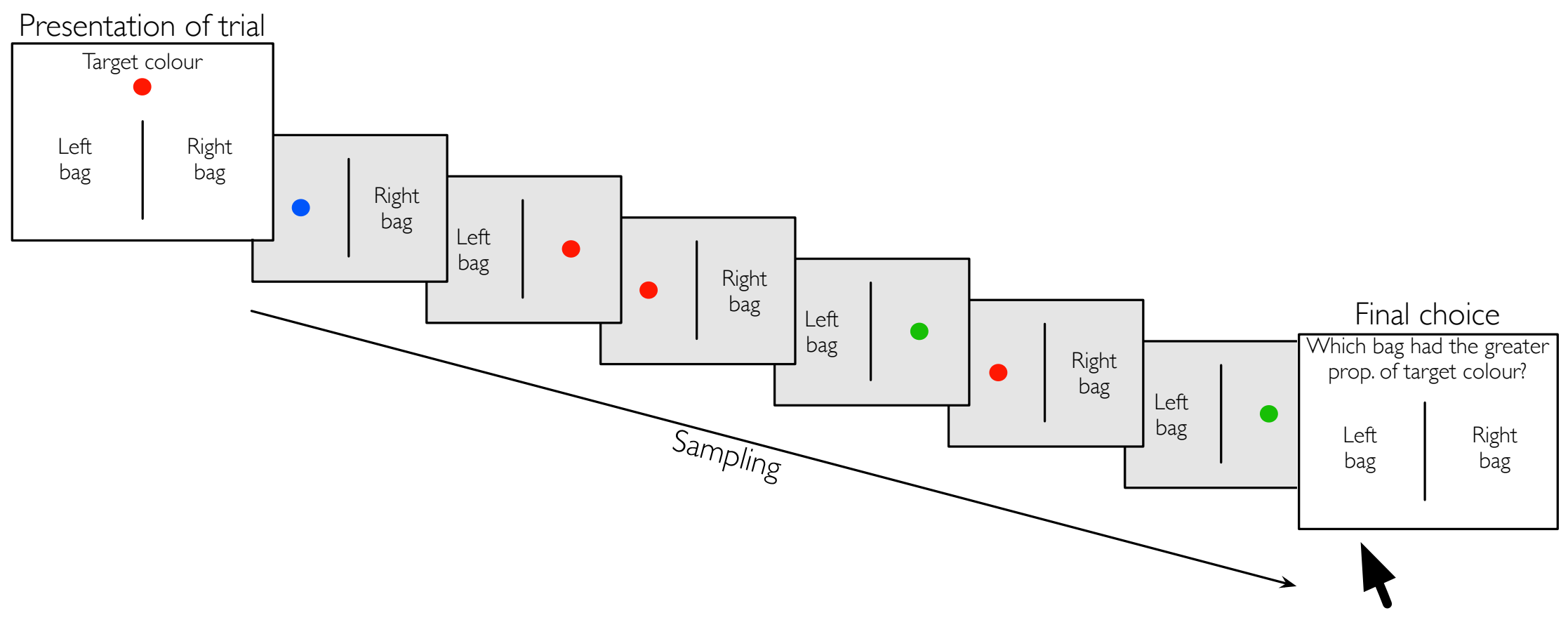

FIGURE 1. Illustration of the marbles task

First the trial is presented to the participant and the target colour for that trial is identified. This is followed by a self-paced sampling phase (six samples are shown - three from each bag - sampled using a strictly piecewise pattern). Once participants have sampled to their satisfaction they make their final choice for that trial. 


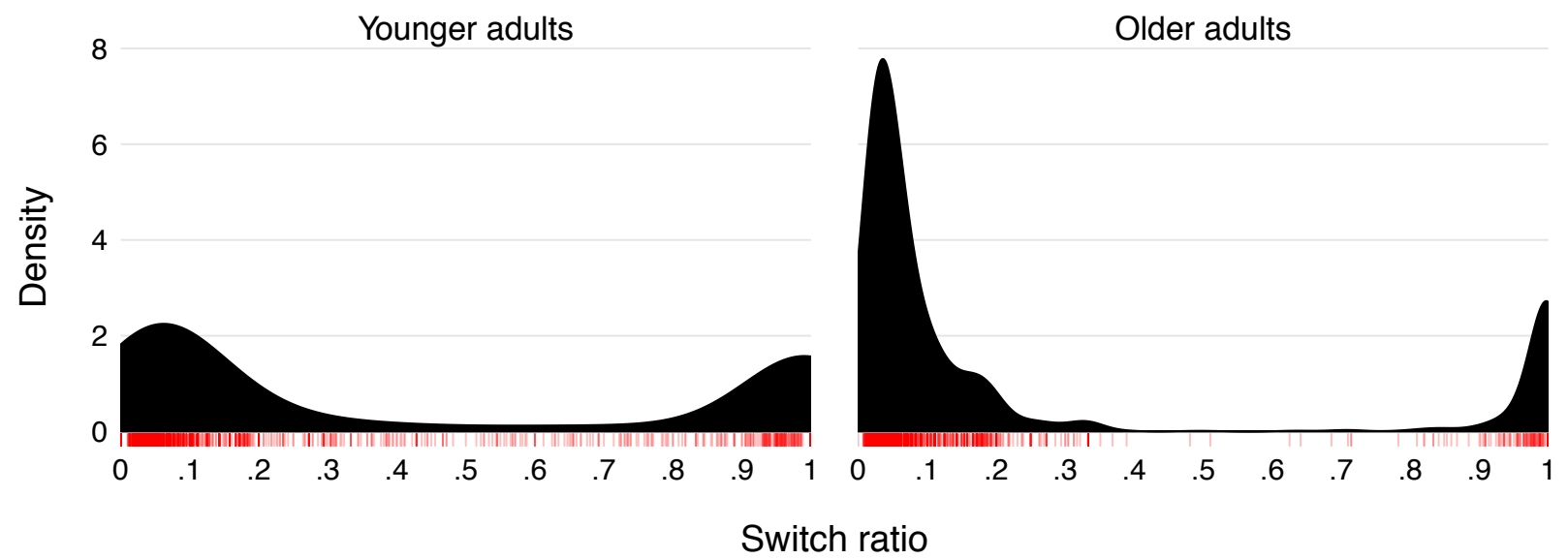

FIGURE 2. Kernel density plot of switch ratios, across participants in each age group in Experiment 1 Switch ratios describe patterns of pre-decisional information search. Switch ratio values nearer o represent less frequent switching (comprehensive search) whereas switch ratio values nearer 1 represent more frequent switching (piecewise search). The rug lines below the density plot show switch ratios for each trial. Age-related search pattern differences are pronounced, younger adults' trials are roughly split between the two patterns, including many trials evenly distributed between the two extremes; older adults are more strongly biased towards comprehensive search. 


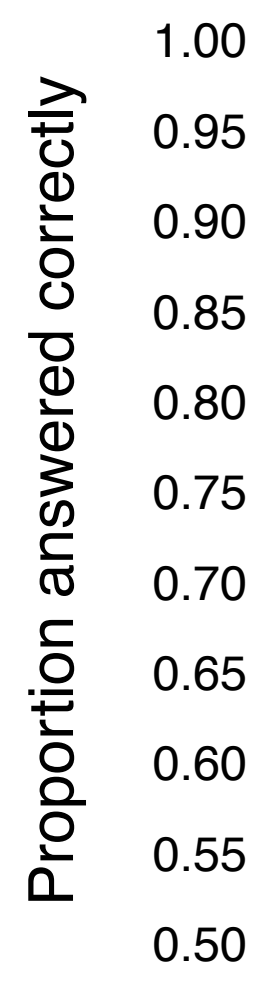

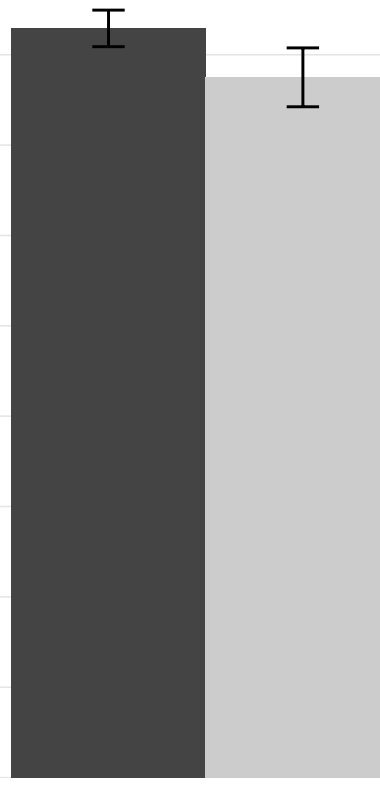

Piecewise

Younger adults Older adults

FIGURE 3. Experiment 2: Proportion of correct responses as a function of age group and pattern of information search

Non-adjusted means are shown. Error bars indicate the standard error of the mean. 

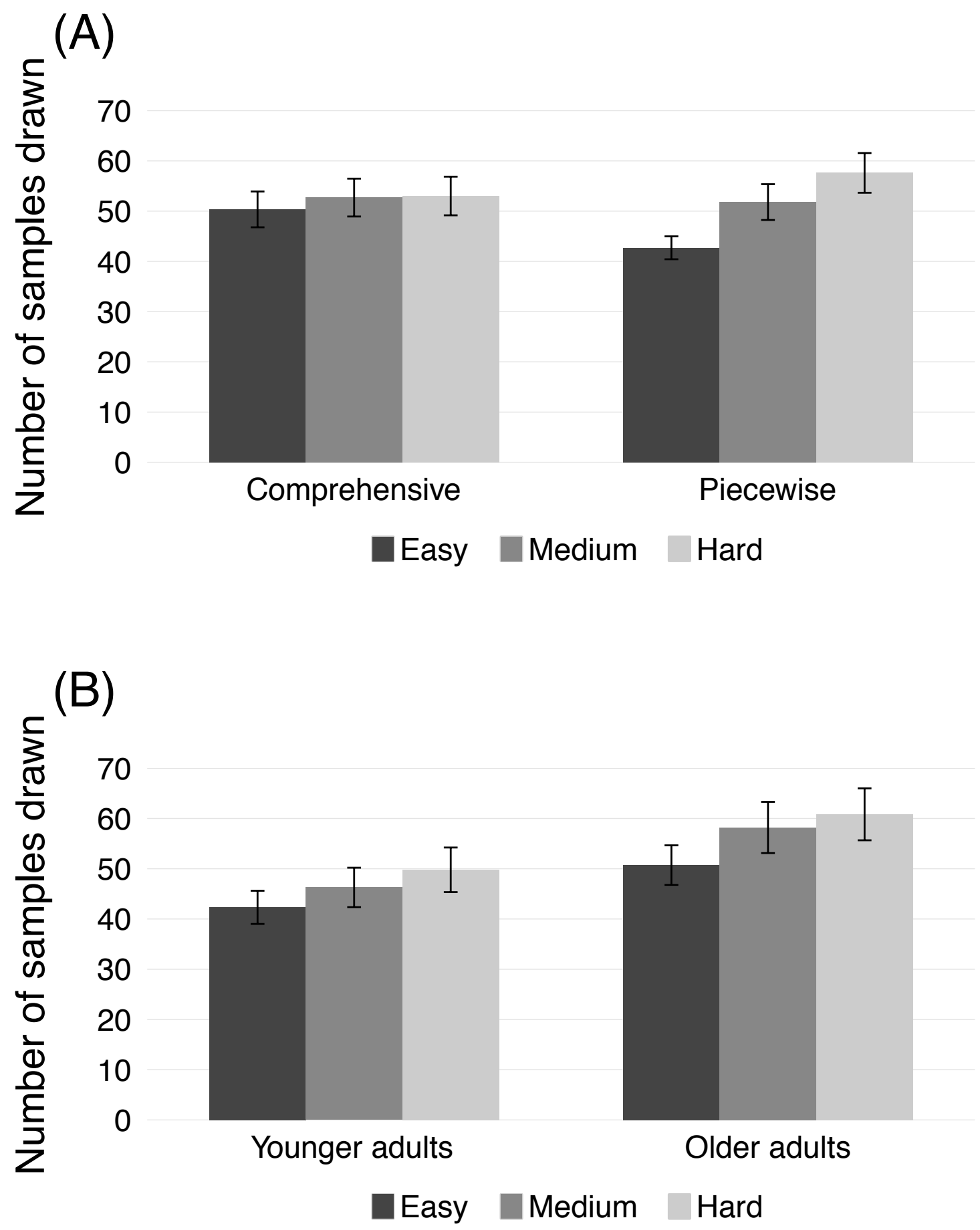

FIGURE 4. Experiment 2: Number samples drawn as a function of trial difficulty, shown for both $(A)$ patterns of search and (B) age groups

Error bars indicate the standard error of the mean. 


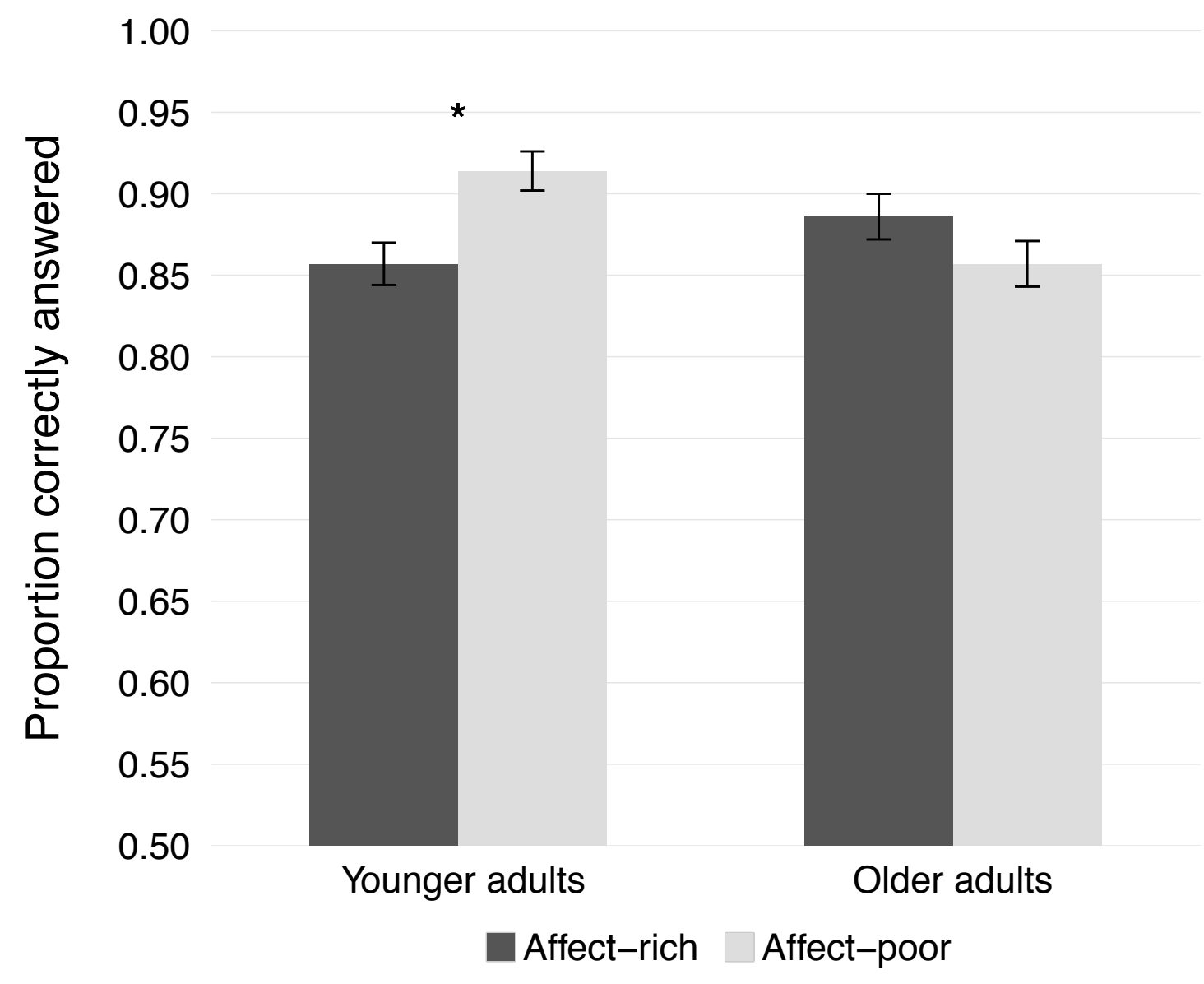

FIGURE 5. Experiment 3: Proportion of correct responses as a function of age group and feedback type Error bars indicated standard error of the mean. 



\section{RYERSONUNIVERSITY}

\section{RESEARCH ETHICS BOARD}

To: Piotr Wegier Psychology

Re: REB 2012-285: Age-related changes to information search and risky choice behaviour in decision-making tasks

Date: October 30, 2012

\section{Dear Piotr Wegier,}

The review of your protocol REB File REB 2012-285 is now complete. The project has been approved for a one year period. Please note that before proceeding with your project, compliance with other required University approvals/certifications, institutional requirements, or governmental authorizations may be required.

This approval may be extended after one year upon request. Please be advised that if the project is not renewed, approval will expire and no more research involving humans may take place. If this is a funded project, access to research funds may also be affected.

Please note that REB approval policies require that you adhere strictly to the protocol as last reviewed by the REB and that any modifications must be approved by the Board before they can be implemented. Adverse or unexpected events must be reported to the REB as soon as possible with an indication from the Principal Investigator as to how, in the view of the Principal Investigator, these events affect the continuation of the protocol.

Finally, if research subjects are in the care of a health facility, at a school, or other institution or community organization, it is the responsibility of the Principal Investigator to ensure that the ethical guidelines and approvals of those facilities or institutions are obtained and filed with the REB prior to the initiation of any research.

Please quote your REB file number (REB 2012-285) on future correspondence.

Congratulations and best of luck in conducting your research.

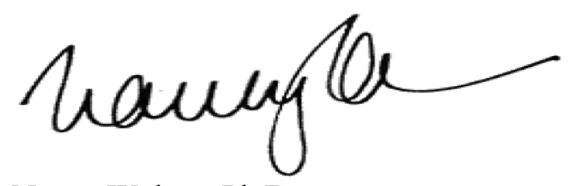

Nancy Walton, Ph.D.

Chair, Research Ethics Board 
RYERSON

UNIVERSITY

\section{PARTICIPANTS NEEDED}

The Memory and Decision Processes Lab is looking for individuals

to participate in a PAID decision-making study!

What you need to know:

- You must be aged 18-35 and in good health

- The study is a single, on-campus session, for 60-90 minutes

- You will complete a series of paper-and-pencil questionnaires and computer-based decision-making tasks

- You don't need any computer experience to participate

- You will be financially compensated for your time, \$10/hour

Email for details and to determine if you are eligible to participate!

Email: DM@psych.ryerson.ca

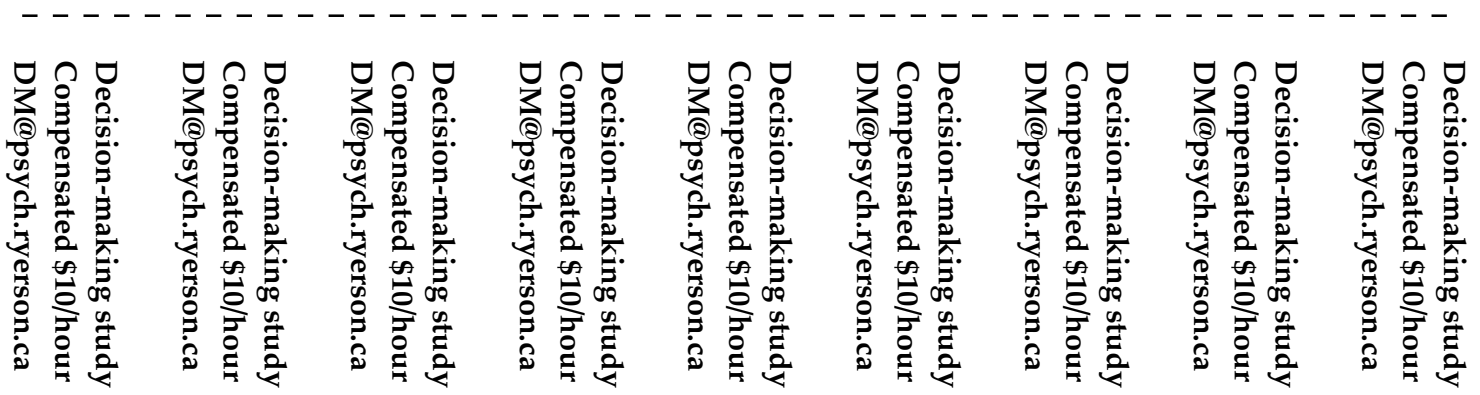


APPENDIX III. Sample consent form

\section{CONSENT FORM}

Information search and decision-making

\section{INVESTIGATOR}

Pete Wegier, PhD student, Department of Psychology, Ryerson University.

This research is being conducted as part of a PhD dissertation project, supervised by Dr. Julia Spaniol of the Department of Psychology, Ryerson University. Contact information for Dr. Spaniol is provided on the reverse of this page.

PURPOSE OF STUDY

In this study, we will examine how your information search behaviour is related to the quality of decisions you make. Although some of the tasks you will complete are computer-based, you are not required to have computer experience. Your eligibility to participate was determined on the basis of your answers to questions regarding health and other characteristics.

\section{DESCRIPTION}

For this study, you will participate in a single testing session at Ryerson University. During this session you will complete a combination of computer-based decision-making tasks and paperand-pencil questionnaires. If you choose to participate, your identity will be kept confidential and your responses will be presented in a way that will not allow others to identify you. You will receive a copy of this consent form, which contains the names and contact numbers of the study investigators.

During the study, you will complete a number of tasks, which include an information search task and a memory capacity task. You will also complete a set of paper-and-pencil questionnaires. The experimenter will explain each of the tasks to you in more detail and will answer any questions you may have before signing this form.

\section{CONFIDENTIALITY}

Your individual results are confidential. Only the investigator knows the results of the sessions and any identifying information linking you to those results. No personal or identifying information will be disclosed as a result of public or private presentation.

You will be assigned a randomly generated participant number. All paperwork completed by you will carry this number, and no other identifying information (i.e. first or last names). Any and all paperwork (including questionnaires) will be kept in a locked cabinet in the Psychology 
Research and Training Centre. Only members of the study team will have access to the data. The master list linking names to participant, and any other electronic files pertaining to the research, will be kept by the researcher in an encrypted, password-protected database. After the study has been published or presented, or after a maximum of 7 years, all paper records (forms, questionnaires, etc.) we collect from you will be shredded.

\section{BENEFITS}

The results of this study may help us better understand how individuals seek out information prior to making a decision. Your participation will not directly benefit you, but knowledge will be gained that may benefit others. Furthermore, you may find the study fun and educational. The potential benefits of this study for science and society are a greater understanding of how decision behaviour is shaped by information search, and how these patterns change with age. RISKS

You may have never participated in such a study before and may feel anxious. Please keep in mind, however, that your individual results will not be shared, but rather the group as a whole will be analyzed. You may also withdraw from participation at any time during the study.

\section{COMPENSATION}

You will receive $\$ 10$ per hour for your participation upon completion of the study. In addition, you may receive a bonus, up to $\$ 7 \cdot 40$, based on your performance during the session.

\section{PARTICIPATION}

Your participation is voluntary and you may, if you wish, withdraw your participation at anytime during the course of this study.

\section{QUESTIONS}

If you have any questions feel free to ask them at any time during the study. Questions can also be directed to the investigator, Pete Wegier, by emailing pwegier@psych.ryerson.ca.

The project supervisor may be contacted at:

\author{
Dr. Julia Spaniol \\ Department of Psychology, Ryerson \\ University \\ 350 Victoria Street \\ Toronto, Ontario \\ $\mathrm{M}_{5} \mathrm{~B} 2 \mathrm{~K}_{3}$
}

Phone: (416) 979-5000 ext. 2268

Email: jspaniol@psych.ryerson.ca
Ryerson Ethics board may be contacted at:

\section{Toni Fletcher}

Office of the Vice President, Research and Innovation, Ryerson University 350 Victoria Street, Room YDI 1135

Toronto, Ontario

$\mathrm{M}_{5} \mathrm{~B}_{2} \mathrm{~K}_{3}$

Phone: (416) 979-5000 ext. 7112

Fax: (416) 979-5336

Email: toni.fletcher@ryerson.ca 


\section{AGREEMENT}

By signing below you indicate that (1) you have read the information provided above and agree to participate in this study; (2) you are aware that you may ask questions at any time during the study; (3) you are aware that you may withdraw your consent to participate in this study at any time; (4) you are aware that you are not giving up any legal rights; (5) you are giving consent for the results gathered today to be used in publications, presentations, and theses, with identifying information removed.

Name of Participant (please print)

Signature of Participant Date

Signature of Investigator Date 
APPENDIX IV. Demographic screening form

\section{DEMOGRAPHICS}

CONTACT

Name:

PERSONAL Gender: Male Female

Age:

Handed: Right Left Ambidextrous

EDUCATION

Students

What year of university are you currently in?

What is your area of study?

Have you previously obtained a degree / diploma?

YES

NO

What was your area of study?

LANGUAGE What is your first (native) language?

Do you speak any other languages?

HEALTH

Vision

Do you have wear:

GLASSES

CONTACTS

NONE

Have you ever had any operations on your eyes?

YES

$\mathrm{NO}$

Do you have any form of colour blindness?

YES

$\mathrm{NO}$

Specify:

Hearing

Do you have any problems with your hearing?

YES

$\mathrm{NO}$

Specify: 
Conditions Have you ever had any of the following conditions?

$\begin{array}{lcc}\text { Stroke } & \text { YES } & \text { NO } \\ \text { Tumor } & \text { YES } & \text { NO } \\ \text { Cancer } & \text { YES } & \text { NO } \\ \text { Neurological diseases } & \text { YES } & \text { NO } \\ \text { Head injury } & \text { YES } & \text { NO } \\ \text { Concussion } & \text { YES } & \text { NO } \\ \text { Depression } & \text { YES } & \text { NO } \\ \text { Seizure } & \text { YES } & \text { NO } \\ \text { Aneurysm } & \text { YES } & \text { NO } \\ \text { Learning disability } & \text { YES } & \text { NO } \\ \text { Psychiatric illness } & \text { YES } & \text { NO } \\ \text { Epilepsy } & \text { YES } & \text { NO } \\ \text { High blood pressure } & \text { YES } & \text { NO } \\ \text { Heart attack } & \text { YES } & \text { NO }\end{array}$

Have you ever been in a serious car accident? YES NO

Have you ever hit your head badly? YES NO

Have you ever been unconscious? $\quad$ YES NO

Cause:

How long?

Have you been taking any medications in the last six months? 
APPENDIX V. The Positive and Negative Affect Schedule

This scale consists of a number of words and phrases that describe different feelings and emotions. Read each item and then mark the appropriate answer in the space next to that word. Indicate how you feel RIGHT NOW (that is, at the present moment). Use the following scale to record your answers:

$\mathbf{I}$

Very slightly or
2

A little
3

Moderately
4

Quite a bit
5

Extremely

not at all

Hostile

Afraid

Excited

Active

Guilty

Scared

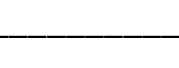

Alert

Inspired

Nervous

Ashamed

Attentive

Interested

Jittery

Upset

Determined

Proud

Irritable

Distressed

Enthusiastic

Strong 
APPENDIX VI. Need for Cognition Scale

Please indicate whether the following statements are True $(T)$ or False $(F)$ about you by entering $T$ or $F$ in each space. Please give an answer for each statement.

1. I would prefer complex to simple problems.

2. I like to have the responsibility of handling a situation that requires a lot of thinking.

3. Thinking is not my idea of fun.

4. I would rather do something that requires little thought than something that is sure to challenge my thinking abilities.

5. I try to anticipate and avoid situations where there is likely chance I will have to think in depth about something.

6. I find satisfaction in deliberating hard and for long hours.

7. I only think as hard as I have to.

8. I prefer to think about small, daily projects as opposed to long-term ones.

9. I like tasks that require little thought once I've learned them.

10. The idea of relying on thought to make my way to the top appeals to me.

11. I really enjoy a task that involves coming up with new solutions to problems.

12. Learning new ways to think doesn't excite me very much.

13. I prefer my life to be filled with puzzles that I must solve.

14. The notion of thinking abstractly is appealing to me.

15. I would prefer a task that is intellectual, difficult, and important to one that is somewhat important but does not require much thought.

16. I feel relief rather than satisfaction after completing a task that required a lot of mental effort.

17. It's enough for me that something gets the job done; I don't care how or why it works.

18. I usually end up deliberating about issues even when they do not affect me personally. 
APPENDIX VII. Lipkus et al. (2001) Numeracy Scale

Please answer the following questions to the best of your ability.

1. Which of the following numbers represents the biggest risk of getting a disease? (Circle an answer)
1 in 100
1 in 1000
1 in 10

2. Which of the following represents the biggest risk of getting a disease? (Circle an answer)

$$
1 \% \quad 10 \% \quad 15 \%
$$

3. If the chance of getting a disease were $10 \%$, how many people would be expected to get the disease out of 100 ?

4. If the chance of getting a disease were $10 \%$, how many people would be expected to get the disease out of 1000 ?

5. If the chance of getting a disease were 20 out of 100 , this would be the same as having a $\%$ chance of getting the disease.

6. If Person A's risk of getting a disease is $1 \%$ in ten years, and Person B's risk is double that of A's, what is B's risk? (express as a percentage)

7. If Person A's chance of getting a disease is 1 in 100 in ten years, and Person B's risk is double that of A, what is B's risk? (express as a fraction)

8. In the BIG BUCKS LOTTERY, the chances of winning a $\$ 10.00$ prize are $1 \%$. What is your best guess about how many people would win a $\$ 10.00$ prize if 1000 people each buy a single ticket from BIG BUCKS?

9. Imagine that we roll a fair, six-sided dice 1000 times. Out of 1000 rolls, how many times do you think the die would come up even? (an even number is 2, 4, 6, etc.)

10. The chance of getting a viral infection is .0005. Out of 10,000 people, about how many of them would you expect to get infected?

11. In the ACME PUBLISHING SWEEPSTAKES, the chance of winning a car is 1 in 1000 . What percent of tickets of ACME PUBLISHING SWEEPSTAKES win a car? 
APPENDIX VIII. Digit span task

Subject should be tested on two lists from each span length. Read out one digit per second. If the subject recalls one out of the two lists correct, proceed to the items in the next set. Continue until the subject cannot recall either of the lists from the set. Record the subject's Digit Span as the maximum length of the lists of which the subject recalled at least one correctly.

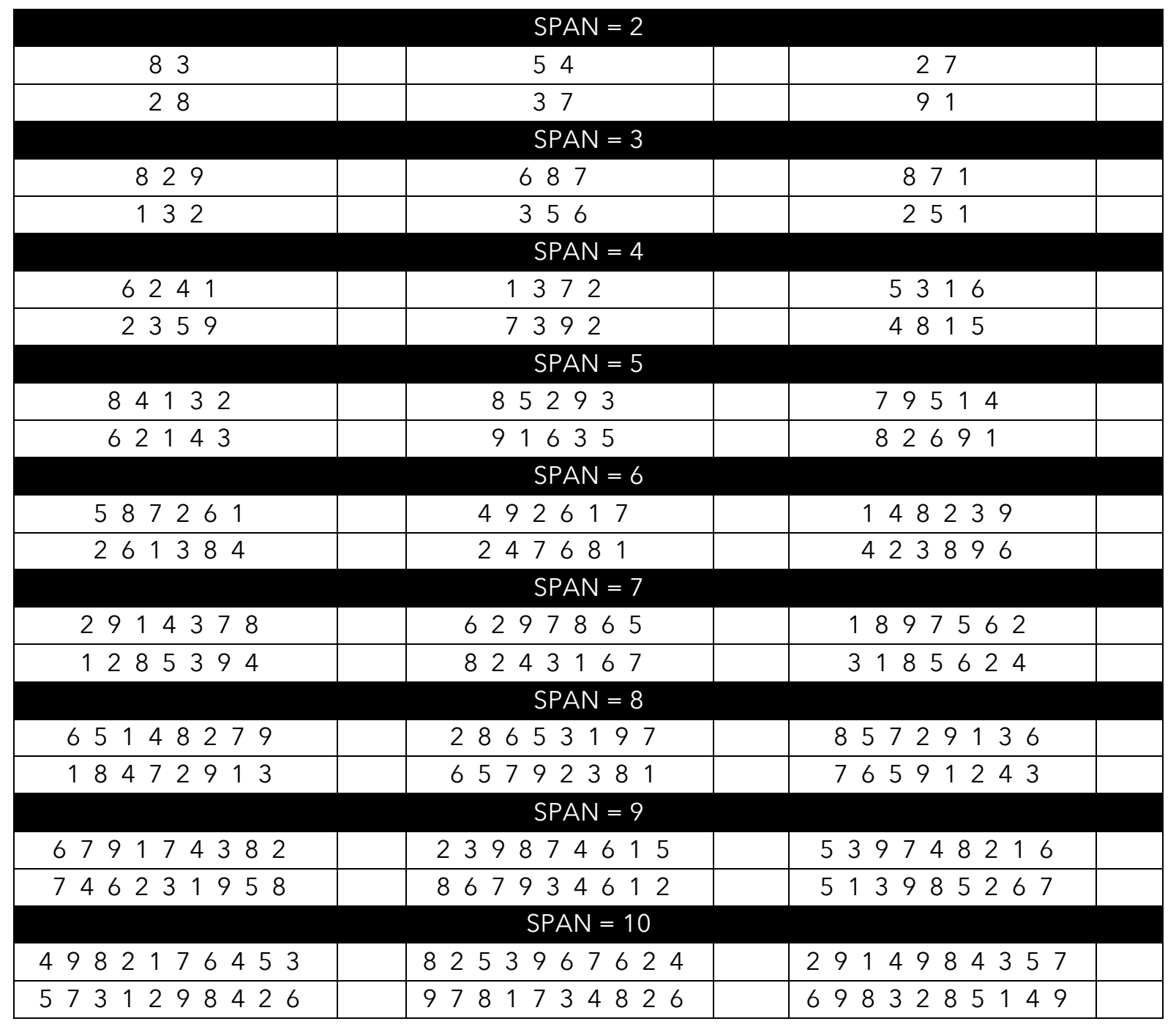

Digit span $=$ 
APPENDIX IX. Mini Mental State Exam

ORIENTATION (10)

What year is it?

What season is it?

What is today's date? (2)

What day of the week is it?

What province are we in?

What country are we in?

What city are we in?

What building is this?

What floor are we on?

\section{REGISTRATION (3)}

Repeat the following words: BUS... DOOR... ROAD

\section{AtTEnTION AND CALCUlation (5)}

I'm going to say a word, please spell it backwards: WORLD

RECALL (3)

What were those three words I had you repeat?

\section{LANGUAGE (9)}

What is this? (Hold up a pencil)

What is this? (Point to watch)

Repeat this after me: "No ifs, ands, or buts."

I'm going to hand you a piece of paper. I want you to take it with your right hand, fold it in half, and lay it on your lap (3)

Open the paper, read ALOUD what it says, then do it

At the top of the page, please right a complete sentence

Copy the design on the page below as carefully as you can

TOTAL: 
APPENDIX X. Affect-rich feedback images used in Experiment 3

\section{HAPPY FACE}

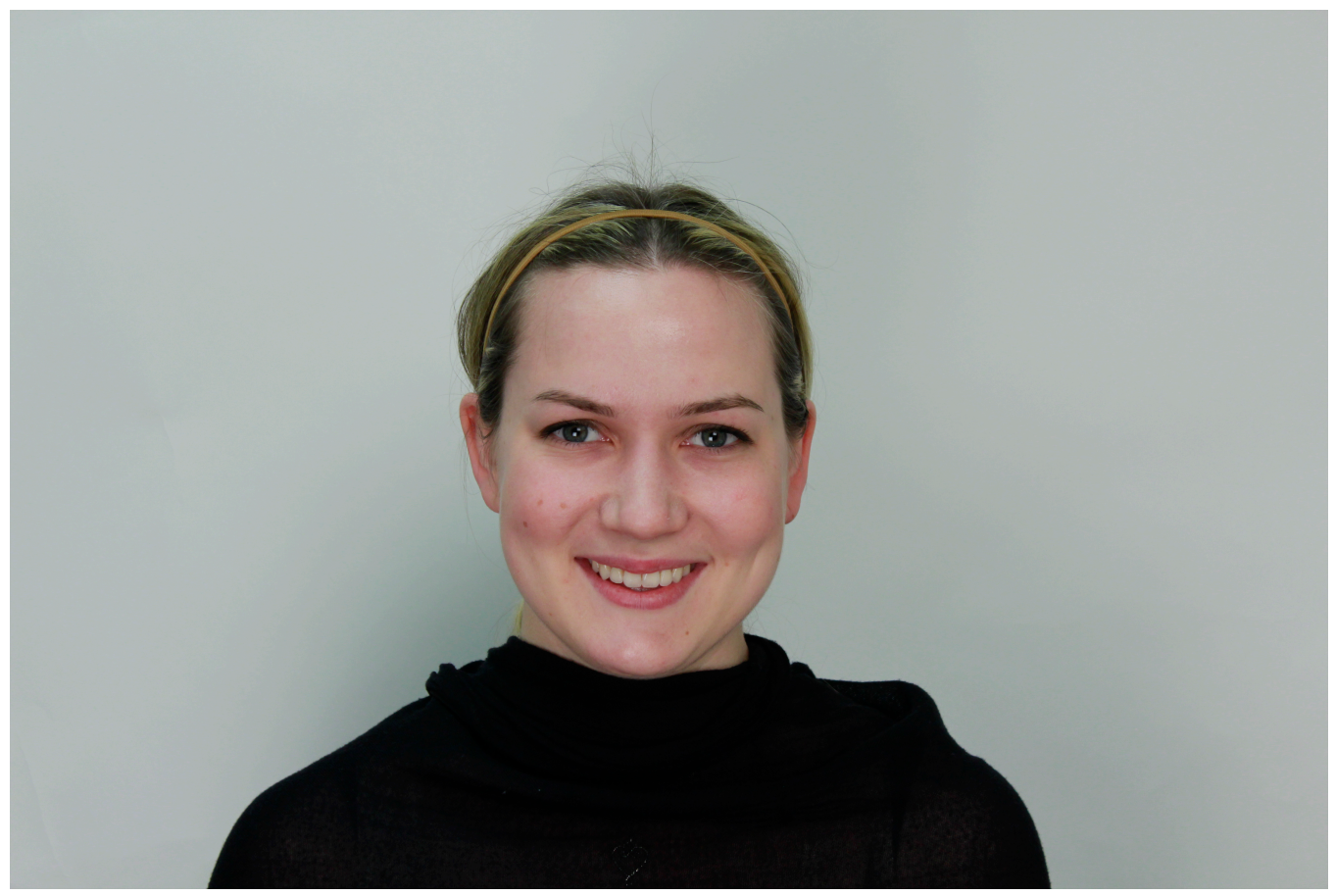

ANGRY FACE

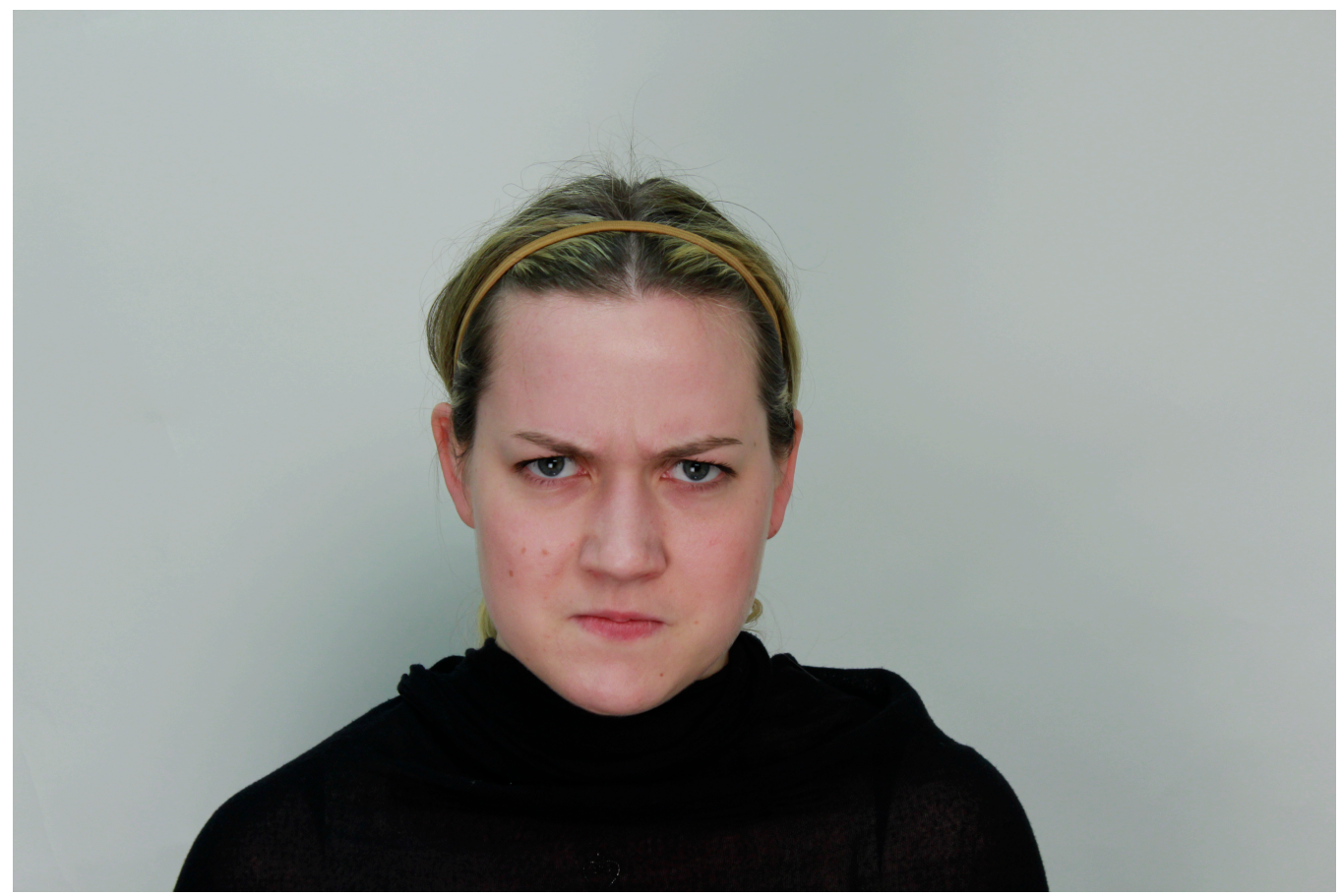





\section{REFERENCES}

Anastasi, J. S., \& Rhodes, M. G. (2006). Evidence for an Own-Age Bias in Face Recognition. North American Journal of Psychology.

Baltes, P. B., Staudinger, U. M., \& Lindenberger, U. (1999). Lifespan psychology: Theory and application to intellectual functioning. Annual Review of Psychology, 50(1), 471-507. http://doi.org/10.1146/annurev.psych.50.1.471

Barratt, E. (1959). Anxiety and impulsiveness related to psychomotor efficiency. Perceptual and Motor Skills, 9, 191-198.

Beall, P. M., \& Herbert, A. M. (2008). The face wins: Stronger automatic processing of affect in facial expressions than words in a modified Stroop task. Cognition E Emotion, 22(8), 16131642. http://doi.org/10.1080/02699930801940370

Berch, D. B., Krikorian, R., \& Huha, E. M. (1998). The Corsi Block-Tapping Task: Methodological and theoretical considerations. Brain and Cognition, 38(3), 317-338.

http://doi.org/10.1006/brcg.1998.1039

Blanchard-Fields, F. (2007). Everyday problem solving and emotion. Current Directions in Psychological Science, 16, 26-31.

Blanchard-Fields, F., Chen, Y., \& Norris, L. (1997). Everyday problem solving across the adult life span: Influence of domain specificity and cognitive appraisal. Psychology and Aging, 12(4), 684-693. http://doi.org/10.1037/0882-7974.12.4.684

Blanchard-Fields, F., Jahnke, H. C., \& Camp, C. (1995). Age differences in problem-solving style: The role of emotional salience. Psychology and Aging, 10(2), 173-180. http://doi.org/10.1037/0882-7974.10.2.173

Brainard, D. H. (1997). The Psychophysics Toolbox. Spatial Vision, 10(4), 433-436. http://doi.org/10.1163/156856897x00357

Bröder, A. (2000). Assessing the empirical validity of the "Take-the-best" heuristic as a model of human probabilistic inference. Journal of Experimental Psychology: Learning, Memory, and Cognition, 26(5), 1332-1346. http://doi.org/10.1037/0278-7393.26.5.1332

Bröder, A. (2003). Decision making with the "adaptive toolbox": Influence of environmental structure, intelligence, and working memory load. Journal of Experimental Psychology: Learning, Memory, and Cognition, 29(4), 611-625. http://doi.org/10.1037/0278-7393.29.4.611

Bröder, A., \& Schiffer, S. (2003). Take The Best versus simultaneous feature matching: Probabilistic inferences from memory and effects of representation format. Journal of 
Experimental Psychology: General, 132(2), 277-293. http://doi.org/10.1037/0096-3445.132.2.277

Bruine de Bruin, W., Parker, A. M., \& Fischhoff, B. (2010). Explaining adult age differences in decision-making competence. Journal of Behavioral Decision Making, 25(4), 352-360. http://doi.org/10.1002/bdm.712

Cacioppo, J. T., Petty, R. E., \& Kao, C. F. (1984). The efficient assessment of need for cognition. Journal of Personality Assessment, 48(3), 306-307. http://doi.org/10.1207/s15327752jpa4803_13

Carstensen, L. L., \& Mikels, J. A. (2005). At the intersection of emotion and cognition: Aging and the Positivity Effect. Current Directions in Psychological Science, 14(3), 117-121.

Carstensen, L. L., Isaacowitz, D. M., \& Charles, S. T. (1999). Taking time seriously: A theory of socioemotional selectivity. The American Psychologist, 54(3), 165-181. http://doi.org/10.1037//0003-066X.54.3.165

Carstensen, L. L., Pasupathi, M., Mayr, U., \& Nesselroade, J. R. (2000). Emotional experience in everyday life across the adult life span. Journal of Personality and Social Psychology, 79(4), 644655. http://doi.org/10.1037/0022-3514.79.4.644

Castel, A. D., Rossi, A. D., \& McGillivray, S. (2012). Beliefs about the "hot hand" in basketball across the adult life span. Psychology and Aging, 27(3), 601-605. http://doi.org/10.1037/a0026991

Charles, S. T., Mather, M., \& Carstensen, L. L. (2003). Aging and emotional memory: The forgettable nature of negative images for older adults. Journal of Experimental Psychology: General, 132(2), 310-324. http://doi.org/10.1037/0096-3445.132.2.310

Chen, T., \& Li, D. (2007). The roles of working memory updating and processing speed in mediating age-related differences in fluid intelligence. Aging, Neuropsychology, and Cognition, 14(6), 631-646. http://doi.org/10.1080/13825580600987660

Chin, J., Payne, B., Battles, A., Fu, W.-T., Morrow, D., \& Stine-Morrow, E. A. L. (2012). Information foraging in the unknown patches across the life span. In N. Miyake, D. Peebles, \& R. P. Cooper (Eds.), (pp. 1404-1409). Presented at the 34th Annual Conference of the Cognitive Science Society, Sapporo: Cognitive Science Society.

Cole, C. A., \& Balasubramanian, S. K. (1993). Age differences in consumers' search for information: Public policy implications. Journal of Consumer Research, 157-169.

Estrada, C. A., Isen, A. M., \& Young, M. J. (1997). Positive affect facilitates integration of information and decreases anchoring in reasoning among physicians. Organizational Behavior and Human Decision Processes, 72(1), 117-135. http://doi.org/10.1006/obhd.1997.2734

Figner, B., \& Weber, E. U. (2011). Who takes risks when and why?: Determinants of risk taking. 
Current Directions in Psychological Science, 20(4), 211-216.

http://doi.org/10.1177/0963721411415790

Finucane, M. L., Alhakami, A. S., Slovic, P., \& Johnson, S. (2000). The affect heuristic in judgments of risks and benefits. Journal of Behavioral Decision Making, 13(1), 1-17.

Finucane, M. L., Mertz, C. K., Slovic, P., \& Schmidt, E. S. (2005). Task complexity and older adults' decision-making competence. Psychology and Aging, 20(1), 71-84. http://doi.org/10.1037/0882-7974.20.1.71

Finucane, M. L., Slovic, P., Hibbard, J. H., Peters, E., Mertz, C. K., \& MacGregor, D. G. (2002). Aging and decision-making competence: An analysis of comprehension and consistency skills in older versus younger adults considering health-plan options. Journal of Behavioral Decision Making, 15(2), 141-164. http://doi.org/10.1002/bdm.407

Fiser, J., \& Aslin, R. N. (2001). Unsupervised statistical learning of higher-order spatial structures from visual scenes. Psychological Science, 12(6), 499-504.

Fiser, J., \& Aslin, R. N. (2002). Statistical learning of higher-order temporal structure from visual shape sequences. Journal of Experimental Psychology: Learning, Memory, and Cognition, 28(3), 458-467. http://doi.org/10.1037//0278-7393.28.3.458

Ford, J. K., Schmitt, N., Schechtman, S. L., Hults, B. M., \& Doherty, M. L. (1989). Process tracing methods: Contributions, problems, and neglected research questions. Organizational Behavior and Human Decision Processes, 43, 75-117.

Frey, R., Hertwig, R., \& Rieskamp, J. (2014). Fear shapes information acquisition in decisions from experience. Cognition, 132(1), 90-99. http://doi.org/10.1016/j.cognition.2014.03.009

Fung, H. H., \& Carstensen, L. L. (2003). Sending memorable messages to the old: Age differences in preferences and memory for advertisements. Journal of Personality and Social Psychology, 85(1), 163-178. http://doi.org/10.1037/0022-3514.85.1.163

Geary, D. C., \& Wiley, J. G. (1991). Cognitive addition: Strategy choice and speed-of-processing differences in young and elderly adults. Psychology and Aging, 6(3), 474-483. http://doi.org/10.1037/0882-7974.6.3.474

Geary, D. C., Frensch, P. A., \& Wiley, J. G. (1993). Simple and complex mental subtraction: Strategy choice and speed-of-processing differences in younger and older adults. Psychology and Aging, 8(2), 242-256. http://doi.org/10.1037/0882-7974.8.2.242

Glimcher, P. W. (2008). Understanding risk: A guide for the perplexed. Cognitive, Affective, $\mathcal{E}$ Behavioral Neuroscience, 8(4), 348-354. http://doi.org/10.3758/CABN.8.4.348

Gorlick, M. A., Mather, M., Giguère, G., Glass, B. D., Nix, B. N., \& Maddox, W. T. (2013). 
Attenuating age-related learning deficits: Emotional valenced feedback interacts with task complexity. Emotion, 13(2), 250-261. http://doi.org/10.1037/a0030071

Grossmann, I., Karasawa, M., Izumi, S., Na, J., Varnum, M. E. W., Kitayama, S., \& Nisbett, R. E. (2012). Aging and Wisdom: Culture Matters. Psychological Science, 23(10), 1059-1066. http://doi.org/10.1177/0956797612446025

Grossmann, I., Karasawa, M., Kan, C., \& Kitayama, S. (2014). A cultural perspective on emotional experiences across the life span. Emotion, 14(4), 679-692.

http://doi.org/10.1037/a0036041

Hanoch, Y., Wood, S., \& Rice, T. (2007). Bounded rationality, emotions and older adult decision making: Not so fast and yet so frugal. Human Development, 50(6), 333-358.

http://doi.org/10.1159/000109835

Hartman, M., Dumas, J., \& Nielsen, C. (2001). Age differences in updating working memory: Evidence from the Delayed-Matching-To-Sample Test. Aging, Neuropsychology, and Cognition, 8(1), 14-35. http://doi.org/10.1076/anec.8.1.14.847

Hau, R., Pleskac, T. J., \& Hertwig, R. (2010). Decisions from experience and statistical probabilities: Why they trigger different choices than a priori probabilities. Journal of Behavioral Decision Making, 23(1), 48-68. http://doi.org/10.1002/bdm.665

Hau, R., Pleskac, T. J., Kiefer, J., \& Hertwig, R. (2008). The description-experience gap in risky choice: the role of sample size and experienced probabilities. Journal of Behavioral Decision Making, 21(5), 493-518. http://doi.org/10.1002/bdm.598

Hertwig, R. (2009). The description-experience gap in risky choice. Trends in Cognitive Sciences, 13(12), 517-523. http://doi.org/10.1016/j.tics.2009.09.004

Hertwig, R., Barron, G., Weber, E. U., \& Erev, I. (2004). Decisions from experience and the effect of rare events in risky choice. Psychological Science, 15(8), 534-539.

http://doi.org/10.2139/ssrn.1301100

Hibbard, J. H., Slovic, P., Peters, E., Finucane, M. L., \& Tusler, M. (2001). Is The Informed-Choice Policy Approach Appropriate For Medicare Beneficiaries? Health Affairs, 20(3), 199-203. http://doi.org/10.1377/hlthaff.20.3.199

Hills, P. J., \& Lewis, M. B. (2011). The own-age face recognition bias in children and adults. The Quarterly Journal of Experimental Psychology, 64(1), 17-23.

http://doi.org/10.1080/17470218.2010.537926

Hills, T. T., \& Hertwig, R. (2010). Information search in decisions from experience: Do our patterns of sampling foreshadow our decisions? Psychological Science, 21(12), 1787-1792. http://doi.org/10.1177/0956797610387443 
Hills, T. T., \& Hertwig, R. (2012). Two distinct exploratory behaviors in decisions from experience: Comment on Gonzalez and Dutt (2011). Psychological Review, 119(4), 888-892. http://doi.org/10.1037/a0028004

Hills, T. T., Noguchi, T., \& Gibbert, M. (2013). Information overload or search-amplified risk? Set size and order effects on decisions from experience. Psychonomic Bulletin E Review, 20(5), 1023-1031. http://doi.org/10.3758/s13423-013-0422-3

Holliday, S. G. (1988). Risky-choice behavior: A life-span analysis. International Journal of Aging $\mathcal{E}$ Human Development, 27, 25-33.

Horn, J. L., \& Cattell, R. B. (1967). Age differences in fluid and crystallized intelligence. Acta Psychologica, 26, 107-129.

Horn, S. S., Pachur, T., \& Mata, R. (2015). How does aging affect recognition-based inference? A hierarchical Bayesian modeling approach. Actpsy, 154(C), 77-85.

http://doi.org/10.1016/j.actpsy.2014.11.001

Isen, A. M. (2001). An influence of positive affect on decision making in complex situations: Theoretical issues with practical implications. Journal of Consumer Psychology, 11(2), 75-85.

Johnson, M. M. S. (1990). Age differences in decision making: A process methodology for examining strategic information processing. Journal of Gerontology, 45(2), P75-P78.

Johnson, M. M. S. (1993). Thinking about strategies during, before, and after making a decision. Psychology and Aging, 8(2), 231-241. http://doi.org/10.1037/0882-7974.8.2.231

Johnson, M. M. S. (1997). Individual differences in the voluntary use of a memory aid during decision making. Experimental Aging Research, 23(1), 33-43. http://doi.org/10.1080/03610739708254025

Johnson, M. M. S., \& Drungle, S. C. (2000). Purchasing over-the-counter medications: The influence of age and familiarity. Experimental Aging Research, 26(3), 245-261. http://doi.org/10.1080/036107300404886

Kahneman, D. (2003). A perspective on judgment and choice: Mapping bounded rationality. The American Psychologist, 58(9), 697-720. http://doi.org/10.1037/0003-066X.58.9.697

Kahneman, D. (2011). Thinking, fast and slow. New York: Farrar, Straus and Giroux.

Kahneman, D., \& Tversky, A. (1979). Prospect theory: An analysis of decision under risk. Econometrica, 47(2), 263-291.

Kessels, R. P. C., van Zandvoort, M. J. M., Postma, A. A., Kappelle, L. J., \& de Haan, E. H. F. (2000). The Corsi Block-Tapping Task: Standardization and normative data. Applied Neuropsychology, 7(4), 252-258. http://doi.org/10.1207/S15324826AN0704_8 
Kuefner, D., Macchi Cassia, V., Picozzi, M., \& Bricolo, E. (2008). Do all kids look alike? Evidence for an other-age effect in adults. Journal of Experimental Psychology: Human Perception and Performance, 34(4), 811-817. http://doi.org/10.1037/0096-1523.34.4.811

Lambert-Pandraud, R., Laurent, G., \& Lapersonne, E. (2005). Repeat purchasing of new automobiles by older consumers: Empirical evidence and interpretations. Journal of Marketing, 97-113.

Lauriola, M., \& Levin, I. P. (2001). Personality traits and risky decision-making in a controlled experimental task: An exploratory study. Personality and Individual Differences, 31(2), 215226. http://doi.org/10.1016/S0191-8869(00)00130-6

Lee, A. Y., \& Sternthal, B. (1999). The effects of positive mood on memory. Journal of Consumer Research, 26(2), 115-127. http://doi.org/10.1086/209554

Lemaire, P., Arnaud, L., \& Lecacheur, M. (2004). Adults' age-related differences in adaptivity of strategy choices: Evidence from computational estimation. Psychology and Aging, 19(3), 467481. http://doi.org/10.1037/0882-7974.19.3.467

Lerner, J. S., \& Keltner, D. (2001). Fear, anger, and risk. Journal of Personality and Social Psychology, 81(1), 146-159. http://doi.org/10.1037/0022-3514.81.1.146

Lipkus, I. M., Samsa, G., \& Rimer, B. K. (2001). General performance on a numeracy scale among highly educated samples. Medical Decision Making, 21(1), 37-44. http://doi.org/10.1177/0272989X0102100105

Loewenstein, G., Hsee, C. K., Weber, E. U., \& Welch, N. (2001). Risk as feelings. Psychological Bulletin, 127(2), 267-286. http://doi.org/10.1037//0033-2909.127.2.267

Löckenhoff, C. E., \& Carstensen, L. L. (2007). Aging, emotion, and health-related decision strategies: Motivational manipulations can reduce age differences. Psychology and Aging, 22(1), 134-146. http://doi.org/10.1037/0882-7974.22.1.134

Löckenhoff, C. E., \& Carstensen, L. L. (2008). Decision strategies in health care choices for self and others: Older but not younger adults make adjustments for the age of the decision target. The Journals of Gerontology Series B: Psychological Sciences and Social Sciences, 63(2), P106-P109. http://doi.org/10.1093/geronb/63.2.p106

Luce, M. F., Bettman, J. R., \& Payne, J. W. (1997). Choice processing in emotionally difficult decisions. Journal of Experimental Psychology: Learning, Memory, and Cognition, 23(2), 384-405. http://doi.org/10.1037/0278-7393.23.2.384

Luce, M. F., Payne, J. W., \& Bettman, J. R. (2000). Coping with unfavorable attribute values in choice. Organizational Behavior and Human Decision Processes, 81(2), 274-299.

http://doi.org/10.1006/obhd.1999.2872 
Mata, R., \& Nunes, L. (2010). When less is enough: Cognitive aging, information search, and decision quality in consumer choice. Psychology and Aging, 25(2), 289-298.

http://doi.org/10.1037/a0017927

Mata, R., Helversen, von, B., \& Rieskamp, J. (2010). Learning to choose: Cognitive aging and strategy selection learning in decision making. Psychology and Aging, 25(2), 299-309. http://doi.org/10.1037/a0018923

Mata, R., Josef, A. K., Samanez-Larkin, G. R., \& Hertwig, R. (2011). Age differences in risky choice: a meta-analysis. Annals of the New York Academy of Sciences, 1235(1), 18-29. http://doi.org/10.1111/j.1749-6632.2011.06200.x

Mata, R., Schooler, L. J., \& Rieskamp, J. (2007). The aging decision maker: Cognitive aging and the adaptive selection of decision strategies. Psychology and Aging, 22(4), 796-810. http://doi.org/10.1037/0882-7974.22.4.796

Mata, R., Wilke, A., \& Czienskowski, U. (2013). Foraging across the life span: Is there a reduction in exploration with aging? Frontiers in Neuroscience, 7. http://doi.org/10.3389/fnins.2013.00053

Mather, M. (2006). A review of decision-making processes: Weighing the risks and benefits of Aging. In L. L. Carstensen \& C. R. Hartel (Eds.), When I'm 64 (1st ed., pp. 145-173). Washington, DC: The National Acadmies Press.

Mather, M., \& Carstensen, L. L. (2003). Aging and attentional biases for emotional faces. Psychological Science, 14(5), 409-415. http://doi.org/10.1111/1467-9280.01455

Mather, M., Knight, M., \& McCaffrey, M. (2005). The allure of the alignable: Younger and older adults' false memories of choice features. Journal of Experimental Psychology: General, 134(1), 38-51. http://doi.org/10.1037/0096-3445.134.1.38

Mather, M., Mazar, N., Gorlick, M. A., Lighthall, N. R., Burgeno, J., Schoeke, A., \& Ariely, D. (2012). Risk preferences and aging: The "certainty effect" in older adults' decision making. Psychology and Aging, 27(4), 801-816. http://doi.org/10.1037/a0030174

Mellers, B. A., \& McGraw, A. P. (2001). Anticipated emotions as guides to choice. Current Directions in Psychological Science, 10(6), 210-214.

Mellers, B. A., Schwartz, A., \& Ritov, I. (1999). Emotion-based choice. Journal of Experimental Psychology: General, 128(3), 332-345. http://doi.org/10.1037/0096-3445.128.3.332

Meyer, B. J. F., Russo, C., \& Talbot, A. P. (1995). Discourse comprehension and problem solving: Decisions about the treatment of breast cancer by women across the life span. Psychology and Aging, 10(1), 84-103. http://doi.org/10.1037/0882-7974.10.1.84 
Mikels, J. A., \& Reed, A. E. (2009). Monetary losses do not loom large in later life: Age differences in the framing effect. The Journals of Gerontology Series B: Psychological Sciences and Social Sciences, 64B(4), 457-460. http://doi.org/10.1093/geronb/gbp043

Murphy, N. A., \& Isaacowitz, D. M. (2008). Preferences for emotional information in older and younger adults: A meta-analysis of memory and attention tasks. Psychology and Aging, 23(2), 263-286. http://doi.org/10.1037/0882-7974.23.2.263

Mutter, S. A., \& Goedert, K. M. (1997). Frequency discrimination vs frequency estimation: Adult age differences and the effect of divided attention. The Journals of Gerontology Series B:

Psychological Sciences and Social Sciences, 52B(6), P319-P328.

http://doi.org/10.1093/geronb/52B.6.P319

Newell, B. R., \& Shanks, D. R. (2003). Take the best or look at the rest? Factors influencing "onereason" decision making. Journal of Experimental Psychology: Learning, Memory, and Cognition, 29(1), 53-65. http://doi.org/10.1037/0278-7393.29.1.53

Novak, D. L., \& Mather, M. (2007). Aging and variety seeking. Psychology and Aging, 22(4), 728737. http://doi.org/10.1037/0882-7974.22.4.728

Okun, M. A. (1976). Adult age and cautiousness: A review of the literature. Human Development, 19(4), 220-233.

Pachur, T., \& Scheibehenne, B. (2012). Constructing preference from experience: The endowment effect reflected in external information search. Journal of Experimental Psychology: Learning, Memory, and Cognition, 38(4), 1108-1116.

http://doi.org/10.1037/a0027637

Pachur, T., Mata, R., \& Schooler, L. J. (2009). Cognitive aging and the adaptive use of recognition in decision making. Psychology and Aging, 24(4), 901-915. http://doi.org/10.1037/a0017211

Patton, J. H., Stanford, M. S., \& Barratt, E. S. (1995). Factor structure of the Barratt impulsiveness scale. Journal of Clinical Psychology, 51(6), 768-774. http://doi.org/10.1002/10974679(199511)51:6<768::AID-JCLP2270510607>3.0.CO;2-1

Peters, E. (2008). Numeracy and the perception and communication of risk. Annals of the New York Academy of Sciences, 1128(1), 1-7. http://doi.org/10.1196/annals.1399.001

Peters, E., Dieckmann, N. F., \& Weller, J. A. (2010). Age differences in complex decision making. In K. W. Schaie \& S. L. Willis (Eds.), Handbook of the Psychology of Aging (7 ed., pp. 133-148). Academic Press.

Rakow, T., Demes, K. A., \& Newell, B. R. (2008). Biased samples not mode of presentation: Reexamining the apparent underweighting of rare events in experience-based choice. 
Organizational Behavior and Human Decision Processes, 106(2), 168-179. http://doi.org/10.1016/j.obhdp.2008.02.001

Reed, A. E., Mikels, J. A., \& Simon, K. I. (2008). Older adults prefer less choice than young adults. Psychology and Aging, 23(3), 671-675. http://doi.org/10.1037/a0012772

Reyna, V. F. (2004). How people make decisions that involve risk a dual-processes approach. Current Directions in Psychological Science, 13(2), 60-66. http://doi.org/10.1111/j.09637214.2004.00275.x

Reyna, V. F., \& Brainerd, C. J. (1995). Fuzzy-trace theory: An interim synthesis. Learning and Individual Differences, 7(1), 1-75. http://doi.org/10.1016/1041-6080(95)90031-4

Rieskamp, J., \& Hoffrage, U. (2008). Inferences under time pressure: How opportunity costs affect strategy selection. Acta Psychologica, 127(2), 258-276. http://doi.org/10.1016/j.actpsy.2007.05.004

Riggle, E. D. B., \& Johnson, M. M. S. (1996). Age difference in political decision making: Strategies for evaluating political candidates. Political Behavior, 18(1), 99-118. http://doi.org/10.1007/BF01498661

Rottman, B. M. (2014). Information Search in an Autocorrelated Causal Learning Environment. In P. Bello, M. McShane, \& B. Scassellati (Eds.). Presented at the 36th Annual Conference of the Cognitive Science Society, Austin, TX.

Saffran, J. R., Aslin, R. N., \& Newport, E. L. (1996). Statistical learning by 8-month-old infants. Science, 274(5294), 1926-1928.

Salthouse, T. A. (1979). Adult age and the speed-accuracy trade-off. Ergonomics, 22(7), 811-821. http://doi.org/10.1080/00140137908924659

Shiv, B., \& Fedorikhin, A. (1999). Heart and mind in conflict: The interplay of affect and cognition in consumer decision making. Journal of Consumer Research, 26(3), 278-292. http://doi.org/10.1086/209563

Simon, J. R., \& Gluck, M. A. (2013). Adult age differences in learning and generalization of feedback-based associations. Psychology and Aging, 28(4), 937-947.

http://doi.org/10.1037/a0033844

Simon, J. R., Howard, J. H., \& Howard, D. V. (2010a). Adult age differences in learning from positive and negative probabilistic feedback. Neuropsychology, 24(4), 534-541. http://doi.org/10.1037/a0018652

Simon, J. R., Howard, J. H., \& Howard, D. V. (2010b). Age differences in implicit learning of probabilistic unstructured sequences. The Journals of Gerontology Series B: Psychological 
Sciences and Social Sciences, 66B(1), 32-38. http://doi.org/10.1093/geronb/gbq066

Spaniol, J., \& Bayen, U. J. (2005). Aging and conditional probability judgments: A global matching approach. Psychology and Aging, 20(1), 165-181. http://doi.org/10.1037/08827974.20.1.165

Spaniol, J., \& Wegier, P. (2012). Decisions from experience: Adaptive information search and choice in younger and older adults. Frontiers in Neuroscience, 6. http://doi.org/10.3389/fnins.2012.00036

Spinella, M. (2007). Normative data and a short form of the Barratt Impulsiveness Scale. International Journal of Neuroscience, 117(3), 359-368. http://doi.org/10.1080/00207450600588881

Stanovich, K. E., \& West, R. F. (2000). Individual differences in reasoning: Implications for the rationality debate? Behavioral and Brain Sciences, 23(5), 645-665. http://doi.org/10.1017/S0140525X00003435

Starns, J. J., \& Ratcliff, R. (2010). The effects of aging on the speed-accuracy compromise: Boundary optimality in the diffusion model. Psychology and Aging, 25(2), 377-390. http://doi.org/10.1037/a0018022

Statistics Canada. (2012). The Canadian Population in 2011: Age and Sex (No. 98-311-X2011001). Ottawa: Ministry of Industry. Retrieved from http://www12.statcan.gc.ca/censusrecensement/2011/as-sa/98-311-x/98-311-x2011001-eng.pdf

Sugden, N., \& Moulson, M. (2013). SuMo Face Database: How to use this publicly available highly-standardized, validated database of static and dynamic images of faces of diverse ethnicities posing emotional or neutral expressions. Presented at the 74th Annual Canadian Psychological Association Convention, Quebec City, Quebec.

Susskind, J. M., Lee, D. H., Cusi, A., Feiman, R., Grabski, W., \& Anderson, A. K. (2008). Expressing fear enhances sensory acquisition. Nature Neuroscience, 11(7), 843-850. http://doi.org/10.1038/nn.2138

Talbot, A. P., Meyer, B. J. F., \& Ranalli, C. (2007). Why older adults make more immediate treatment decisions about cancer than younger adults. Psychology and Aging, 22(3), 505-524. http://doi.org/10.1037/0882-7974.22.3.505

Thornton, W. J. L., \& Dumke, H. A. (2005). Age differences in everyday problem-solving and decision-making effectiveness: A meta-analytic review. Psychology and Aging, 20(1), 85-99. http://doi.org/10.1037/0882-7974.20.1.85

Watson, D., Clark, L. A., \& Tellegen, A. (1988). Development and validation of brief measures of positive and negative affect: the PANAS scales. Journal of Personality and Social Psychology, 
54(6), 1063-1070.

Weber, E. U., Shafir, S., \& Blais, A.-R. (2004). Predicting risk sensitivity in humans and lower animals: Risk as variance or coefficient of variation. Psychological Review, 111(2), 430-445. http://doi.org/10.1037/0033-295X.111.2.430

Weller, J. A., Levin, I. P., \& Denburg, N. L. (2010). Trajectory of risky decision making for potential gains and losses from ages 5 to 85. Journal of Behavioral Decision Making, 24(4), 331344. http://doi.org/10.1002/bdm.690

Wiese, H., Kachel, U., \& Schweinberger, S. R. (2013). Holistic face processing of own- and otherage faces in young and older adults: ERP evidence from the composite face task. NeuroImage, 74(C), 306-317. http://doi.org/10.1016/j.neuroimage.2013.02.051

Xin, Z., Lai, Z.-R., Li, F., \& Maes, J. H. R. (2014). Near- and far-transfer effects of working memory updating training in elderly adults. Applied Cognitive Psychology, 28(3), 403-408. http://doi.org/10.1002/acp.3011

Yoon, C., Cole, C. A., \& Lee, M. P. (2009). Consumer decision making and aging: Current knowledge and future directions. Journal of Consumer Psychology, 19(1), 2-16. http://doi.org/10.1016/j.jcps.2008.12.002

Zwahr, M. D., Park, D. C., \& Shifren, K. (1999). Judgments about estrogen replacement therapy: The role of age, cognitive abilities, and beliefs. Psychology and Aging, 14(2), 179-191. http://doi.org/10.1037/0882-7974.14.2.179 